\title{
Reconceptualizing Civic Duty: \\ A New Perspective on Measuring Civic Duty in Voting Studies
}

by

\author{
Nicole J. Goodman
}

A thesis submitted to the Faculty of Graduate and Postdoctoral Affairs in partial fulfillment of the requirements for the degree of

Doctor of Philosophy

in

Political Science

Carleton University

Ottawa, Ontario

(C) 2012

Nicole J. Goodman 
Library and Archives

Canada

Published Heritage

Branch

395 Wellington Street

Ottawa ON K1A ON4

Canada
Bibliothèque et

Archives Canada

Direction du

Patrimoine de l'édition

395 , rue Wellington

Ottawa ON K1A ON4

Canada
Your file Votre référence

ISBN: 978-0-494-93673-3

Our file Notre référence

ISBN: $978-0-494-93673-3$
NOTICE:

The author has granted a nonexclusive license allowing Library and Archives Canada to reproduce, publish, archive, preserve, conserve, communicate to the public by telecommunication or on the Internet, loan, distrbute and sell theses worldwide, for commercial or noncommercial purposes, in microform, paper, electronic and/or any other formats.

The author retains copyright ownership and moral rights in this thesis. Neither the thesis nor substantial extracts from it may be printed or otherwise reproduced without the author's permission.
AVIS:

L'auteur a accordé une licence non exclusive permettant à la Bibliothèque et Archives Canada de reproduire, publier, archiver, sauvegarder, conserver, transmettre au public par télécommunication ou par l'Internet, prêter, distribuer et vendre des thèses partout dans le monde, à des fins commerciales ou autres, sur support microforme, papier, électronique et/ou autres formats.

L'auteur conserve la propriété du droit d'auteur et des droits moraux qui protege cette thèse. $\mathrm{Ni}$ la thèse ni des extraits substantiels de celle-ci ne doivent être imprimés ou autrement reproduits sans son autorisation.
In compliance with the Canadian Privacy Act some supporting forms may have been removed from this thesis.

While these forms may be included in the document page count, their removal does not represent any loss of content from the thesis.
Conformément à la loi canadienne sur la protection de la vie privée, quelques formulaires secondaires ont été enlevés de cette thèse.

Bien que ces formulaires aient inclus dans la pagination, il n'y aura aucun contenu manquant. 


\begin{abstract}
The civic duty to vote is one of the most influential attitudinal concepts that helps us understand and explain an elector's decision to participate or abstain in elections. Researchers frequently point to weakening senses of duty when accounting for declining voting turnout. Despite its explanatory power however, civic duty is currently operationalized one-dimensionally, commonly defined as the importance associated with the act of voting per se (Pammett and LeDuc, 2003; see also Blais, 2000). This definition, developed by voting behaviour scholars, has not been revisited despite the reconceptualization of other important political attitudes such as efficacy and political knowledge (Morrell, 2003; Lupia, 2008b) and well-documented change in values, attitudes, and citizenship norms (Dalton, 2008; Goodman et al., 2011; Inglehart, 1990; Nevitte 1997). This thesis seeks to reconceptualize the way we think about and measure the civic duty to vote by first probing young people's perceptions of what it means to be a citizen in an election campaign (Goodman et al., 2011) to formulate alternate dimensions of the duty to vote and then evaluating the validity of these new conceptions with a special national sample of Canadians. Findings indicate that while electors still associate with the traditional operationalization of civic duty, many, particularly those aged 18 to 26, identify with alternate dimensions of electoral duty. The most powerful dimension, 'conditional duty', represents a belief in 'sometimes participation,' which takes the decision to participate in elections as contingent upon contextual factors relating to political knowledge/ information and the stakes or importance of an election. Rather than perceiving voting as a moral obligation in all elections, electors identifying with conditional duty believe that they have a duty to consider voting. If they deem themselves to be knowledgeable or perceive the election as important their sense of electoral obligation heightens, thus necessitating a vote. If one or more of these factors is not present abstaining is perfectly acceptable behaviour. Overall, the project presents significant findings that there are alternate dimensions of duty researchers should be studying to obtain a fuller picture of the electoral decision-making of citizens.
\end{abstract}




\section{Acknowledgements}

First and foremost I would like to thank my supervisor, Dr. Jon Pammett, for his guidance, assistance, and council on every aspect of this project and beyond. He has provided me with exceptional mentorship and support throughout my time at Carleton and has had a profound impact on my academic path. For his patience, positive reinforcement, and sincerity I will be forever grateful. I may lose a supervisor through the submission of this dissertation, but I have gained a lifelong friend. I have learnt so much from you -- Thank you.

Next, I would like to thank my second reader, Dr. Scott Bennett, for being unfailingly generous with his time and comments with regards to this thesis and for his assistance with other matters of professional development. His quick, thoughtful responses and good judgment on methodological matters have significantly improved the caliber of this project. A sincere thank you for his patience is also in order.

Third, a special thank you to committee member Dr. André Turcotte for his careful reading and constructive criticism, which had an important effect on the development and final draft of this thesis. For his patience and kindhearted nature I am also grateful.

In addition, I would like to express my gratitude for the instruction and support of other faculty members and staff at Carleton. Particularly, Dr. Laura MacDonald, without whose kind words and encouragement to continue with the $\mathrm{PhD}$ in my first year I might have followed another route. Thank you also to Carleton University and Department of Political Science for their generous financial support. And, my sincere thanks to Adam Froman, Delvinia CEO, for graciously providing the primary quantitative data set for this thesis.

Finally, a project of this scope cannot be successfully completed without a great deal of nonacademic support. I must thank my family -- Mom, Jay, Lindsay, Nathan, Babcia, Dziadu and everyone else -- for all the ways in which they helped and supported me over the course of this experience. Their constant encouragement and belief in my abilities, even when I doubted myself, gave me the strength to complete this dissertation. 


\section{Table of Contents}

Chapter 1 : The importance of the civic duty to vote ....................................................................... 1

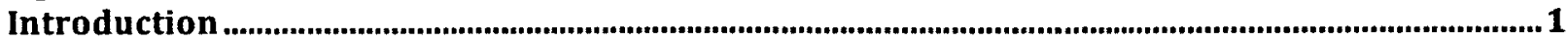

The problem of turnout decline and weakening duty ..............................................................................5

Chapter 2 : Citizenship and Participation .............................................................................................18

Political participation and civic duty literature ................................................................................... 24

Chapter 3 : Assessment of civic duty survey measures in the United States, Britain and

Canada .............................................................................................................................................................37

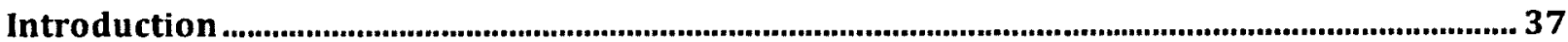

Importance of duty in surveys and its relationship with turnout .................................................... 38

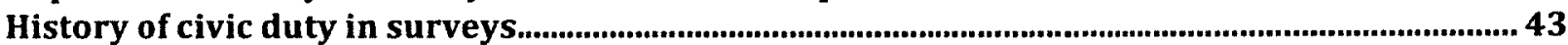

Civic duty in surveys and voting behaviour research: ........................................................................46

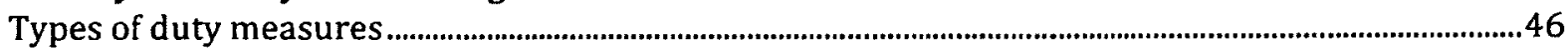

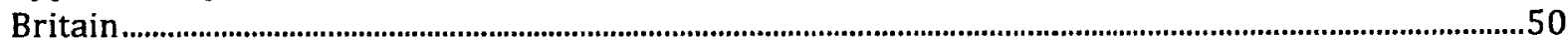

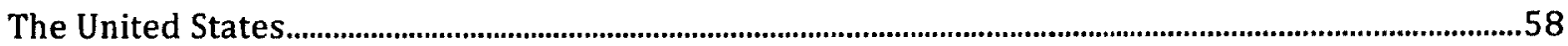

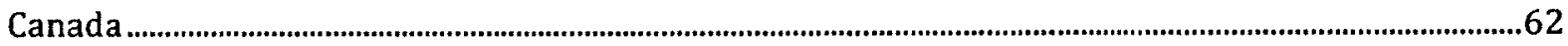

International comparative surveys ……….......................................................................................................65

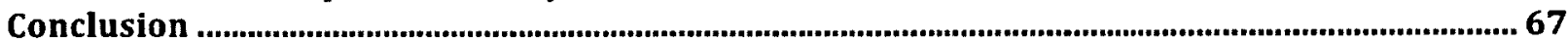

Chapter 4 : Trends in the civic duty to vote over time...................................................................70

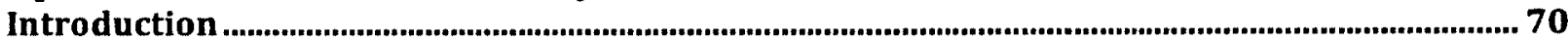

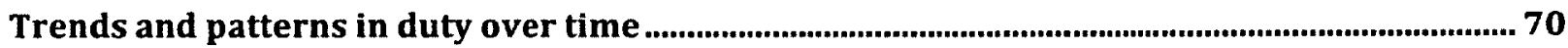

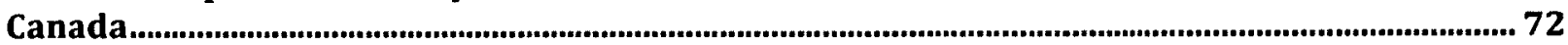

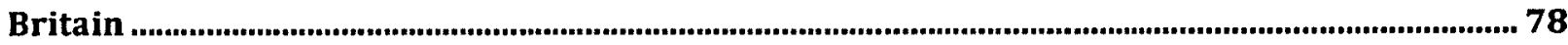

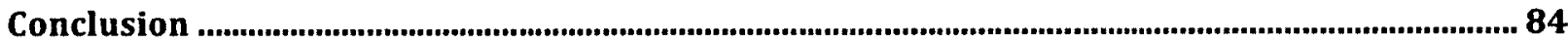

Chapter 5: New conceptions of duty: the 2008 Facebook study ..................................................85

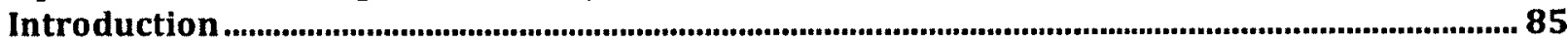

Why use a qualitative Facebook research design? ................................................................................. 85

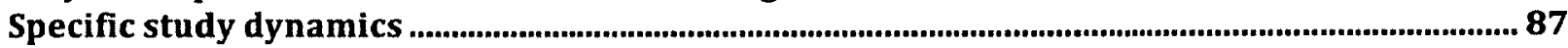

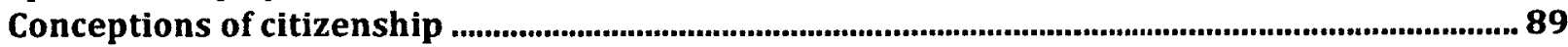

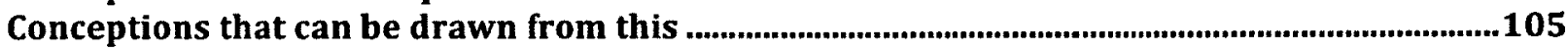

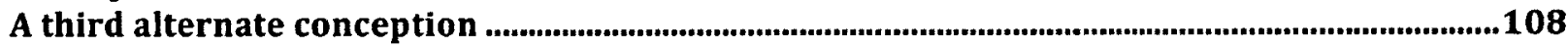

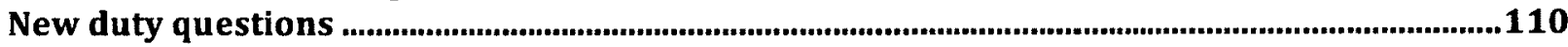

Chapter 6 : Construction and Performance of new civic duty factors ................................ 115

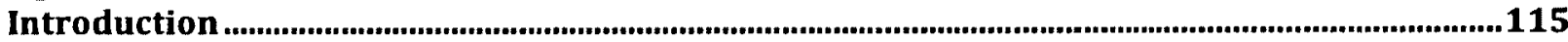

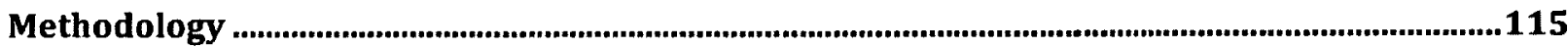

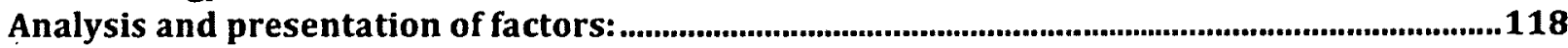

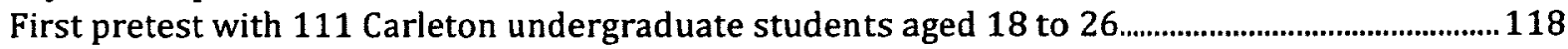

Refinement of duty questions ............................................................................................................................125

Second Pretest, 97 Google survey respondents, all ages...............................................................................128

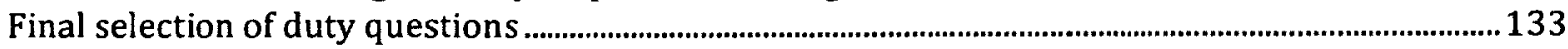

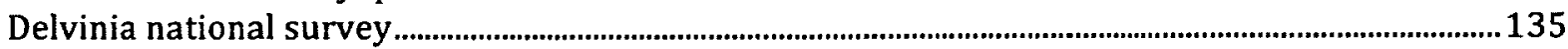

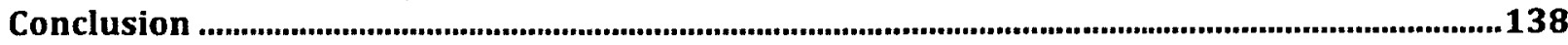

Chapter 7: The impact of civic duty on voting and other attitudes ........................................ 140

Introduction .................................................................................................................................................................140

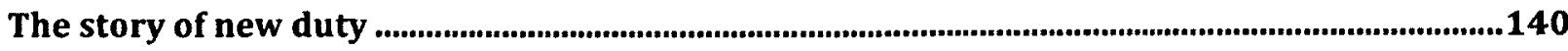

New duty's relationship with voting ...................................................................................................146 
Young people, new duty and voting ..................................................................................................149

The relationship of new duty dimensions with other dependent variables ...............................153

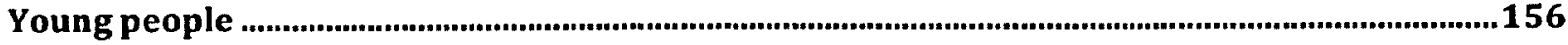

Traditional duty and conditional duty profiles ........................................................................................159

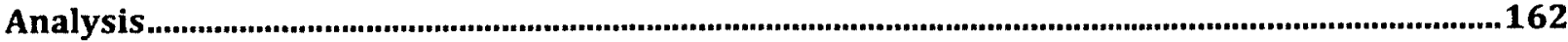

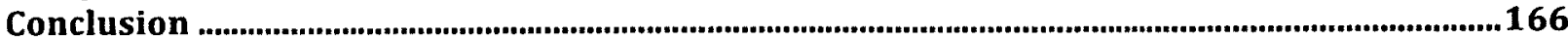

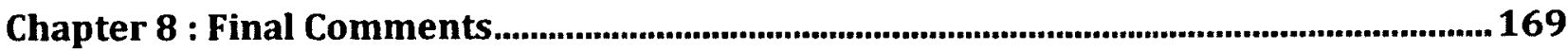

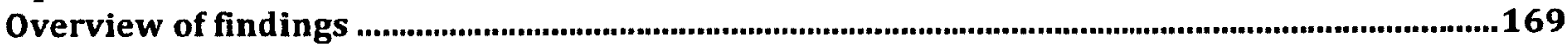

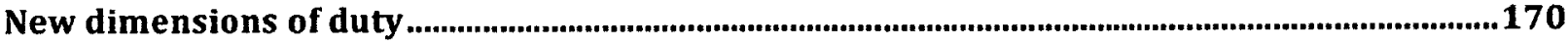

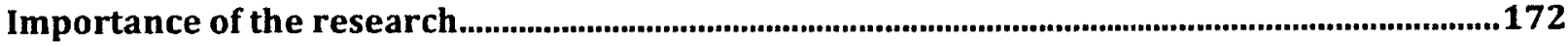

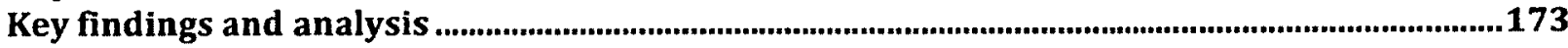

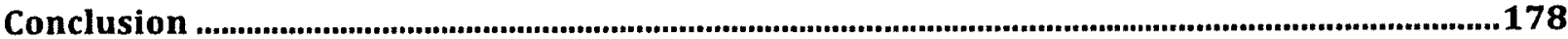




\section{List of Tables}

Table 3.1: Civic duty questions in surveys ...............................................................................................47

Table 3.2: Questions probing civic duty in American, British, and Canadian surveys ...................54

Table 4.1: Mean scores by age from Canadian surveys ................................................................................75

Table 4.2: Mean scores by age from Canadian surveys ..............................................................................75

Table 4.3: Correlation of traditional civic duty with the vote in Canadian election surveys .....77

Table 4.4: Mean scores by age from British surveys.................................................................................8

Table 4.6: Correlation of Civic Duty with the Vote in British Election surveys ................................83

Table 5.1: First Round of Duty Questions ................................................................................................113

Table 6.1: Factor Analysis Pretest 1: Carleton undergraduate students aged 18 to 26 .............119

Table 6.2: Second Round of Duty Questions..................................................................................................126

Table 6.3: Factor Analysis Pretest 2: Google survey, all ages...............................................................129

Table 6.4: Final Round of Duty Questions ..........................................................................................134

Table 6.5: Factor Analysis Delvinia national survey ...........................................................................136

Table 7.1: Correlations (tau-c) of civic duty dimensions with reported voting in past federal elections for all electors, and for young and older age groups ................................................. 147

Table 7.2: Correlations (tau values*) of civic duty dimensions with trust, internal and external efficacy and interest for all electors

Table 7.3: Correlations (tau values*) of all civic duty dimensions with trust, internal and external efficacy and interest for young people aged 18 to 26 .....................................................157 


\section{List of Figures}

Figure 1.1 Voter turnout in Canadian federal elections, 1988-2011 ................................................. 6

Figure 1.2: Estimated turnout by new cohort in Canadian federal elections*................................... 7

Figure 4.1: Percentage high in traditional duty for best questions in Canadian surveys ............73

Figure 4.2: Percentage high of traditional duty by age in Canada ........................................................74

Figure 4.3: Percentage high in traditional duty by voting behaviour in Canadian surveys........77

Figure 4.4: Percentage high in traditional duty for best questions in British surveys .................79

Figure 4.5: Civic duty responses in British surveys, 1991-2009........................................................80

Figure 4.6: Percentage high for traditional duty by voting behaviour in British surveys ...........82

Figure 5.1: Conceptions of citizenship and orientations to voting ...................................................93

Figure 5.2: A citizen's role during an election and orientations to voting ..........................................99

Figure 7.1: Agreement with duty statements by age .............................................................................. 142

Figure 7.2: Agreement with duty statements by voting behaviour...................................................145

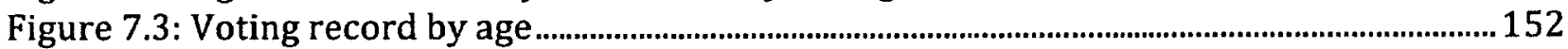

Figure 7.4: Correlations with Traditional duty by age ............................................................................. 161

Figure 7.5: Correlations with Conditional duty by age ....................................................................... 162 


\section{List of Appendices}

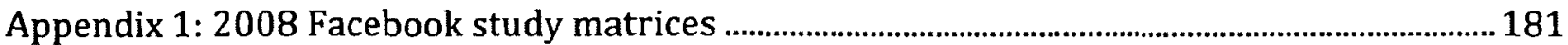

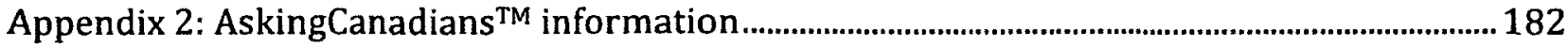

Appendix 3: Delvinia AskingCanadians ${ }^{\mathrm{TM}}$ survey, final civic duty questionaire............................ 183 


\section{Chapter 1 : The importance of the civic duty to vote}

\section{Introduction}

In recent decades established democracies throughout the world have experienced declining levels of electoral participation among citizens, particularly the youngest cohorts of the population. While the phenomenon of turnout decline is evident among all cohorts of potential voters, research suggests a substantial portion of the drop is attributable to the abstention of young people (Blais et al., 2004; Milner, 2004; O'Neill, 2003, Rubenson et al., 2004). In addition to their electoral disengagement, youth today are also more likely to have lower senses of civic duty, shy away from traditional channels of political involvement and exhibit a general detachment from traditional political objects (Cross, 2004; Norris, 2002a, 2002b; O'Neill, 2007). Many researchers cite these trends as evidence of a democratic crisis (Howe, 2007; Pammett and LeDuc, 2003; Putnam, 2000), whereas others suggest it may be a consequence of changes in how young people conceive of and practice citizenship and civic duty (Dalton, 2008; Norris, 2002a, 2002b). Quantitatively measuring change in citizenship norms is problematic however, given that the formation of the questions used to assess the strength of civic duty in most voting surveys is based on a traditional and static conception of civic responsibility generated by academics and researchers. Adequately charting the changes in young people's perceptions of civic obligation, particularly with regard to elections, requires revisiting how we measure civic duty to ensure that it reflects how it is imagined in the minds of young people. It is also important to make certain that the survey measurement of civic duty has the explanatory power to capture differences in the civic orientations of youth and account for how these orientations are guiding their electoral participation or abstention. 
The purpose of this thesis is to evaluate civic duty as it relates to elections and voting. Specifically, it aims to shed light on whether perceptions of the civic duty to vote are changing among the young and what effect, if any, this has on their willingness to participate electorally. A second purpose is to improve the conceptualization and measurement of civic duty in political surveys by reoperationalizing it to better reflect how young people conceive of it. The thesis relies on quantitative research from Canada, the United States (US), and Britain to provide an assessment of the current state of the duty to vote concept in surveys and corresponding research. It then looks more closely at Canada as a case study, relying on special qualitative and quantitative studies to determine whether the portion of civic duty that has traditionally embodied the importance of elections, and voting within them, is changing and how this can be accurately reflected in survey items.

The first part of the research uses qualitative focus groups to get a better sense of how young Canadians conceive of citizenship and civic duty. Drawing on these qualitative descriptions, the second part of the project devises quantitative survey items that reflect these new conceptions or interpretations of electoral civic duty. These survey items are then tested in a special national study. Overall, findings confirm that the present conceptualization of electoral civic duty is more nuanced than current research describes. The most powerful alternate dimension, termed 'conditional duty,' advocates an approach wherein the decision to participate rests upon an evaluation of electoral circumstances, which may involve the contextual variables of the election and the degree and quality of election information an individual possesses. Whereas traditional duty assumes participation every time, conditional duty justifies occasional or 'sometimes' participation. Evidence suggests these values about 
citizen obligation during elections are most prevalent among the young, but are also detectable in the attitudes of older generations.

The thesis proceeds in eight sections. This first portion serves as an introduction, outlining the scope of the project, summarizing the trend in voter decline and defining civic duty and citizenship. Here the rationale for revisiting electoral civic duty is clearly outlined. The second chapter looks more closely at the tie between electoral participation and civic duty. It begins by briefly examining the history of citizenship as it pertains to participation and how the act of voting developed and became synonymous with good citizenship (see Dalton, 2008 and Pammett, 2009). The chapter proceeds by reviewing the literature addressing political participation and electoral engagement. Central models used to study voting behaviour and the findings of key writings addressing the topic of turnout decline and weakening senses of electoral duty are outlined.

The third chapter focuses more specifically on the construction of civic duty and how it has been operationalized in Canadian, American, and British surveys over time. It points out that the duty to vote has not been treated as a central concept in voting behaviour research despite its explanatory value in turnout models. It proceeds by highlighting the unstructured nature of the duty to vote items, the inconsistency and infrequency with which they have been used, and the one-dimensional nature of the concept. ${ }^{1}$ The fourth section continues to focus on Canadian, American, and British research, looking at survey data from the major election studies to outline trends in electoral duty over time. It also examines levels of identification with traditional duty and investigates whether there is an age relationship with

\footnotetext{
${ }^{1}$ The one-dimensional character of electoral duty as it is currently operationalized.
} 
the traditional operationalization of the concept. Finally, the chapter assesses the degree to which it has had an effect on electoral participation.

The fifth chapter continues by analyzing the data obtained from a qualitative focus group study conducted via Facebook during the 2008 federal election campaign. It examines the accounts of civic duty and citizenship that emerged from this and outlines how these conceptions provide justification for reoperationalizing the construction of the current survey measure. This insight is used to shed light on other possible dimensions of a citizen's duty during elections that remain untapped. Based on these other potential facets of the duty to vote, new questions for measurement are devised.

Using factor analysis in two pre-tests Chapter Six works to refine the newly suggested questions by evaluating them alongside traditional civic duty survey items. Once sufficiently developed, the new measures are appraised in a special national survey and their value as potential future survey items assessed. Chapter Seven continues the evaluation of these measures by assessing what they mean for political participation. The relationship between traditional electoral civic duty and voting and the new dimensions of duty and voting are compared. Then, connections with other political attitudes popularly associated with explaining political participation are explored, particularly political trust, interest and efficacy. This analysis helps explain how we can characterize electors with a traditional sense of civic duty compared to those that better identify with and embody the attitudes associated with new dimensions of duty.

The final chapter concludes by exploring what we can learn from this research in terms of changing perceptions of duty among the young and also the importance of revising and testing tools of measurement used in research. This portion assesses what new duty 
dimensions mean for the electoral motivations of young people, future participation patterns, and electoral democracy more broadly. Suggested programmes for future research are also identified.

\section{The problem of turnout decline and weakening duty}

Elections are an essential component of the democratic system, often referred to in the literature as the "cornerstone of representative democracy" (Haste and Hogan, 2006:475) and as one of "the defining institutions of modern democracy" (Katz, 1997:1). The participation of citizens in the electoral process can be considered the 'lifeblood' of democracy, providing an important measure of democratic health (Franklin, 1996:216). Elections allow citizens to have a say in government, helps ensure public interests are represented and reflected in public policies, serve as a check on abuses of power by affording people the opportunity to remove a government, and act as a measure of legitimacy for the election of

governments. Voting is also one of the simplest means of political participation for citizens because it requires relatively little effort. Given the importance of elections for evaluating democratic prosperity and upholding the legitimacy of the political system, it is not surprising that turnout decline is considered problematic and raises questions concerning the future of democratic government.

In the past few decades rates of voting turnout have experienced persistent decline in most western liberal democracies (IDEA, 2002). A large portion of the decline can be attributed to the abstention of young people. In Canada for example, national turnout levels have fallen on a relatively consistent basis from 75 percent in 1988 to a record low of 59 percent in the 2008 federal election (Elections Canada, 2012; Goodman, 2005; Simon Fraser University, 2012) (see Figure 1.1). Turnout among young Canadians follows a similar pattern 
of decline by cohort and election (Blais and Loewen, 2011) (see Figure 1.2). Research suggests that these findings are consistent with patterns of engagement in other countries and regions, particularly in the United Kingdom, European Union, and the United States (Dalton, 2008; Delli Carpini, 2000; Norris, 2002a, 2002b; Print, 2007). Furthermore, despite the presence of compulsory voting, there is evidence that young people in Australia are increasingly shying away from their "electoral responsibilities" as well, albeit not to the same extent (Print, 2007:329).

Figure 1.1 Voter turnout in Canadian federal elections, 1988-2011

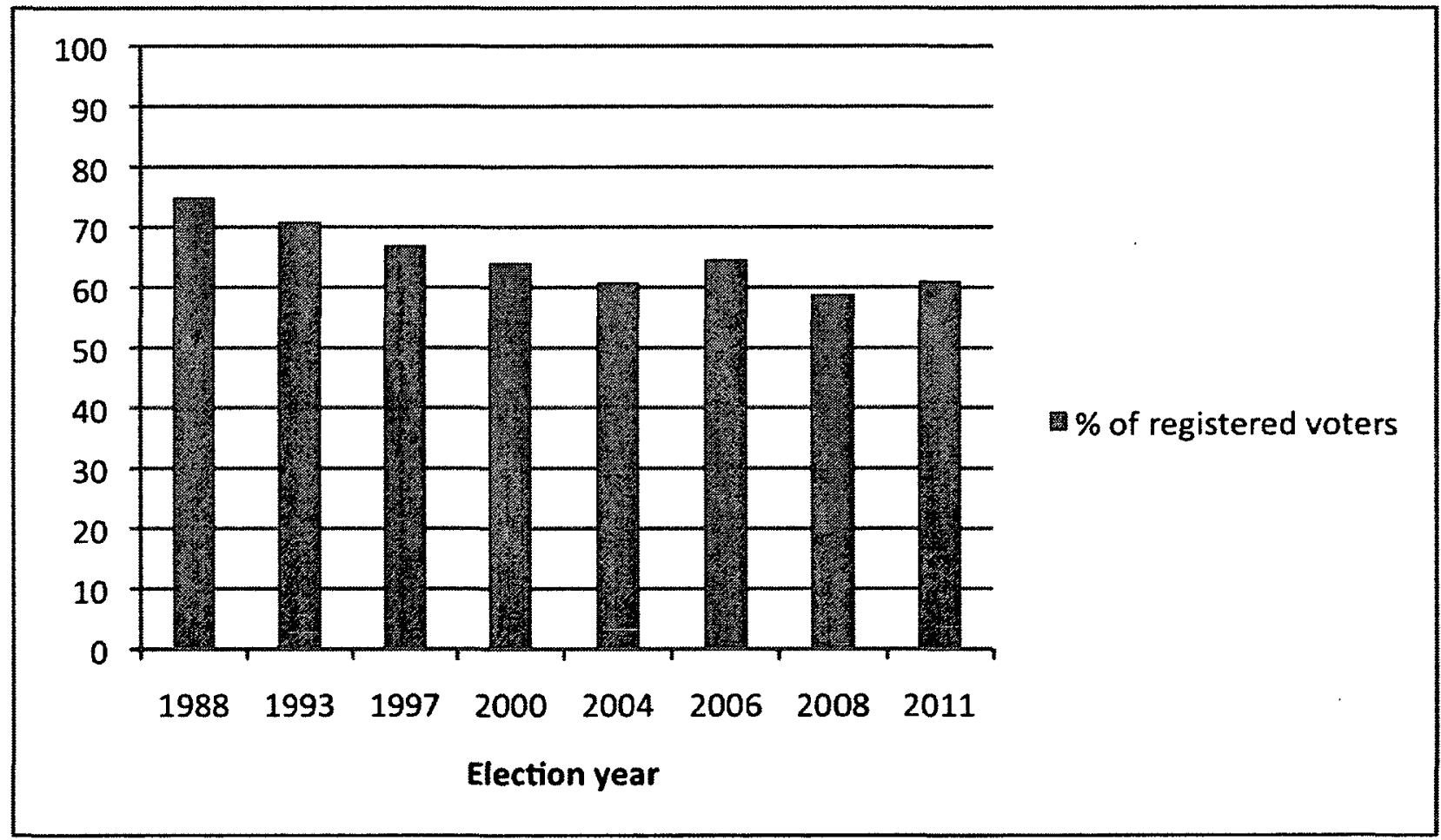

Source: Data taken from Elections Canada website (www.elections.ca) and Simon Fraser University's Elections website (http://www.sfu.ca/ aheard/elections/historical-turnouthtml). 
Figure 1.2: Estimated turnout by new cohort in Canadian federal elections*

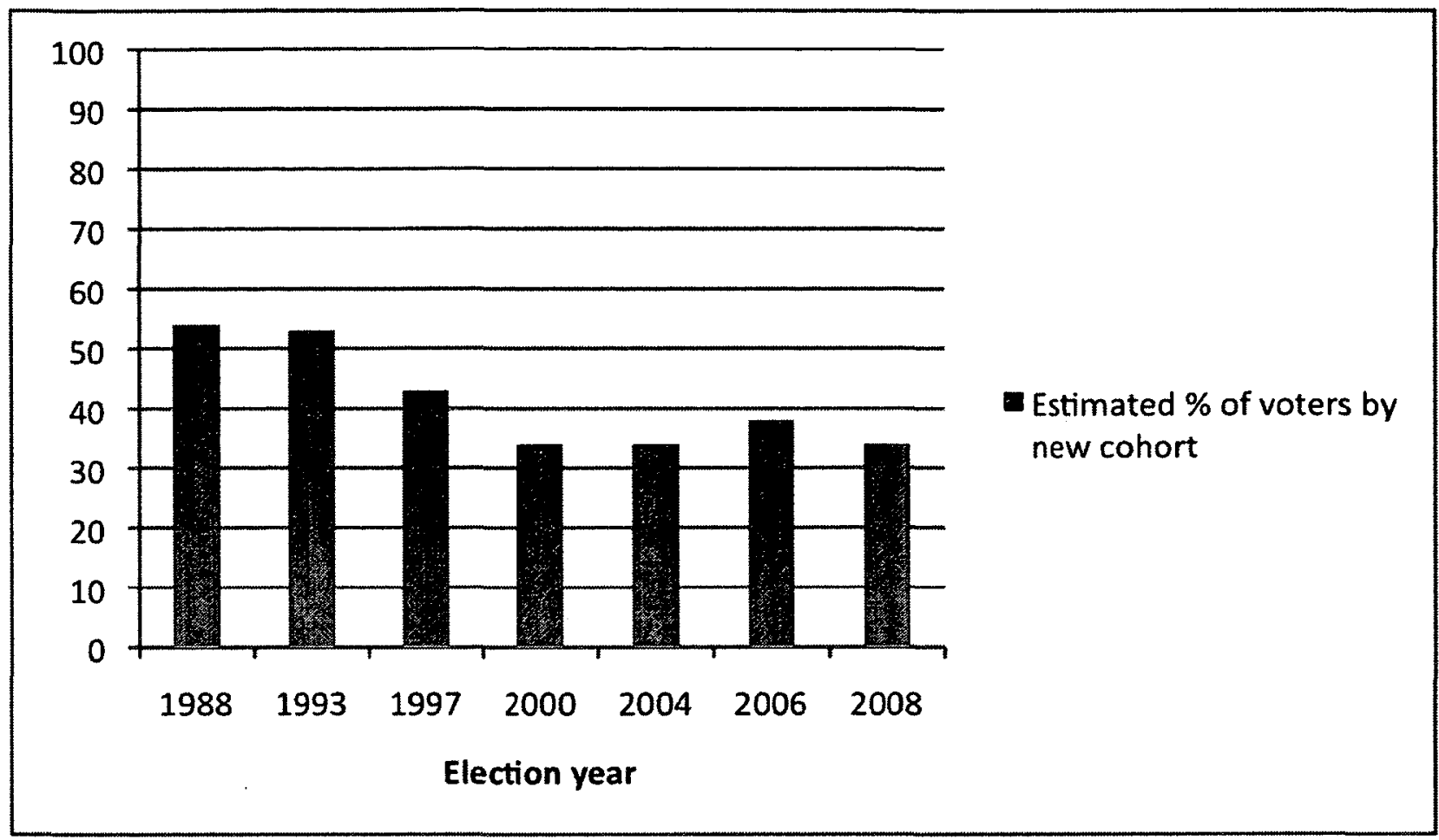

Source: Data taken from Blais and Loewen's Youth Electoral Engagement in Canada published by Elections Canada in January 2011. These are turnout estimates for newly eligible cohorts derived from a logistic regression model. *Note that the same cohort is used for 2004 through 2008 because in 2006 and 2008 there were not enough voters in the sample to be able to provide an accurate estimation.

While young people have always voted at lower rates than older electors, the recent decline presents a paradox because it has occurred despite the emergence of trends that have been theoretically and empirically linked to increased turnout. Notably, young electors today are more educated, have greater access to political information, and are the target of many comprehensive programs designed to promote electoral participation. Increases in education do not seem to have positively affected the political knowledge of young people nor strengthened their disposition toward traditional civic obligation despite the fact that research has established a strong level of association between education and voting (Jackson, 1995; Wolfinger and Rosenstone, 1980). The ability to access information more easily has not 
positively impacted the political knowledge and attentiveness of young people (Howe, 2010) and although mobilization tactics have been cited as effective engagement tools for electors, especially the young (CIRCLE, 2006; Gerber and Green, 2008) efforts by elections agencies and concerned organizations in Canada and many other western liberal democracies are not bringing the desired increases in voter turnout.

Besides the immediate decline in turnout, research reveals that the voting habits of young citizens are not developing as they have historically (Rubenson et al., 2007; Pammett and LeDuc, 2003; Wattenburg, 2007). This means that the voting habits of young potential voters are unlikely to reach the levels of turnout exhibited by their elders. In short, young people today do not attach the same degree of importance to the act of voting as their predecessors. They have weaker senses of electoral duty and are not developing stronger feelings over time like older generations. Electoral or civic duty to vote is typically cited by voters in surveys as a primary reason for participating and has been proven to be a powerful motivating factor in the decision to vote (see for example, Blais, 2000; Blais et al., 2002; Pammett and LeDuc, 2003). Concern that the public ethic of participation is declining and worry about the renewal of democracy by successive generations has surfaced in response to weakening levels of the civic duty to vote because of its intimate connection with turnout rates (Blais et al., 2002; Howe, 2007; Pammett and LeDuc, 2003; Wattenberg, 2007). Despite an abundance of scholarly research addressing the decline in the electoral engagement of young Canadians, recent reports continue to call for additional research and data collection and conclude, "we [still] do not know much about the causes of this decline" (Blais and Loewen, 2011:3). 


\section{Other types of participation and potentially changing duty}

In addition to the problem of voter decline and weakening senses of civic duty, levels of party and interest group membership, feelings of efficacy and trust in government, and involvement in civic associations such as unions and churches are also lower than in the past and do not show signs of improvement (Cross, 2004; Norris, 2002a; 0'Neill, 2007). Young people today are also less interested in politics and pay less attention to traditional media sources than older cohorts of potential voters (Wattenberg, 2007). Some research suggests that this indifference to traditional politics is supplemented by alternate patterns of participation which reflect engagement, albeit not as conventionally defined by political science literature or mainstream understanding of political involvement. Some of these nontraditional political activities include opportunities for Internet activism through interfaces such as Facebook, MySpace, YouTube and Twitter ${ }^{2}$ and other technological spaces such as cell phones and text messaging (Milner, 2010; O'Neill, 2007). Additional options are the participatory channels created by the emergence of new transnational social movements and policy networks and activities such as boycotting, buycotting, culture jamming, protesting, contacting the media, and signing petitions (Delli Carpini 2000; Gueorguieva, 2008; Norris, 2002a, 2002b; O'Neill, 2007; Print, 2007; Stolle et al., 2005). If the nature of civic and political engagement is evolving or expanding to include new dimensions it is important to understand and interpret how young people now conceive of the traditional duty to vote and the importance they attach to elections.

\footnotetext{
2 These interfaces are part of a new group of web applications called Web 2.0, which is distinct from traditional web pages in that they allow for two-way communication between the individual or group that posts the content and other users. These interfaces permit users to share pictures, videos, and information instantly, while allowing others the potential to comment and engage with the content virtually. Twitter in particular has been a key instrument of mobilization in recent social movement protests such as the Arab Spring and the Occupy demonstrations (Economist, April 7, 2012; Goodman and Copeland, 2011; Globe and Mail, August 19, 2011; Small, 2008; Small, 2010).
} 
Another related argument speculates that the norms of citizenship that shape political behaviour are changing and types and patterns of participation are shifting as a consequence (Dalton, 2008). It is plausible that conceptions of duty are changing to reflect alternate beliefs about participation and the priority given to elections. It may be that the portion of civic duty that has traditionally related to elections is conceptualized differently in the minds of young people than current measurement accounts for.

Aside from its intimate relationship with turnout, examining the duty to vote also requires paying close attention to basic conceptions of citizenship given the research finding that the level and scope of a person's engagement is typically reflective of their citizenship perspective (Pammett, 2009; Theiss-Morse, 1993). Recent work focusing on citizenship among young Americans (Dalton, 2008) highlights the interrelated relationship between citizenship and civic duty by breaking down what it means to be a good citizen into norms of citizenship. Within these norms (duty and engagement) Dalton theoretically and empirically establishes the interdependence that exists between perceptions of citizenship and notions of duty and obligation. Most scholarship that examines changes to notions of citizenship or citizenship norms however, centres little to no attention on the operationalization of the attitude of civic duty despite the interrelatedness of the concepts (Coffe and van der Lippe, 2010; Dalton 2006; 2008; 2011). Scholars have also focused attention on redefining civic engagement, but fail to substantially expand on duty (Delli Carpini, 2000; Milan, 2009; Norris, 2002a, 2002b; O'Neill, 2007). While there is speculation that perceptions and practice of citizenship and civic engagement are changing, there is little consideration that the various dimensions of duty may also be substantially influenced by the structural and cultural changes occurring in the world. In particular, researchers continue to view and test the 
portion of duty that relates to electoral participation by relying on its traditional operationalization.

The emergence of new actors and political spaces has fostered the development of new influences that impact our way of life and how we define concepts like identity, ideas of citizenship, and the elements of civic duty. Notably, the human rights movement in Canada and civil rights movement in the US both significantly impacted civil liberties as well as race acceptance. The women's movements in the 1970s and 1980s also had a profound effect on society, transforming the nature of historic gender roles. Furthermore, Canada has grown to be more ethnically diverse than ever before, critically changing the composition of civil society and perhaps altering traditional conceptions of citizenship. In addition, globalization, changes to the media climate, political processes, as well as changes to the political and economic environment are all factors that have impacted how citizenship is conceived and how democratic politics operates. Given the important effect of these influences on Canadian politics and the drastic social change that has occurred over the past 50 years it would be naïve to think that popular perceptions of the constituent parts of civic duty have not undergone a transformation, particularly its connection with electoral participation.

Dissecting the determinants of civic duty as they relate to elections is an important step toward developing a clearer understanding of the assumptions behind electoral participation and contributing to the creation of a more inclusive measure. Devising a more nuanced conception of duty has important implications for government, the formation of public policy, and citizenship. More generally, it has significant effects for the renewal and effectiveness of democratic institutions. Conducting voting studies with a more nuanced 
measure of civic duty will also hopefully shed light on the phenomenon of declining turnout among the young.

\section{Defining civic duty}

Civic duty is defined in Dictionary.com (2010) as "the responsibilities of a citizen." Interestingly, neither the Merriam-Webster nor Oxford dictionaries include mention of civic duty as an expression. Their definitions for duty however, include "obligatory tasks, conduct, service, or functions that arise from one's position (as in life or in a group)" (MerriamWebster, 2010) and "a moral or legal obligation" (Oxford, 2010). Civic, by comparison, is defined as "of or relating to a citizen, a city, citizenship, or community affairs" and civic duty and civic pride are offered as synonyms. Based on this information it would seem logical to conceptualize civic duty as the responsibilities or obligations that come with citizenship.

In political science literature, researchers often use civic duty as a means of evaluating 'good citizenship,' an important portion of which is intimately linked with the intention to vote (Almond and Verba, 1963; Dalton, 2008; Pammett, 2009). Membership in a community comes with various privileges and commitments and with the extension of rights there is also the implication of responsibilities. More specifically, the obligations that comprise the dimensions of civic duty or civic responsibility are conceptualized as corresponding to the rights of being a citizen (Conover et al., 1993; Isin and Turner, 2002; Pammett, 2009). These obligations or duties can be numerous or few, including, but not limited to, responsibilities such as military service, paying taxes, jury duty, contributing to the community, and voting. While there are multiple correlates of duty, which include various rights and obligations, the focus of this thesis is the dimension of duty that is central to electoral participation and elections - a citizen's electoral duty. Although the term civic duty can be used broadly to refer 
to many implied responsibilities on the part of the citizen it is customary in political science literature to speak about the dimension of duty that relates to elections and voting as 'civic duty.' Therefore, this thesis uses the term civic duty to refer to the same, sometimes making reference to a citizen's electoral duty or the duty to vote. Furthermore, for the purposes of stylistic relief terms such as obligation and responsibility are also used to refer to electoral duty.

The duty to vote is defined by Pammett and LeDuc in their 2003 Explaining Turnout Decline in Canadian Federal Elections: A New Survey of Non-voters as "the feeling that participation is to be valued for its own sake, or for its contribution to the overall health of the polity, and does not need to be justified on instrumental grounds" (38). The authors point out that factors such as the closeness of the race, charismatic leadership or parties, or important policy issues do not entice a dutiful voter to cast a ballot; rather it is the intrinsic value of voting itself that motivates these electors. Blais (2000) similarly defines electoral duty as "the belief that not voting in a democracy is wrong" (93). He explains that having a sense of duty means adhering to a norm or ethical judgment that voting is the right thing to do and not voting is wrongful behaviour. The empirical test to determine whether people adhere to the norm of duty simply requires assessing whether they would feel they were doing something wrong if they did not participate electorally. These definitions possess two common elements: (1) voting is perceived as a moral obligation; and (2) they are based on a belief in the importance of democracy and an appreciation of the value associated with the right to vote. These elements are echoed in other discussions about the meaning and benefits associated with citizen duty (see Riker and Ordeshook, 1968). In the traditional sense then, civic duty, as it relates to elections, can be defined as a moral obligation in which participation is valued for 
the health of democracy. Other literature also emphasizes a citizen's duty to vote as being a moral obligation rather than a legal one and confirms that duty is a motivating factor in the decision to vote and as such, is a strong predictor of voter turnout (Blais, 2000; Blais et al., 2004; Dalton, 2006; Gidengil et al., 2005; Wolfinger and Rosenstone, 1980).

The fact that there is a moral rationale behind traditional duty suggests that voting is what a good citizen should do (Blais, 2000). Other research supports that civic duty is an important social norm and as a consequence has many "expectations of how one ought to behave as a 'good member' of a particular group" associated with it (Raney and Berdahl, 2009). Dalton (2008) in particular suggests that civic duty is part of an important group of citizenship norms, which structure and inform how citizens perceive being a "good citizen." Research confirms that norms are often rooted in obligation (Campbell, 2006) and are important for supporting democratic participation (Putnam, 1993; 2000). The duty to vote then, as traditionally conceptualized, can be considered not only a moral obligation, but also an important social norm which helps understand and explain political participation, particularly voting in elections.

\section{Measuring civic duty}

Election and public opinion surveys have based empirical measures of civic duty on its scholarly definition. The duty to vote is assessed by a fairly limited range of indicators, which primarily focus on the importance associated with the act of voting, including the notion of voting as a moral obligation and voting as "an expression of faith in democracy" (Blais, 2000:111). Comparing electoral surveys from the same country in different election years, and across countries, reveals widespread repetition of questions. Because initially these questions were deemed to work well in assessing whether respondents considered voting a 
civic duty, the same statements have been repeated over time. While they may have been good measures of traditional duty at the time, they do not consider whether identification with voting in elections has changed or whether this conception truly captures the dimensions electoral duty comprised from the outset. Unfortunately, it is commonplace for widely used survey instruments to be similar in structure and content for consistency's sake over time and there is often not a substantial, sometimes not even a minimal, assessment of measures (Birch, 2008). For example, most survey items measuring duty, particularly the battery of questions used in many major election studies such as the Canadian Election Studies (CES), American National Election Studies (ANES) and the British Election Study (BES), measure duty by probing the degree of importance a participant assigns to voting per se, regardless of circumstances.

Specifically, the ANES has traditionally asked respondents to indicate whether they agree strongly, agree somewhat, neither agree nor disagree, disagree somewhat, or disagree strongly with the following statement, I feel strongly that I have a duty to vote in every election even if I'm busy or not very interested (ANES, 2008). Similarly and using the same scale, the BES asks participants to indicate how much they agree or disagree with the following statements, I would be seriously neglecting my duty as a citizen if I didn't vote, I would feel very guilty if I did not vote in a general election, and It is every citizen's duty to vote in an election (BES, 2005). ${ }^{3}$ The CES by comparison, has probed respondents to agree or disagree that, It is EVERY citizen's duty to vote in federal elections and I would feel very guilty if I did not vote in a general election (CES, 2000; CES, 2006). These questions are only some examples that point to

\footnotetext{
3 Please note that the emphasis here is taken from the question as written in the BES survey.
} 
the analogous operationalization of civic duty in surveys. ${ }^{4}$ Responses that report weak senses of duty by these standards form the basis of claims that civic duty is declining. Since strong senses of duty among citizens are taken as an indicator of democratic health, weakening notions of obligation are often cited as either an effect or cause of democratic erosion. To get a better sense of whether civic duty is actually weakening and should be taken as an indicator of a democratic deficit in established democracies or whether norms of civic obligation and engagement are changing among the citizenry, particularly the young, it is important to revisit and critically assess how we conceive of and measure the duty to vote.

Researchers and analysts often take for granted the ways in which survey measures are constructed and assume they are valid assessments of respondent attitudes or that there is a 'common understanding' between the researcher and the survey participant even though this may be false (Henn et al., 2002:168-9; Lupia, 2008a). The responsiveness of survey measures, particularly the "steps that a scholar adopts in the process of assigning a particular meaning to, or drawing a particular inference from, a given data set" are also questionable (Lupia, 2008a:733). It is important to make clear the key assumptions and conclusions that underlie the construction of terms and measures to ensure a greater degree of procedural transparency. This thesis aims to improve how civic duty is conceptualized and measured by researchers and evaluate whether it exhibits the same powerful relationship with the decision to vote that is assumed in current survey research. This research is not only theoretically important because it may help people to think differently about electoral duty, but also has practical relevance for government, public policy, concerned organizations, civil society, and the maintenance and renewal of democratic institutions and political processes.

\footnotetext{
${ }^{4}$ This aspect will be explored more fully in Chapter Two.
} 
The following section explores how participation, primarily in elections, has become a moral obligation and requirement of good citizenship. It begins by defining citizenship, examining its connection with participation, and briefly examining its history, tracing its roots back to Greek ideas of citizenship. This is followed by a discussion regarding how the relationship between citizenship and the act of voting developed and has become synonymous with the notion of the good citizen. 


\section{Chapter 2 : Citizenship and Participation}

\section{Introduction}

This chapter defines citizenship through a participatory lens and provides a brief historical context outlining how the connection between citizenship and participation emerged and has developed over the years. While there are many elements to citizenship and the story of its advancement is complex, this thesis only discusses the historical evolution of citizenship as it relates to participation and public involvement particularly through elections since the component of electoral duty is the primary focus of this work. A literature review addressing works on political participation and civic duty follows suit, setting the stage for the importance of the concept for research yet its underutilization in current writings.

\section{The link between citizenship and participation}

Defining citizenship is a challenging task given its fluidity and the many aspects it can refer to. As Tilly (1996) remarks, "no standard definition of citizenship has yet gained scholarly consensus" (8). He goes on to explain, however, that the concept of citizenship can "refer to a category, to a tie, to a role, or to an identity, built on one of them, even on several of them" (8). Multiple meanings and uncertainty as to the boundaries, which structure the practice of citizenship and what it encompasses, make assigning a particular definition difficult. One of the more comprehensive definitions of citizenship is presented by Bernard Crick (2004) wherein he argues that citizenship can carry four meanings: (1) it can recognize legal status as well as rights and duties within the state; (2) it can refer to the belief that countries with representative government and democracy depend upon high levels of 
participation by active citizens; (3) it can refer to the ideal of global citizenship and the notion of acting as citizens of one world; (4) and can also signify an educational process whereby people are taught in school how to carry out the duties implied in the second and third meanings. These meanings can either stand-alone or blend together to form popular conceptions of citizenship.

Despite the ambiguity associated with the meaning of citizenship, many agree it possesses two central constituent parts - rights and obligations. On the one hand, being a citizen bestows individual rights such as freedom of speech, the right to vote, to work, to own property, etc. On the other, it suggests responsibilities to the community, which can include paying taxes, serving in the military, jury duty, and voting. So while citizenship enables political freedom and privilege, it denotes a degree of responsibility as well. Obligation is an important aspect of citizenship because it "requires us to remain critical of our political institutions and to help those who are alienated from the system to develop a sense of obligation and commitment to it" (Faulks, 2000:81). Faulks explains that duties may be perceived as responsibilities that are imposed by law or by which disobedience results in some kind of sanction, whereas obligations may be regarded as voluntary acts or as expressions of empathy. Fulfilling the "conditions of the community" in healthy democratic societies however, only requires a sense of obligation instead of "imposed duties" (Faulks, 2000:82). Despite this distinction, responsibilities, obligation, and duty seem to be used somewhat interchangeably when referring to a citizen's duties (particularly a duty to participate). Furthermore, many types of obligations or responsibilities are often perceived as facets of a person's civic duty even though failure to honour them may not result in any particular sanction. The obligation to vote is one of these duties, albeit one of many. As noted 
earlier, there are multiple aspects or correlates of duty that include various rights and obligations, and one of these dimensions of duty, a citizen's electoral duty, relates to electoral participation and elections. While voting in elections is not the only aspect of civic duty, the portion of duty that relates to elections and voting is the focus of this research.

For the purposes of this project Aristotle's explanation of citizenship, which recognizes citizens as "all who share in the civic life of ruling and being ruled in return" provides a useful definition (Barker, 1946:1283). This definition suggests citizenship is democratic because it implies the importance of citizens sharing in governing (even if only through elections or other participatory means) and that the system must be responsive to the interests of most of those citizens (Thompson, 1970). It also emphasizes the ethic of public participation and the balance between rights and responsibilities that comes with the extension of citizenship. Other works (e.g. Faulks, 2000; Pateman, 1970) also recognize political participation as the central bridge uniting both rights and responsibilities. Because the status of citizenship suggests membership and inclusion in a community, it affords individual autonomy while at the same time recognizing individual contributions to that community. Faulks (2000) argues that this autonomy is reflected in rights and that their presence signifies political agency on the part of the citizen. For this reason, he says, "a key defining characteristic of citizenship...is an ethic of participation" (4).

Schumpeter (1950) also emphasizes the election of leaders as a primary function of citizenship and points to the dependence of democratic theory on active citizen-participation. Dalton (2006:2) refers to participation as the "prime criterion for defining the democratic citizen and his or her role in the political process" and many others echo that public participation in the political process, particularly through voting, is a central component of 
democratic citizenship (e.g. Dahl, 1998; Pateman 1970; Verba et al., 1995). Furthermore, historical and contemporary accounts of active citizenship are often treated as synonymous with good citizenship. Normative assumptions about what is considered good citizenship are also commonly associated with a commitment to political participation and a citizen's duty to participate electorally (Dalton, 2008; Pammett, 2009). As Heater (2004) remarks, "During the course of this century it has generally been held to be a mark of good citizenship for the citizen to use his or her vote" (97). Thus, according to the literature, voting is not only a core component of citizenship, but active participation in the political process (e.g. voting) is also a defining characteristic of good citizenship.

\section{History of citizenship as it relates to participation}

Historically, the concept of citizenship has been about an individual's interactions with the state. The earliest records of citizenship emerged with the Greeks who believed that participation in public life was an essential prerequisite if man were to achieve his full potential. Aristotle (1941) in particular, defines a good citizen as one who possesses "the knowledge and the capacity requisite for ruling as well as being ruled" (Barker, 1958:1277). Similar to his more general definition, themes of obedience and responsibility are also central here. For the Greeks citizenship depended more on the citizen responsibility aspect rather than on the rights to be claimed. It was a type of bond that was forged by participation in public life. Service to the community (e.g. military service or political participation) was primarily seen as an expression of good citizenship (Heater, 2004; Preuss, 2003). These obligations however, were not perceived as legal duties, but rather opportunities to serve the community. The political community and not the individual was the focus of loyalty and guidance. This conception highlights that, since its emergence, the notion of citizenship and 
the ideal of a good citizen has been intimately linked to participation in political affairs.

In Roman times citizenship's focus on participation shifted somewhat. Although voting in the assembly remained a central privilege, citizenship became increasingly detached from participation and used as a tool for social control to advance interests related to territorial expansion. While the focal point of good citizenship in Roman times remained service to the state, it was not as much associated with political participation (although it was still very much a requirement) as it was on military service. The Church also replaced the political community as the focus of loyalty and guidance. Medieval citizenship was also not as centrally focused on participation, emphasizing people as subjects and the importance of their allegiance to the Church and the Crown. That said, obeying laws and participating in the life of the community remained part of being a citizen. Therefore, despite changes in citizenship regimes, participation continued to be a moral obligation of citizenship (Heater, 2004; Smith, 2002).

Though there are variations of the concept of modern citizenship, a core element was action that supported civic responsibility and citizen action for the betterment of the community. The emergence of the concept of the nation-state made defining citizenship, and the boundaries it operated within, easier to navigate. There continued to be a high level of political consciousness during this time, despite the fact that enfranchisement was still limited to property owners. Discussing citizenship in the modern era, Kalberg (1993) remarks that during this time it was not political and civil rights that were given prominence, but rather "the duties and obligations of citizens to participate in political decision-making processes" (98). He goes on to explain the importance of citizen activism for the maintenance of democracy and upholding the ideal of a government 'by the people'. As the Church became 
less important during this time, the legacy of civic activism and participation carried on. Furthermore, the conception of citizenship gradually expanded to include activities beyond voting such as political party membership, writing letters to government representatives, petitions, involvement in interest groups, and taking part in protest activities.

During the development of modern citizenship, theorists such as Locke emphasized the importance of popular consent for the legitimacy of government and argued that the needs and wishes of citizens should be a priority for government. Rousseau also stressed the necessity of each citizen partaking in political decision-making through participation (see Pateman, 1970: Chapter 2). These kinds of ideas reinforced beliefs about the importance of political participation, particularly voting. Voting continued to be regarded as a core tenet of democracy and as such, a primary requirement of citizenship.

The importance of voting and citizen participation has been carried through to present day conceptualizations of citizenship and citizen responsibilities. Discussing the evolution of citizenship Thompson (1970) explains that the ideals of Athenian citizenship that survive today imply "active involvement in political life" and the capacity to influence politics (2). He identifies participation, discussion, and voting as standards of citizenship that are important in attaining various degrees of democracy. The primary differences between Greek citizenship and the modern idea include the expansion of the right to vote to all eligible citizens and the belief that citizens participate politically not only to express public interests, but also personal ones. The moral imperative of citizens is to have a say in the decisions that affect them through participation in regular elections (Katz, 1997:93). A core component of democratic citizenship remains citizen involvement, of which voting is an important element (Dahl, 1998; Katz, 1997; Pateman, 1970; Thompson, 1970). Though there are many ways of 
participating politically voting continues to be a considered a significant expression of active citizenship because of its participatory contribution, particularly its promotion of selfrealization and legitimacy.

Other facets of citizenship, such as its relationship with capitalism, social welfare, social control, etc. are not mentioned in the brief history above despite the fact that they may be important concepts in understanding the general evolution of citizenship. They are not included in the discussion, however, because they are not as relevant to the development of the relationship between citizenship and participation and are beyond the scope of this thesis.

Based on the preceding discussion it is evident that citizenship, at least the democratic kind, demands participation by citizens. Of the potential forms of participation, voting is the most common and is intimately linked to electoral processes. The fact that voting in elections is regarded as a core activity and responsibility of citizens clarifies why researchers consider voter turnout to be a key indicator of democratic health. In part, it also accounts for why low levels of electoral participation are deemed problematic for maintaining a healthy democracy.

\section{Political participation and civic duty literature}

The body of literature addressing the topic of political behaviour, particularly studies that focus on Canada, is primarily concerned with unmasking the causal factors responsible for declining voter participation. Explaining declines in political party membership and involvement, increasingly negative orientations toward attitudes such as political trust, interest, feelings of efficacy, and civic duty, and falling levels of political knowledge are also important areas of focus. The majority of literature addresses voter turnout, however, because of the assumption that it is a primary marker of a country's democratic health. This section provides a review of the literature on political participation. It looks briefly at the four 
principal models used to explain changes in turnout and affiliated research which seeks to identify the determinants responsible for non-voting among young people in Canada and other western liberal democracies. The main theoretical arguments are situated in the literature and evidence provided in a Canadian context. The goal is to provide an overview of the literature and illustrate that the Canadian case is consistent with the patterns of disengagement that research has identified.

The sociological or socioeconomic model (SES) first developed by Berelson et al. (1954) and later expanded on by Verba and Nie (1972) argues that components of an individual's socio-economic status such as education, income and employment as well as their civic orientations have great importance for explaining citizen participation in elections. Factors such as age, gender and race also serve to apply a sociological pressure that influences a citizen's electoral behaviour. For example, the greater the level of education people have and the more developed their civic skills, the better able they are to understand the complexities of the political process and the more likely they are to be socialized to view voting as an important act. Education and age are especially important in explaining turnout among young potential voters. In particular, the notion of age as an explanatory factor in electoral participation is the basis for two of the more prominent explanations presented in the literature that attempt to theorize why there is a drop in turnout and why this decline is largely confined to young potential voters.

The first framework takes age as an important sociological pressure on the act of voting, arguing that voting habits develop with "life-cycle" change (Blais et al., 2004; Nevitte et al., 2000; O'Neill, 2003, 2007; Pammett and LeDuc, 2003; Wolfinger and Rosenstone, 1980). It posits that as individuals mature and encounter the responsibilities of adulthood (e.g. 
marrying, purchasing a house and attaining full-time work, etc) their perceived stake in the political process increases. Likewise, an individual's sense of civic duty is strengthened with age as the duty to vote becomes more important because of increases in education, the establishment of roots in the community, and influence from politically active colleagues, friends and family. As life-cycle change occurs, voting rates increase correspondingly. Therefore, the likelihood of voting increases with age.

The second framework, based on generations, argues that the widespread disengagement of young people is the result of long-term social change. There are four important theories within the literature that support the notion of generational change, albeit crediting the change to different causes. These include the erosion of social capital (Putnam 1993, 2000), value change (Inglehart 1990; Nevitte, 1996), a change in civic norms (Dalton, 2008), and a decline in community and subsequent rise of individualism (Howe, 2007; Inglehart, 1990; Nevitte, 1996; Putnam, 2000). Each theory takes a different position as to why the political attitudes, and habits of electoral participation, among today's youth are different, but the central cause of the difference in the perceived importance of elections and electoral involvement is generational change.

Originally introduced in Making Democracy Work (1993), and more fully developed in his study Bowling Alone (2000), Robert Putnam argues that long-term social changes have influenced the nature of modern democracy and prompted the erosion of social capital by emphasizing the importance of volunteer groups and civic associations for political engagement and stable government. Particularly, he argues that young people's political attitudes and non-voting behaviour reflect their lack of participation in social networks such as voluntary associations, membership in groups, electoral opportunities such as voting and 
campaigning, and political forms of engagement such as contacting the media. This decline in social networks and "the norms of reciprocity and trustworthiness that arise from them" has eroded the levels of social capital within American society, significantly impacting the political behaviour of younger cohorts of citizens (19). With generational change the supply of social capital is shrinking and negatively impacting the political and civic involvement of young people, particularly their electoral participation.

Pippa Norris (2002a; 2002b) also focuses on the concept of social capital to illustrate an evolution in the opportunities for political participation. She argues that the theoretical frameworks and core concepts we rely on to explain and understand political participation require revision to better reflect and analyze the significant shift in both the scope and type of opportunities for participation that have emerged in the twenty-first century. She contends that in recent decades there has been a 'diversification' in the political agencies, repertoires, and targets available to citizens. This includes a transformation in the "collective organizations structuring political activity", the actions available for political expression, and the political actors that participants focus on influencing (2002a:216; 2002b:1). Instead of asserting that political participation and mobilization has deteriorated, Norris argues there is significant evidence that the avenues of democratic engagement have merely evolved in response to the creation of new spaces and consequently the emergence of a new structure of opportunities. To support this reasoning she points to large increases in protest politics, the emergence of new social movements, and the expansion of Internet activism.

The post-materialism theory advanced by Ronald Inglehart (1990) and applied to Canada by Neil Nevitte (1996), also addresses social change and is relevant to declining levels of political participation and civic duty. Inglehart and Nevitte attribute the generational 
differences of today's young people to a shift in values from a materialist outlook to one characterized by post-materialism. They argue that the value priorities individuals develop in the formative years of life are a product of the social and political conditions at the time. Young people today have alternate conceptions of civic responsibility and do not attach the same importance to the act of voting because their social values are different from older generations of citizens given that they were not exposed to similar physical, social, and economic threats to security. Specifically, in his examination of Western Europe, Inglehart (1990) illustrates that younger citizens were indeed more likely to embrace post-materialist values than older citizens. This value change in young people has actualized politically by giving new issues such as environmentalism and non-traditional political activities greater importance.

Nevitte's (1996) expansion highlights that young people in advanced industrial democracies are less deferential and accepting of traditional norms than older groups of citizens and points to the implications of this for democratic citizenship. Importantly, given that they are less deferential to authority, youth today are more likely to reject the dimension of civic duty which suggests that participation in elections is an important civic obligation. Studies that have since examined the impact of the political attitudes of young people on their electoral behaviour support Nevitte's thesis showing that youth are less likely to perceive voting as an important political act and therefore have lower senses of civic duty (Howe 2007; Gidengil et al., 2002; O'Neill, 2007, Pammett and LeDuc, 2003, among others). Archer and Wesley (2006:1) in particular, conclude that civic duty is likely "at the heart of youth disengagement." They highlight the power of civic duty in explaining turnout decline among youth over other predictors of voting such as resources, party mobilization, socialization, 
disengagement from civic affairs, and attitudes toward the political system.

Drawing on the premise of generational change in his analysis of citizenship in America, Dalton (2008) argues that the social restructuring of American society has facilitated dramatic changes to the norms of citizenship, creating two types of citizenship: duty based and engaged. Duty-based citizenship reflects the traditional expectations and norms of citizenship, and includes participation in activities such as voting, paying taxes, membership in a political party and so on. Engaged citizenship, by contrast, reflects a broader notion of citizenship and civic duty. It stresses a more assertive role for citizens, recognizing the welfare of others and social concerns as elements of citizenship. Dalton argues that young people may be increasingly disengaged from duty-based citizenship, but their commitment to norms of engaged citizenship is growing.

Building on the work of Putnam, Inglehart, and Nevitte, Paul Howe (2007) outlines another explanation that potentially accounts for declining levels of participation and senses of civic duty, which he argues, "emerged out of a common thread running through the social capital and post-materialist accounts of the evolution of contemporary society" (251). He highlights that Putnam, Inglehart, and Nevitte all point to a rise in individualism and corresponding decline of community among citizens today, particularly youth; although they take different positions about whether this change is positive or negative. Howe argues that Inglehart and Nevitte are optimistic about this newfound autonomy whereas Putnam laments the loss of community (252). The more individually oriented people become, the less likely they are to vote for the benefit of the community since voting is a community activity that brings people together and often extends a sense of belonging. A dearth in the importance of community translates into a decrease in the stock of strong senses of civic duty within civil 
society. Instead of voting for the greater good of the community because it is a civic obligation, young people today are more likely to pursue activities that further their own agenda.

Within these theories about the effect of generational change on the political participation patterns of youth, there are two separate currents of opinion concerning the decline of political engagement: those who warn about the future health of democracy because of citizens' lack of engagement in conventional methods of political involvement and activism (see Haid, 2003; Howe, 2007; Pammett and LeDuc, 2003; Putnam, 2000 and others), and those who question traditional assumptions about citizen engagement by arguing that democracy is evolving, not endangered. This latter group also advises that we must critically re-evaluate the theoretical frameworks and conceptual tools we use to analyze these processes to adequately understand these changes (see particularly Dalton, 2008 and Norris, $2002 a ; 2002 b)$. Thus it is not clear at this point whether we should lament a decline in the importance of elections and electoral involvement among young people, or if their rejection of traditional networks, norms, and channels of engagement and apparent affinity toward nontraditional political activities is indicative of a broader shift in their political and civic consciousnesses. While it is clear that change is occurring the extent of the change and the democratic implications associated with it merit further research.

The importance of age is also relevant for the socio-psychological model because it has an effect on attitudes such as political efficacy, political interest, and political knowledge. This framework argues that psychological determinants are more powerful than sociological influences when it comes to predicting voting behaviour (Campbell et al., 1960; Delli Carpini and Keeter, 1996; Prewitt and Nie, 1971). For example, the more developed a citizen's 
cognitive skills, the more able $\mathrm{s} / \mathrm{he}$ is to disseminate and collect political information, and navigate through the political process connecting political options to preferences. Research on the political behaviour of young Canadians confirms that age has an effect on political interest and levels of political knowledge. For example, drawing on data from the 2000 Canadian Election Survey André Blais et al. (2002; see also Gidengil et al., 2003; Rubenson et al., 2004) argue that young people today are "tuned out" of politics, meaning they are not interested or paying attention. The authors show that young Canadians (born after 1970) report an average interest score of 4 on a scale of 0 to 10 , whereas those born before 1945 report an average score of $6(52)$. They suggest that low levels of interest in political objects may be the result of weakening senses of duty among youth.

A competing examination of the same election by André Turcotte (2004) suggests that young people are not necessarily "tuned out" as they are "turned off" politics, given that the system caters to older citizens. Using POLLARA data, Turcotte provides evidence that young Canadians have different priorities and, as a consequence, interact with the political process differently than older cohorts of potential voters. His 2007 project confirms this finding by exploring the factors apart from disinterest that account for why young people are less likely to vote (Turcotte, 2007).

Likewise, in terms of knowledge Gidengil et al. (2004) demonstrate that young Canadians know less about politics than their elders. Though they attribute much of this to life-cycle change, work by Howe $(2003 ; 2006)$ which also shows declining levels of political knowledge among young people in Canada, argues that increasing gaps in knowledge are the result of cohort effects and reports that a lack of knowledge has an important effect on the turnout of young people. Other research (Milner, 2002) also provides support for the 
widening knowledge gap between younger cohorts and older voters arguing that young people have lower levels of civic literacy. In addition, although the patterns of decline are not as distinct across age groups for feelings such as efficacy and trust there is evidence that levels of trust are not particularly high (0’Neill, 2007).

Aside from the importance of attitudes in vote choice, the socio-psychological model primarily focuses on party identification and its power to filter attitudes toward issues, political party candidates, and political parties, which are considered to be the more proximate determinants affecting the decision to vote (Campbell et al., 1960). Research focusing on Canada has shown that young Canadians have weak and unstable partisan ties and cite this as another factor associated with turnout decline (Bélanger, 2004; Clarke et al., 1996; Cross, 2004; Cross and Young, 2004; Gidengil et al., 2002; Rubenson et al., 2004). Clarke et al. (1996) for example, highlight the brokerage character of federal political parties as fostering pliable ties between parties and potential voters given that watered down mandates make it more challenging for people to distinguish between policies. While the exact effect of anti-partyism on the voting habits of young people has not been clearly established, later research provides support for the claim of anti-party sentiment among young Canadians (Bélanger, 2004; Gidengil et al., 2002) and simply weaker ties than older generations (Rubenson et al., 2004). There is also evidence that young people are less likely to seek out membership in party organizations, or involvement within them more generally (Cross, 2004; Cross and Young, 2004).

Mobilizational models, by comparison, explain turnout based on opportunity structure and resources. Solicitation from various groups or networks such as political organizations, associations, political parties, family, friends, and colleagues improves a citizen's attitudes 
toward politics and create social pressures that render an elector more likely to vote (Rosenstone and Hansen, 1993; Verba and Nie, 1972). The stronger the external motivation to vote the more likely an individual's internal motivation will be. Frameworks that focus more on resources (see Verba, Brady, and Scholzman, 1995) posit that the motivation to participate is contingent upon various assets such as money, time, and civic skills.

Presumably, the 'richer' the citizen with respect to these resources the greater the likelihood that he or she will participate politically. The erosion of social capital, for example, can be taken as a resource whose declining stock negatively impacts mobilization. In a Canadian context, Pammett and LeDuc (2003) provide evidence that party contact is a useful predictor of turnout. As well, work by Gidengil et al. (2002) and Black (2003) confirm the effect of mobilizational factors in terms of party contact and the shift in voting registration procedures from enumeration to a permanent register of electors.

Finally, a prominent explanation for the motivation to vote and its relationship with civic duty is the 'calculus of voting' or rational choice model first developed by Anthony Downs (1957) and later expanded by Riker and Ordeshook (1968) and others (Ferejohn and Fiorina, 1974; 1975). Rational choice focuses on the expected benefits of voting. It takes various preferences (e.g. values, attitudes, beliefs) as the basis for voting behaviour. It asserts that an individual will assess the expected utility of all possible decisions and then based on his or her preferences will select the option that delivers the greatest benefits. For voting to be rational however, the personal benefits have to outweigh the personal costs. This is contingent upon the probability that an individual's vote will be 'decisive' in the sense that it will impact whether his or her preferred candidate wins or loses. Within this framework voting is not 'rational' in many instances because of the sheer number of votes cast. Based on 
this logic it would hardly be rational to vote, yet many do. To amend this conflict a 'D term' was added into the rational choice equation. For Downs D represented "the value of seeing democracy continue" (1957:267-70) and was refined further by Riker and Ordeshook to symbolize citizen duty in an election or "compliance with the ethic of voting" (1968:28) and other values such as efficacy and support for the political system. In both cases the $D$ term proved to have a powerful effect on the decision to vote or abstain.

Many scholars refer to the rational choice model to explain the behaviour of Canadian electors, particularly youth (e.g. Blais, 2000; Blais and Achen, 2010; Pammett and LeDuc, 2003; Turcotte, 2007). In their Survey of Non-Voters for example, Pammett and LeDuc (2003) find that electors are more likely to vote in certain situations where their vote is likely to make a difference or matter. Likewise, Blais et al., 2002 find that the likelihood of abstaining is greater when an election is not competitive. In fact, many of the reasons cited for young people not participating can be accounted for with rational choice logic such as low levels of political interest (Turcotte, 2007), a lack of understanding or information, and being "too busy" to participate on election day (Pammett and LeDuc, 2003). In these instances the costs of voting outweigh the benefits of participating and so the rationality of voting is negative. It may be, in part, that young people today perceive voting to be an irrational act because the costs of participating are greater than the benefits (Goodman et al., 2011).

Although this is not a comprehensive account of the literature that addresses turnout, briefly reviewing the arguments that attempt to explain both a variation in turnout and the lack of political engagement on the part of young people suggests that there are multiple important predictors of turnout. Levels of political interest and knowledge, attitudes toward political parties and party leaders, involvement in voluntary organizations and civic 
associations, changing citizenship norms, transformation of opportunity structure and opportunities for involvement, value change, and weakening senses of civic duty are all cited as competing explanations. Likely a combination of factors has the greatest explanatory power to account for the low levels of turnout among youth.

\section{Conclusion}

While civic duty is not the only determinant that is linked to turnout decline, it is an important indicator of a citizen's willingness to participate. Given its salient relationship with elections, both as a moral obligation to participate and a belief in the importance of voting for democracy, civic duty is a necessary component in interpreting and understanding turnout and the meaning of elections. Its importance also stems from the intrinsic relationship between duty and citizenship. Yet while there is much debate surrounding the causal factors responsible for declining turnout, there is relatively little work or critical assessment of the tools researchers use to measure attitudinal variables like civic duty. It is useful to continually use similar tools of measurement for purposes of comparison, but these tools are only efficient if they are accurately targeting the information they are designed to obtain. If the researcher and research subject do not possess the same construction or understanding of the attitude to be tested, data can easily be misinterpreted. For this reason it is important to regularly review and test tools of measurement used by political researchers, especially when the data they collect is used as the basis for broad and important conclusions about democracy and citizenship.

Justification for a project of this nature is clearly outlined by Russell Dalton in his book, The Good Citizen, where he observes: "The fact remains, we cannot return to the politics of the 1950 s, and we probably should not want to. But we can improve the democratic process if we 
first understand how...[the] world...[is] really changing" (2008:6). By understanding how civic norms are presently conceptualized in the minds of young citizens we will be better able to chart their transformation as well as devise more accurate tools of measurement. Developing a more authentic portrait of young people's civic duty today will facilitate more careful theory development and will give scholars, researchers, governments, political parties, concerned organizations, and citizens a clearer look at where political participation, citizenship, and democracy are headed.

The subsequent chapter more carefully outlines how civic duty is theoretically defined and assesses how this construction is problematic. It also addresses, in greater detail, how we measure and evaluate civic duty in empirical studies, particularly large scale statistical surveys (voting surveys and other surveys that probe people's political attitudes). The similarities and differences of these measures are compared and contrasted. The chapter also outlines existing measures from Canadian, American, and British surveys and problematizes them in preparation for the results portion addressed in Chapter Seven. 


\section{Chapter 3 : Assessment of civic duty survey measures in the United States, Britain and Canada}

\section{Introduction}

This chapter focuses on how the civic duty to vote has been operationalized and measured in empirical surveys over time. It begins by discussing the importance of duty and its relationship with turnout, which includes discussion regarding the purpose of the concept, why it emerged, and the role it serves. It then examines the history of duty in American, British, and Canadian survey research and critically assesses the types of survey measures that have been used to gauge senses of civic duty to vote. The chapter proceeds by reviewing some of the more prominent publications that have come from voting studies and discusses how they conceptualize and talk about citizen duty in elections. Based on these research findings, this portion also discusses trends or patterns in the civic duty to vote, particularly among young people, given that they are a central focus of this thesis. By shedding light on how civic duty has been measured and used in key writings the goal is to provide a clearer picture of the current conceptualization and the relationship between the ideal of citizen duty and voting in elections.

More specifically, the aim of the chapter is to illustrate the unstructured nature of the current survey measures of civic duty and the inconsistency with which the concept has been measured over time. It points out that despite its establishment as the most powerful predictor of turnout, duty has not occupied a prominent position in a majority of the analyses and research that have emerged from the national election studies and other attitudinal surveys that study public opinion. Furthermore, while no entrenched items or scale of measurement have been developed for duty, its current conceptualization is one-dimensional 
in the sense that it posits a single underlying component or dimension associated with the portion of civic duty that relates to elections. For example, it does not allow for the possibility that duty as conceptualized by citizens has an internal or personal duty dimension (what people perceive is really expected of themselves as citizens today) in addition to a general feeling of external duty for all citizens (a notion of what is expected of all citizens in an ideal context). A duty to cast an informed ballot or be well informed in an election when voting is another possible dimension. Additionally, in its current state, there is no clear explanation of where the concept of duty came from, nor is there a detailed account addressing the nature of the notion civic duty in election context.

\section{Importance of duty in surveys and its relationship with turnout}

Since its emergence in voting surveys civic duty has also been termed a sense of political responsibility and/or a sense of civic obligation. These terms and phrases capture the notion that participating in elections is something that ought to be done, regardless of whether the act of voting is perceived as something that is worthwhile or efficacious (Campbell et al., 1957:194). Over time civic duty has been gauged using many different types of measures, but all have been designed to reflect the same fundamental definition - a belief that voting is important regardless of the circumstances surrounding an election and recognizing the value of voting for democracy. For example, some survey items directly and explicitly include mention of the word "duty," while others indirectly probe the importance a respondent attaches to the act of voting. These latter style questions either clearly include mention of it "being important to vote" regardless of circumstance, odds, or perceived significance, or allude to the importance of casting a ballot by probing feelings of guilt for not participating. 
Items probing civic duty can be further distinguished by positive (e.g. it is important to vote) or negative phrasing (e.g. it doesn't matter whether I vote or not) and whether they are written to target a respondent's opinion generally about the role of citizens in elections (e.g. it is every citizen's duty) or more specifically to evaluate participants' thoughts regarding their personal duty when it comes to elections and voting (e.g. it is my duty to vote). Aside from these alternate wording strategies however, as currently conceptualized the construct of citizen duty can be considered one-dimensional given that all measures of duty take the same definition as their baseline and no further conceptualization has been pursued.

In the context of measuring attitudes one-dimensional can be defined as "a set of items that correlate well with each other" and therefore all items in a given scale "reflect[s] a common construct" (DeVellis, 1991:25; Gardner, 1995:283). Factor analysis is cited as the simplest means of determining whether a scale has multiple dimensions by observing whether items load highly on a single factor (Gardner, 1995). In the case of civic duty there has been no exploration into the possibility that the concept, as it relates to elections, may have multiple dimensions. Furthermore, the conceptualization of the duty construct is not clearly delineated or explained. Despite these considerations and the modernization of other concepts correlated with voting (e.g. efficacy see Morrell, 2003), the operationalization of the civic duty to vote has not been revisited.

Since its emergence civic duty has been inconsistently measured over time by British, American, and Canadian studies. The use of duty in early American surveys and its evolution and usage in other American, British and Canadian and international election and attitudinal studies is highlighted in Table 3.2. Looking to duty items in American election surveys over time for example, reveals that while measures were included in earlier survey years, they 
have been infrequently incorporated in recent decades. In the cases of Canada and Britain by contrast, aside from a few instances in earlier survey years, civic duty items were not regularly included in election surveys until the voting turnout decline caught the attention of governments and scholars in the late 1980s and early 1990s. Given its powerful relationship with the act of voting it is surprising that civic duty has been probed infrequently and inconsistently over time, and has not been critically revisited.

The construct of the civic duty to vote in election surveys first appeared in American research in the 1940s. The concept was initially developed in the first American National Election Study (ANES) in 1952. This study took an attitudinal approach to explaining voting behaviour, pointing to attitudes, group loyalties, and psychological factors as key 'intervening variables'. Specifically, the Michigan research team identified duty as one of six psychological variables having the greatest affect on voter choice and/or an elector's motivation to cast a ballot (Campbell et al., 1957:86). Three of these variables, party identification, issue orientation, and candidate orientation, were the main focus of the publications that came out of this research, but group influence, political efficacy, and civic duty were delineated as important motivating factors in the decision to vote (see also Campbell et al., 1960). The Michigan study was also the first to establish the connection between duty and turnout (Clarke et al., 2002:32).

This research set the tone for election studies in electoral democracies all over the world, notably through the intellectual prominence of the publications that emerged from this group of scholars and the central role they played in helping establish national election study programmes in other countries and training many European researchers. This scholarly influence in part explains "the development of common concepts and measurement 
instruments" in various national election studies (Thomassen, 1994:240) and also perhaps accounts for the acquisition of civic duty's attitudinal lineage and its basic conceptual construction.

Soon after, duty surfaced in other early attitudinal studies such as Almond and Verba's (1963) influential Civic Culture. The belief that the 'ordinary man' ought to participate was outlined as a component of the political attitudes/ participant orientations that comprise the civic culture of a nation and account for why some individuals are active in politics, while others assume a more passive role. In this sense, voting was a symbolic act, which showed citizen trust in elites/government, and was an essential part of the successful operation and maintenance of democracy (Chapter 13). Although the particular concept of duty was not explored in detail, the Civic Culture established the notion of the participant ethic (e.g. duty to participate) as an important political attitude that underlies democracy. Furthermore, the survey question developed by Almond and Verba to probe respondents' feelings about electoral participation explicitly recognizes that some citizens perceive voting in elections as a 'duty'. This survey was the first to directly refer to duty to assess feelings of obligation toward participation in electoral democracy. It was also the first to study the civic duty to vote cross-nationally.

Research from other traditional schools of thought also recognized the importance of duty in the calculus of voting and as an important component of political culture in a democracy (Berelson et al., 1954:31-32). Citizen duty was carried over to British election research as Donald Stokes, one of the Michigan researchers, helped establish the British Election Studies and co-authored Political Change in Britain (1971), a classic contribution to the study of British electoral behaviour. In addition to providing the intellectual inspiration 
for the study of electoral behaviour in Britain (Curtice, 1986) this book identified civic obligation to vote as an aspect of national identity and a key motivation for turnout. Together with colleague David Butler, Stokes helped establish a series of academic election surveys that became the foundation of British election research and set the tone for how to measure and interpret the concept of civic duty to vote.

Based on the classification developed in these early surveys, civic duty has been commonly associated with an attitudinal approach to voting studies, which uses attitudes to explain voting behaviour, as opposed to other approaches that may take values, demographic characteristics, contextual cues, and political opportunities as the primary factors that account for an individual's motivation to vote. Based on its established relationship with the act of voting, the literature has repeatedly identified a sense of civic duty to vote as one of the crucial attitudinal determinants in models of turnout (e.g. Blais, 2000; Blais, 2009; Blais and Achen, 2010; Campbell, 2006; Clarke et al., 2001; Riker and Ordeshook, 1968; Pammett and LeDuc, 2003).

In the specific publications that have emerged from various election studies the civic duty to vote is explained as the link between levels of obligation and levels of engagement (Turcotte, 2007:14). A sense of civic duty to vote is also expressed as a measure of attitudes toward democracy, which is correlated to participation and engagement. Additionally, a citizen's duty to vote is importantly linked to concepts such as efficacy and trust ${ }^{5}$ and exhibits a correlation with levels of political interest and political information (Turcotte, 2007). Furthermore, over-reporting of voting in election surveys is partially a consequence of voting being perceived as an important civic duty. Some respondents are motivated to say they have

5 It has been established that when a sense of duty is absent so too are feelings of efficacy and trust (Turcotte, 2007). 
voted when they have not because it is seen as socially desirable. Overall, civic duty has important linkages with a person's willingness to participate electorally, political attitudes, and voting turnout.

Beyond the established link between duty and voting turnout however, there seems to be no clear account of the nature of civic duty and the rationale for its inclusion. The studies and publications that address or include duty do not offer a real account of the phenomenon and no satisfactory explanation regarding its origin. It has come to be taken as one of a whole set of attitudinal factors that explain and account for an individual's decision to vote, but because of this it is not treated as a unique explanatory factor in and of itself and rather one of a combination of attitudes or values. Furthermore, its inclusion in surveys is inconsistent and its treatment in publications is limited, particularly considering its recognition as a powerful explanatory variable in models of turnout. As Blais and Achen observe (2010), "[In survey research] 'Duty' has been treated as another just attitude [sic], or omitted entirely. Measuring it has been difficult, too. It fell out of favor." Given its strong relationship with the act of voting and turnout, it is surprising that more attention has not been placed on duty as a primary or more prominent explanation related to voting and elections and that there is not more clarity regarding the nature of the concept.

\section{History of civic duty in surveys}

As mentioned, despite its presence in early American surveys measures of civic duty to vote do not have an extensive lineage. Duty measures in the ANES, for example, appeared much more frequently in earlier survey years and, with the exception of the most recent election study (2008), have not been included in the past two decades. The rationale behind the inconsistency of duty measures in American election research is unclear given that the 
principal investigators serve on a rotational basis (Luevano, September 18, 2008). However, it is interesting that duty measures have not been more prominent in recent surveys, as they are in Britain and Canada, given the established correlation between duty and turnout and the fact that turnout in American national elections is equally as low, if not lower, than other established democracies.

Abramson et al. (1987) speculate that interest in electoral citizen duty may have waned because between 1960 and 1980 reported feelings of the civic responsibility to vote changed very little and could not account for the decline in turnout during that period (see also Lipset and Schneider, 1983). Others suggest duty items were dropped because of technical issues involving scale quality (Blais and Achen, 2010; Riker and Ordeshook, 1968). Despite its exclusion from more recent election surveys, civic duty continues to be recognized by American scholars as an important motivation for turnout and a key variable in voting models (Blais and Achen, 2010; Campbell, 2006).

The measurement of civic duty in Britain and Canada by comparison, has followed a different pattern altogether and for the most part items have only been regularly included in the past two decades. In these cases civic duty did not become a major issue until voter turnout began to decline. Since electoral duty was originally identified as the best predictor of whether a person will cast a ballot it suddenly became viewed as an important research tool to shed light on why electors were abstaining. Researchers speculated that perhaps senses of duty were weakening and this in part could explain lower rates of turnout (Blais, 2000; Gidengil, June 9, 2010).

In Canada, federal election turnout began to decline in 1993 and continued in 1997. When it continued to fall in 2000 it became clear that levels of national turnout were 
experiencing an overall decline and not just a fluctuation (Gidengil, June 10,2010). At the same time that turnout became an important item on the research agenda, André Blais' (2000) book, To Vote or Not to Vote: The merits and limits of rational choice theory, highlighted the importance of senses of duty for turnout and, as a result, questions probing civic duty to vote were included in the Canadian Election Study (CES) battery (Gidengil, June 9, 2010).

Similarly in Britain, before the 1990s levels of turnout remained relatively stable over time so there was no need for researchers to develop models of turnout, and hence actively measure civic duty. By the late 1990s however, turnout (which noted a substantial decline in 1997) became an important concern and, as a consequence, there was a greater need to evaluate senses of duty in an effort to get to the bottom of the turnout phenomenon (Sanders, 2010). Others speculate (Clarke et al., 2002) that an additional reason for the lack of duty items in surveys, and attention to it in research, was because of Almond and Verba's (1963) conclusion that the participant ethic in Britain was "highly developed" based on their assessment of the political and civic cultures in several countries. This assertion led British scholars to believe that levels of civic duty were strong among the population and did not need to be studied intensively. This not only inhibited the study of duty generally, but also muted the need to include the measures required to conduct individual-level analyses. For example, the pioneering British election studies by Butler and Stokes $(1971 ; 1974)$ did not make individual-level analyses of turnout a priority. The consequence was that later studies also relegated individual analyses of turnout to a minor theme, not including many of the questions needed to conduct fuller examinations of the motivations to vote and theories of turnout (Clarke et al., 2002). Because of this when duty items were finally introduced in the 
1987 BES the items were all general in nature. No personal style questions were included until 2001.

As civic duty has become a more visible variable in Canadian and British research, other European surveys have also picked up on the value of duty for explaining and accounting for voting behaviour and included duty items in their questionnaires (e.g. the European Social Survey and the International Social Survey Program). On the whole, questions probing the obligation to participate electorally and the components of good citizenship have only become fairly common items in election questionnaires and more general attitudinal surveys in the past decade. The following section delineates the types of survey items that have been used to measure duty in American, British, and Canadian national election studies as well as other prominent domestic and international surveys. The characteristics of these measures are evaluated, followed by an overview of how the major publications that have emerged from these studies use and discuss duty in their analyses.

\section{Civic duty in surveys and voting behaviour research:}

\section{Types of duty measures}

The types of questions that have been used in American, British, and Canadian election surveys over time to probe civic duty can be differentiated by three sets of characteristics, which includes directness (whether duty is mentioned directly or alluded to indirectly), wording (whether the phrasing is positive or negative), and whether the structure is personal or general (see Table 3.1). Direct style questions include explicit mention of the word duty and therefore straightforwardly ask respondents whether they believe they have a moral obligation to participate. Indirectly phrased questions by comparison, take a roundabout approach to investigating duty, which usually involves probing feelings of importance, 
satisfaction, or guilt associated with either voting in elections or elections themselves, and includes no overt mention of civic duty.

Table 3.1: Civic duty question styles in surveys

\begin{tabular}{|c|c|c|}
\hline \multirow[b]{3}{*}{ Positive } & \multicolumn{2}{|c|}{ Direct duty items } \\
\hline & Personal & General \\
\hline & $\begin{array}{l}\text { e.g. It is my duty to vote; I feel } \\
\text { strongly that I have a duty to vote } \\
\text { in every election even if I'm busy } \\
\text { or not very interested; I would be } \\
\text { seriously neglecting my duty as a } \\
\text { citizen if I didn't vote; Generally } \\
\text { speaking, do you believe that you } \\
\text { HAVE A DUTY to vote in every } \\
\text { national election, or do you believe } \\
\text { that you DO NOT HAVE A DUTY to } \\
\text { vote in every national election? }\end{array}$ & $\begin{array}{l}\text { e.g. It is every citizen's duty to vote } \\
\text { in federal elections; It is } \\
\text { everyone's duty to vote }\end{array}$ \\
\hline Negative & $\mathrm{N} / \mathrm{A}$ & N/A \\
\hline
\end{tabular}

\begin{tabular}{l|l|l|}
\multicolumn{2}{c}{ Indirect duty items } \\
\multicolumn{3}{l}{ Personal } \\
\cline { 2 - 3 } Positive & $\begin{array}{l}\text { e.g. It is important to vote even if } \\
\text { my party or candidate has no } \\
\text { chance of winning; I get a feeling of } \\
\text { satisfaction out of it [voting]; }\end{array}$ & $\begin{array}{l}\text { e.g. To be a good citizen...it is } \\
\text { important...to always vote in } \\
\text { elections; In order to preserve } \\
\text { democracy, it is essential to vote; }\end{array}$ \\
\cline { 2 - 3 } & $\begin{array}{l}\text { e.g. So many other people vote in } \\
\text { national elections that it doesn't } \\
\text { matter much whether I vote or } \\
\text { not; If I did not vote, I would feel } \\
\text { guilty. }\end{array}$ & $\begin{array}{l}\text { e.g. A good many local elections } \\
\text { aren't important enough to bother } \\
\text { with.; If a person doesn't care how } \\
\text { an election comes out he shouldn't } \\
\text { vote in it; It's not really worth } \\
\text { voting; People should vote only if } \\
\text { they care who wins; It isn't so } \\
\text { important to vote when your party } \\
\text { doesn't have a chance to win. }\end{array}$ \\
\hline
\end{tabular}

Negative phrases, only found in indirect items, focus on how voting in elections is 'not worth it' and require disagreement to show the respondent has a degree of duty. Guilt-styled 
statements also fall into this category, but they necessitate agreement that not voting would elicit feelings of guilt or shame for not adhering to an important moral obligation. The guilt questions are particularly interesting because they are the flip side of the direct and positively phrased statements, which ask whether respondents agree or disagree that 'it is every citizen's duty to vote.' The idea of probing guilt is another means of shedding light on why people vote and whether they believe they have an obligation to do so.

Finally, statements are either worded so as to target the personal behaviour and/or beliefs of an individual, or more generally to assess respondents' attitudes regarding how citizens in general should conceive of the act of voting and how they should behave on election day. Personal statements use first person to get at feelings about voting as a duty e.g. I have a duty or it is my duty, whereas general items refer to what citizens as a group should or ought to do when it comes to elections and voting.

Despite different characteristics and composition, all of these questions have proven themselves as fairly good measures of the traditional version of civic duty in surveys. In fact, many of them have been repeated, albeit inconsistently, because they are useful determinants of whether an elector identifies with voting as being an obligation of citizenship and to allow for comparisons over time. The variance in the approaches and structures of these questions is not unlike wording strategies used to probe other variables such as political efficacy, although other variables are more refined than the duty framework. The constructs of other attitudinal variables are more clearly conceptualized and the items that are used for measurement are more fully theoretically connected and outlined (see Morrell, 2003).

It is important to note that there are additional questions, which although not explicitly identified as measures of duty, could feasibly be used to assess whether a 
respondent has a strong or weak sense of civic duty. Such statements include: About $25 \%$ of Canadians 18 to 24 years old voted in the 2000 federal election is this... a problem?, used in the 2004 and 2006 versions of the CES ${ }^{6}$, There is no point in voting for a party that will only win a few seats, (also used in various CES versions), and Democracy only works properly if most people vote (used in the BES). In fact, Clarke et al., (2002) include the latter statement in their factor analysis of civic duty using data from the $2001 \mathrm{BES}$ and it loads reasonably highly with other traditional duty probes. While these statements are not a complete list of all the items that could be construed as measures of duty, they highlight that statements which get at the importance of voting regardless of other circumstances or intervening factors and that emphasize the salience of voting for the preservation and value of democracy can be taken as items that are relevant to the duty variable. These statements are typically not listed as measures of duty and are often not treated as such in analyses or modeling, but the case could be made that agreement or disagreement would also offer a reasonably good assessment of whether a person possesses a sense of civic duty.

The fact that duty measures have been frequently alternated or replaced is indicative of a situation whereby civic duty has not been treated as a central concept in election studies, despite it being hailed as the "great beast' in empirical research on voter turnout" (Clarke et al., 2002:43). Failure to clearly establish multiple items as the core determinants of duty also supports this conclusion. Finally, a lack of research and critical analysis into the concept of duty itself (e.g. no revisiting the concept) and how it is operationalized all illustrate that duty has not been given the attention it deserves as the critical variable in explaining and accounting for turnout. Researchers have been searching for the right recipe with which to

\footnotetext{
${ }^{6}$ A similar item was also included in the 2008 CES.
} 
measure duty, but nothing conclusive has been determined. The limited nature of the current operationalization of duty and the inconsistency of measures used to assess it highlight the importance of this thesis project.

\section{Britain}

British surveys have arguably sought to measure civic duty most comprehensively because they have included questions aimed to assess the duty to vote variable in the greatest number of surveys. Questions seeking to measure duty have been consistently included in British Election Studies (BES) since 1987 and in more general attitudinal and value-based surveys such as the British Social Attitudes Surveys (BSA) and the Audit of Political Engagement (APE) since 1998 and 2003 respectively (see Table 3.2 for examples). These surveys have employed many different wording strategies, but all have sought to measure duty using the same baseline definition and operational framework.

Specifically, measuring duty in the BES has been achieved predominately by probing whether respondents feel that voting is every citizen's duty and whether they believe that not voting is neglecting one's duty. ' In some election. years, the statement, I would feel very guilty if I didn't vote in a general election is also taken as an indicator of duty. In early election studies, and all BSA surveys, senses of duty are probed by asking respondents to select one of three statements they identify with best, including: (1) It's not really worth voting, (2) People should only vote if they care who wins, and (3) It's everyone's duty to vote (see Table 3.2). These questions seek to establish whether a respondent feels a sense of obligation or responsibility to participate electorally and also whether they personally consider the act of voting important, regardless of other electoral variables or circumstances. Although in earlier years

\footnotetext{
${ }^{7}$ The APE also measured duty by asking respondents whether they agree or disagree with the statement: It is my duty to vote.
} 
all BES items included only general phrasings, since 2001 there has been a shift in focus to individual behaviour and the expectations of oneself in an election. Taken together however, British surveys use a mixture of phrases. For example, the national election study has used a combination of (1) general, negative, indirect; (2) general, positive, indirect and direct; (3) personal, negative, indirect; and (4) personal, positive, direct items. The BSA, by comparison, has used only general statements, either negative and indirect or positive and direct and the APE included a personal, positive, direct statement to probe duty.

The analyses that have emerged from the data on civic duty center almost exclusively on turnout, or more specifically the relationship between a sense of civic duty to vote and electoral participation. In British analyses duty is taken as more of a selective incentive for participation. BES models of turnout illustrate that civic duty has "significant and correctly signed effects" with voting behaviour (Sanders et al., 2007:16). People with strong senses of civic duty interpret voting as providing system benefits and are more likely to cast a ballot as a consequence (Clarke et al., 2009). In fact, not only is turnout positively affected by senses of civic duty, but the dynamics of civic duty are also the most important when explaining and accounting for patterns of turnout.

For example, Clarke et al., (2001) show that with other predictors held constant the probability of voting rose almost 65 points in 2001 as civic duty increased. In 2005 this figure was 44 points. Models accounting for turnout in the 2001 and 2005 BES studies pointed to duty as the most powerful predictor of electoral participation (Clarke et al., 2001). This data also found strong age-related differences. For example, 62 percent of young people aged 18 to 25 stated that it is every citizen's duty to vote in 1997 and 60 percent in 2001, whereas comparable figures among those 66 and older were 88 and 93 percent respectively. When 
asked if respondents felt that not voting would be seriously neglecting their civic duty even starker differences emerged among age groups, suggesting that generational change may be eroding the voting-civic duty nexus (Clarke et al., 2001:33).

Since duty has been consistently measured in British surveys, the major publications that have emerged from this research confirm findings that young people are less likely than older generations to perceive voting as a civic duty and less likely to believe that not voting defies this duty. While older people have a greater propensity to vote regardless of the circumstances, young electors are more likely to discuss politics but still abstain from voting (Hansard Society, 2009). Overall, British researchers conclude that changes in civic duty and voting turnout are more a reflection of generational differences and less accounted for by lifecycle effects (Clarke et al., 2004).

Looking at BES turnout models more specifically, civic duty items are used to account for the strength of a person's sense of civic duty, individual political orientations, individual or personal benefits, system benefits, and as part of one benefit grouping in general incentives models. Personal statements such as I feel a sense of satisfaction when I vote are commonly used as measures of individual benefits whereas generally phrased items such as It is every citizen's duty to vote in an election are taken as indicators of system benefits, albeit in a few cases personal statements are used here too (Clarke et al., 2004; Phelps, 2006). The placement of duty items in various models over time is interesting because in many cases it varies by election year and publication. In some cases measures, which can be considered traditional duty items, are classified under different categories. For example, the phrase I would feel very guilty if I did not vote is assigned by the BES team in their analysis of the 2005 British General Election as a measure of personal or individual benefits and listed as distinct 
from the duty items (Sanders et al., 2007), although in other years (see Clarke et al., 2009) a very similar version is explicitly listed as an indicator of civic duty. Feeling guilty about not participating implies that not voting is ignoring an obligation to do so and seems closely related to the duty item which probes whether respondents feel not voting is neglecting their duty as a citizen.

In other instances, by comparison, statements that are taken as measures of other concepts or categories can be seen as indicators of duty. In Political Choice in Britain (Clarke et al., 2004:250-252) for example, system benefits are gauged by assessing responses to It is every citizen's duty to vote in an election, a classic measure of duty, and Democracy only works properly if most people vote. This latter statement can be taken as an indicator of duty since feelings of obligation to participate electorally are closely tied to strong beliefs in democracy. The placement of items under various categories can be explained based on the theoretical models of turnout used by the research teams. Survey items have been assigned as measures of different concepts and categories that are implied by the models, but these placements should not be considered absolute. Had a different theory or set of theories been the focus of the election teams or a particular publication, the various statements may have fallen into different theoretical categories (Sanders, June 16, 2010).

The different uses and distribution of the statements that have served as indicators of civic duty highlight the amorphous nature of the concept, and the measures that have been designed to assess it. These items are not fully theoretically connected with one another, nor are they as concretely delineated, as are measures of other variables such as internal and external efficacy or political and social trust. The switch from general statements and a focus on system benefits to more personal phrasings and a concentration on individual-level 
analyses suggests that the quest to measure and assess duty is still very much 'finding its way'.

It may very well be that there are other dimensions of the civic duty to vote in elections.

Table 3.2: Questions probing civic duty in American, British, and Canadian surveys

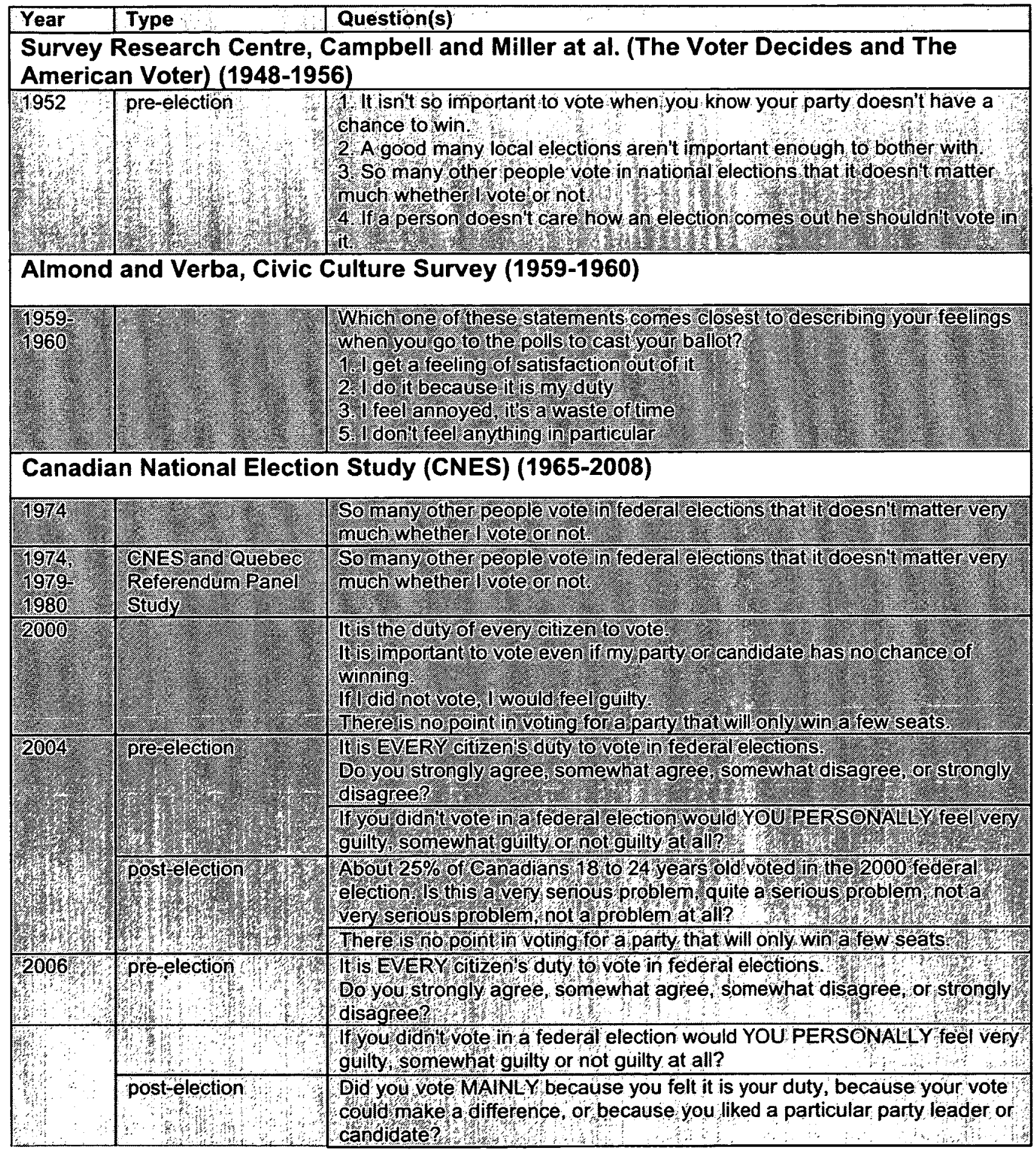




\begin{tabular}{|c|c|c|}
\hline & & There is no point in voting for a party that will only win a few seats. \\
\hline \multirow[t]{5}{*}{2008} & \multirow[t]{3}{*}{ pre-election } & $\begin{array}{l}\text { It is EVERY citizen's duty to vote in federal elections. } \\
\text { Do you strongly agree, somewhat agree, somewhat disagree, or strongly } \\
\text { disagree? }\end{array}$ \\
\hline & & $\begin{array}{l}\text { If you didn't vote in a federal election would YOU PERSONALLY feel very } \\
\text { guilty, somewhat guilty or not guilty at all? }\end{array}$ \\
\hline & & There is no point in voting for a party that will only win a few seats. \\
\hline & \multirow[t]{2}{*}{ post-election } & $\begin{array}{l}\text { Did you vote MAINLY because you felt it is your duty, because your vote } \\
\text { could make a difference, or because you liked a particular party leader or } \\
\text { candidate? }\end{array}$ \\
\hline & & $\begin{array}{l}\text { About } 40 \% \text { of Canadians } 18 \text { to } 24 \text { years old voted in the last } 2 \text { federal } \\
\text { elections, was this a very serious problem, quite a serious problem, not a } \\
\text { very serious problem, not a problem at all? }\end{array}$ \\
\hline \multicolumn{3}{|c|}{ American National Election Study (ANES) (1948-2008) } \\
\hline 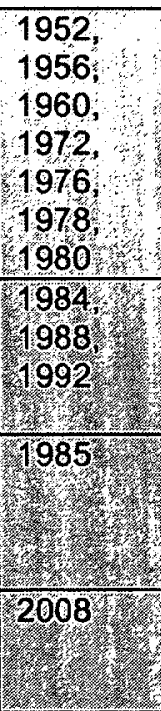 & 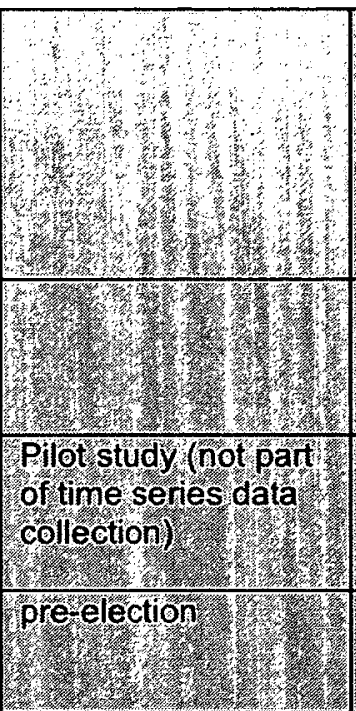 & 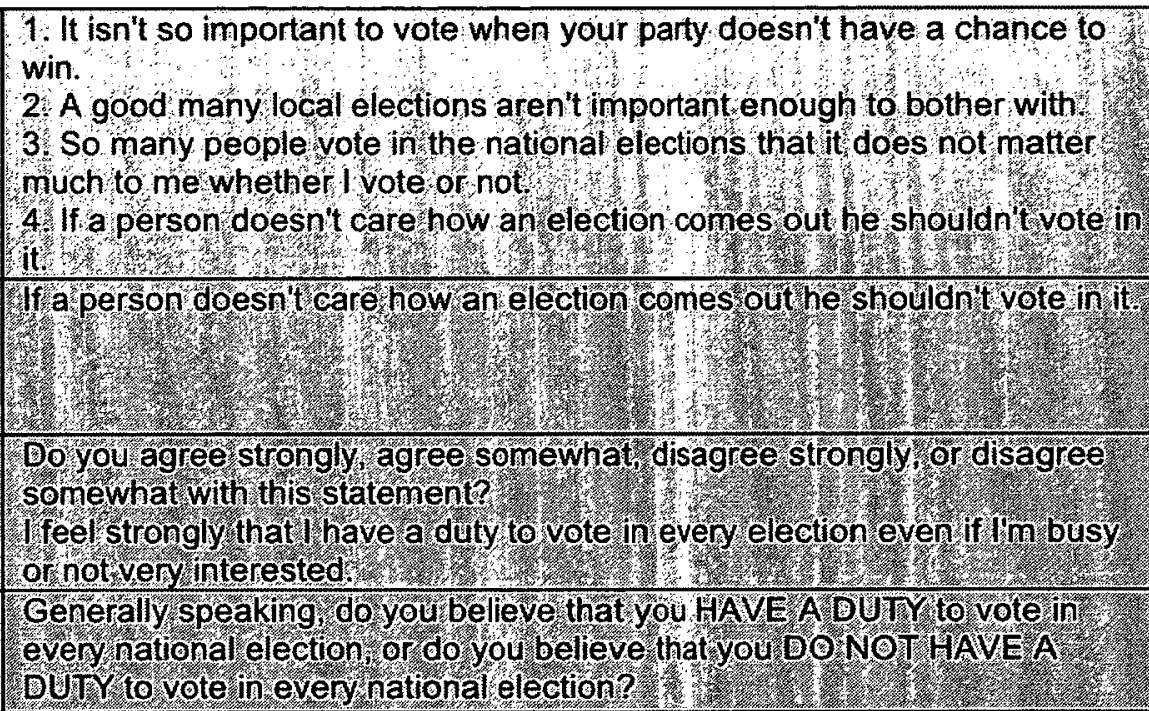 \\
\hline \multicolumn{3}{|c|}{ British Election Study (BES) (1964-2010) } \\
\hline 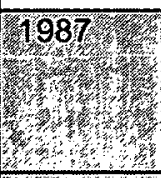 & Why & 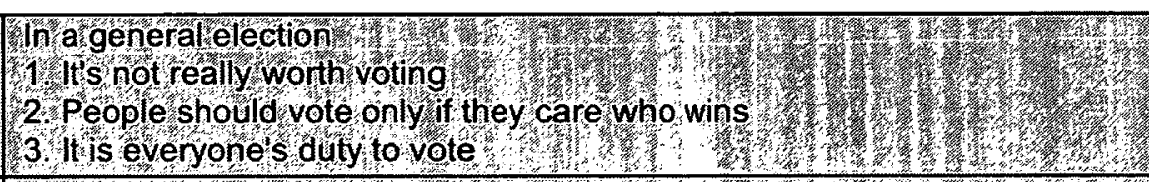 \\
\hline 1992 & panel sample self & $\begin{array}{l}\text { And please tick one box to show which of these statements comes } \\
\text { closest to you views? } \\
\text { ln a general election. } \\
\text { it's not really worth voting } \\
\text { people should only vote if they care who wins } \\
\text { it is everyone's duty to vote }\end{array}$ \\
\hline \multirow[t]{2}{*}{1997} & $\begin{array}{l}\text { Blaise questionnaire } \\
\text { (cross-section } \\
\text { survey) }\end{array}$ & $\begin{array}{l}\text { Thinking now do you think about voting in general elections. Generally } \\
\text { speaking, } \\
\text { 1. ...people need not vote unless they really care who wins, } \\
\text { 2. or, is it everyone's duty to vote? }\end{array}$ \\
\hline & campaign panel & $\begin{array}{l}\text { In a general election } \\
\text { 1. It's not really worth voting } \\
\text { 2. People should vote only if they care who wins } \\
\text { 3. It is everyone's duty to vote }\end{array}$ \\
\hline
\end{tabular}




\begin{tabular}{|c|c|c|}
\hline \multirow[t]{3}{*}{2001} & pre-election & $\begin{array}{l}\text { Please tell me how far you agree or disagree with each of the following } \\
\text { statements. } \\
\text { It is every citizen's duty to vote in an election. }\end{array}$ \\
\hline & \multirow[t]{2}{*}{ post-election } & $\begin{array}{l}\text { Please tell me whether you agree or disagree with each of the following } \\
\text { statements. } \\
\text { I would feel very guilty if I didn't vote in a general election. } \\
\text { I would be seriously neglecting my duty as a citizen if I didn't vote. }\end{array}$ \\
\hline & & $\begin{array}{l}\text { Now, let's talk for a few moments about politics and government } \\
\text { generally. Please tell me whether you agree or disagree with each of the } \\
\text { following statements. } \\
\text { It is every citizen's duty to vote in an election. }\end{array}$ \\
\hline \multirow[b]{2}{*}{ then } & pre-campaign & $\begin{array}{l}\text { Please tell me how far you agree or disagree with each of the following } \\
\text { statements. } \\
\text { It is every citizen's duty to vote in an election. } \\
\text { I would be seriously neglecting my duty as a citizen if I didn't vote. } \\
\text { I would feel very guilty if I didn't vote in a general election. }\end{array}$ \\
\hline & postelection & 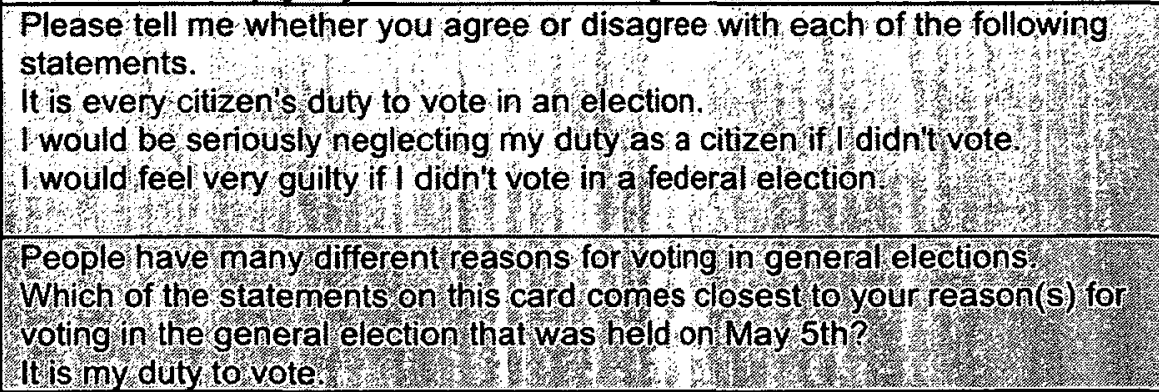 \\
\hline$\frac{2009}{2010}+2$ & 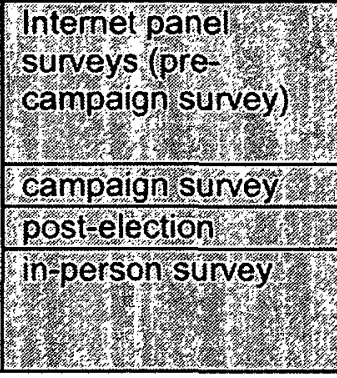 & 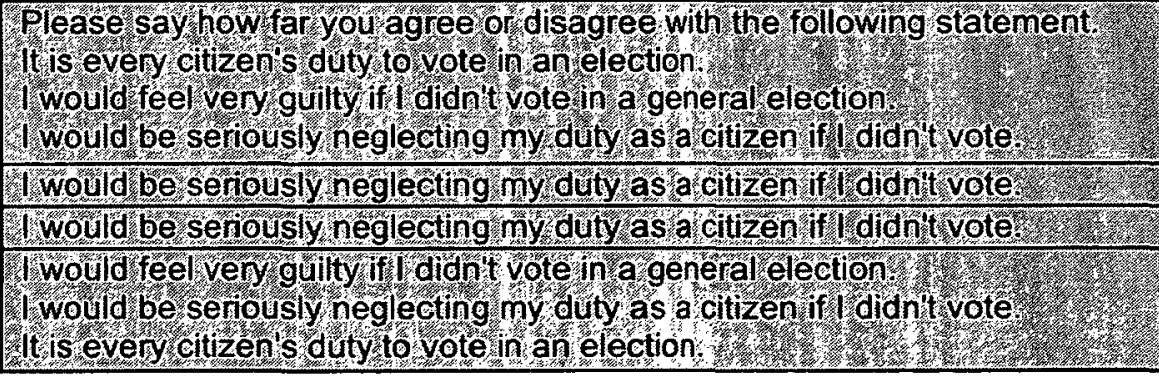 \\
\hline \multicolumn{3}{|c|}{ British Social Attitudes Surveys (BSA) (1983-present, except in 1988 and 1992) } \\
\hline Whe & Young People's & 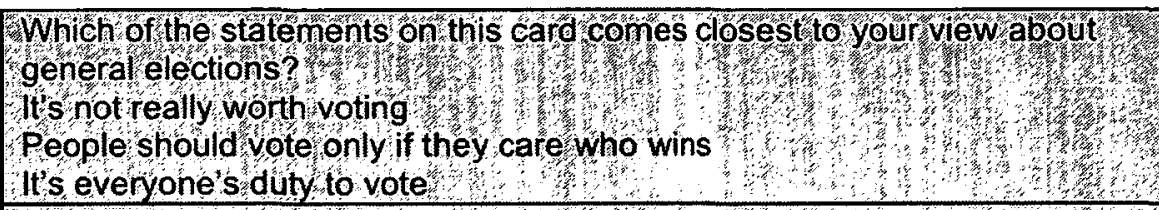 \\
\hline 2003 & $\begin{array}{l}\text { Young People's } \\
\text { Social Attitudes }\end{array}$ & $\begin{array}{l}\text { Which of the statements on this card comes closest to your view about } \\
\text { general elections? } \\
\text { It's not really worth voting } \\
\text { People should vote only if they care who wins } \\
\text { lt's everyone's duty to vote. }\end{array}$ \\
\hline 2000 & & $\begin{array}{l}\text { Which of these statement's comes closest to your view about general } \\
\text { elections? } \\
\text { In a general election... } \\
\text { (i) It's not really worth voting } \\
\text { (ii) People should vote only if they care who wins } \\
\text { (iii) It's everyone's duty to vote }\end{array}$ \\
\hline
\end{tabular}




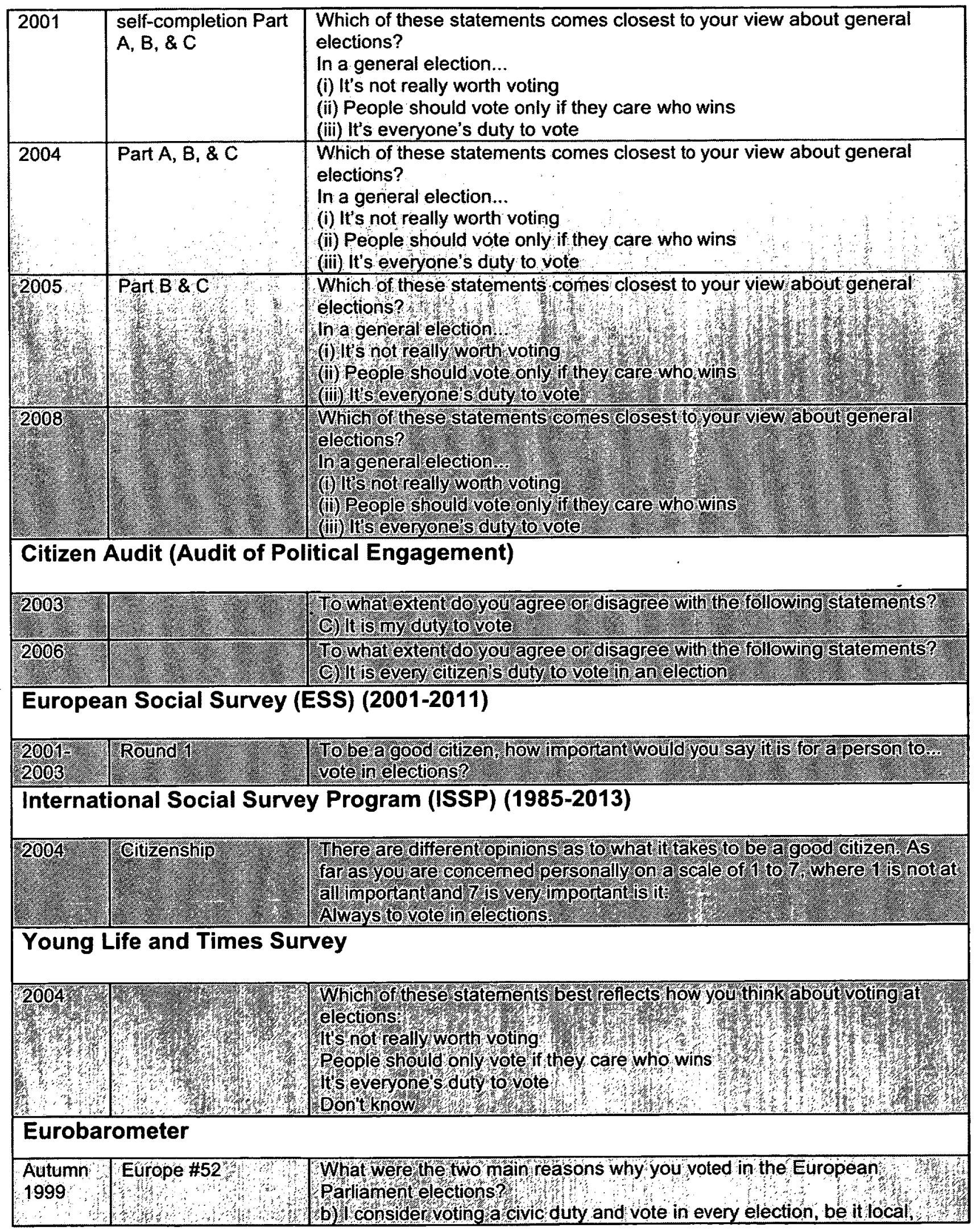




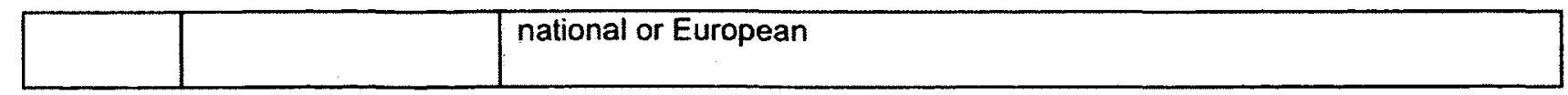

Aside from its role in turnout analyses, duty is also used when discussing political choice and election campaign effects, albeit usually in relation to turnout or motivations to participate. British studies examine duty in the context of party choice and turnout and use it as a key variable in party choice models. Duty is shown as being closely linked with valence judgments about the competence of parties and party leaders as well as other variables such as efficacy and interest (Clarke et al., 2009). Links are also established with the campaign and its potential to influence a person's sense of civic duty and hence their propensity to vote.

\section{The United States}

One of the earliest efforts to tap the perceived obligation to participate in elections comes from a survey done by the National Opinion Research Centre in 1944, wherein respondents were asked: "Do you regard voting more as a duty you owe your country, or more as a right to use if you want to?" (Dennis, 1970:827). The term "sense of citizen duty" was officially coined several years later by a group of scholars as part of the University of Michigan's Survey Centre Research Project, which produced publications such as The Voter Decides and The American Voter. This research expanded the measurement of the civic duty norm into a four-item scale using the following agree-disagree items:

1. It isn't important to vote when you know your party doesn't have a chance to win.

2. A good many local elections aren't important enough to bother with.

3. So many other people vote in the national elections that it doesn't matter much to me whether I vote or not.

4. If a person doesn't care how an election comes out he shouldn't vote in it. 
All of these items are indirect and negative. Two tap personal feelings regarding the perceived obligation to vote, while the others probe more general opinions about all citizens. Though each of these items does not directly "establish the existence of duty...they measure whether something other than self-interest is at work" and were intended to tap the important components of citizen duty (Blais, 2000:94; Campbell et al., 1957:194). These 'components' include the feeling that all elections deserve participation, that the odds of an election should not preclude voting, and that indifference to an outcome should not be a deterrent to participation. Detecting duty in these questions stems from a rational choice perspective. As outlined in Chapter Two, according to rational choice theory an elector casts a ballot because of some instrumental benefit. If, however, an elector believes one should vote irrespective of circumstance or consequence (e.g. s/he has no preference, poor odds, etc.) that person is likely to perceive voting as a moral obligation (Blais and Rubenson, forthcoming). Therefore, expressions of disagreement with these statements would indicate feelings of political obligation or a sense of political responsibility to participate (Campbell et al., 1957).

The battery of questions used to gauge senses of citizen duty in the 1952 and 1956 surveys was repeated in the 1960,1972,1976,1978, and 1980 National Election Studies (again, see Table 3.2). However, after that point only the fourth statement was used as a duty item in the 1984,1988, and 1992 time series surveys (Miller and Traugott, 1989:268). Therefore, the majority of duty statements used in the ANES can be characterized by their indirect and negative phrasings. There are only two exceptions to this. A more direct and positive duty statement, which was also personal, was tested in a 1985 pilot study. It used a 5point Likert scale to gauge respondents' agreement or disagreement with the statement, I feel strongly that I have a duty to vote in every election even if I'm busy or not very interested. Finally, 
the 2008 ANES also used a direct, positive, personal item, asking whether respondents believed they have a duty to vote in every national election or whether they do not have a duty to do so. ${ }^{8}$ These direct items find their origins in surveys like the 1944 National Opinion Research Centre study and Almond and Verba's Civic Culture Survey (1959-1960), which probed a sense of voting duty by asking which statement comes closest to a respondents' feelings about casting his/her ballot and whether respondents identify with the statement, $I$ do it because it is my duty.

It is interesting that a majority of questions probing duty in British and Canadian surveys include direct mention of duty, while the American approach can largely been distinguished by its indirect phrases. Questions that are worded indirectly may be more useful for tapping changes to, or nuances in, traditional duty since what previous cohorts interpreted as a clear-cut moral obligation, today's young electors may perceive as important but not a necessary duty with the same degree of ethical attachment. ${ }^{9}$ These classic surveys, which were instrumental in identifying the importance of citizen duty for electoral participation, also use a scale of measurement that suggests duty is one-dimensional.

Much like British research, analyses of these questions are conducted in the context of voting turnout or in discussion regarding a person's propensity to cast a ballot. These first studies identify civic duty as one of the most powerful correlates of individual voting behaviour. Results show a clear relationship between duty and political participation, revealing that "the more strongly a person feels a sense of obligation to discharge civic duties, the more likely he is to be politically active" regardless of particular demographic status

\footnotetext{
8 The re-addition of a duty item was the result of a request by academics in the ANES call for proposals motivated by economic turnout models and to shed light on the extent to which people perceive voting as a matter of duty or choice (ANES, Justification for Political Participation Questions).

9 This idea will be explored in more detail in a later section that discusses new potential duty items.
} 
(Campbell et al., 1957:199). Later voting model research using the same duty items (see Aldrich, 1976; Dennis, 1970; Riker and Ordeshook, 1968) also detected the same strong relationship between senses of duty and electoral participation. Reported senses of duty among the American public remained consistent until the 1984 election when they dropped substantially from previous levels (58.7 percent of respondents disagreed with the fourth statement in 1980 and only 42.8 percent disagreed in 1984) (Abramson et al., 1987).

A more fulsome analysis of the fourth duty item over time (since it was included in more electoral surveys than the others) illustrates that young people are much less likely than other cohorts of electors to identify voting as a moral obligation and while some of this can be attributed to life-cycle effects it is mostly the result of generational influences. Specifically, older generations of electors (preboomers) are much more likely than their postboomer counterparts to believe that people should vote even if they do not care about an election. This research also shows that those who perceive voting as a duty are twice as likely to cast a ballot as those who do not, which reinforces the finding that citizen duty is a powerful correlate of voting turnout (Blais and Rubenson, forthcoming). Newer research examining ANES data supports the linkage between citizen duty and voting (Blais and Achen, 2010) and, though more recent duty data is not available from the ANES, other research focusing on levels of duty among the young confirm that as their electoral participation wanes their senses of civic virtue are also weakening (Dalton, 2008; Soule and Nairn, 2009; Wattenburg, 2007). Duty is also used in the literature to account for and explain the over-reporting of turnout (for example, Karp and Brockington, 2005; Silver et al., 1986).

On the whole however, there is not an abundance of American publications that use election data to analyze and discuss duty. Part of this may be because in recent years duty 
items have been largely excluded from the ANES, but it is curious that a concept so powerfully linked to turnout is not the focus of more investigation and research. Could its exclusion be linked to its vague theoretical construction and the fact that no unified scale of measurement has been developed? Examining election surveys and research over time in Canada suggests a similar hodge-podge of measurement and no clear roots of the concept.

\section{Canada}

Canadian measurement and assessment of the electoral portion of civic duty resembles a mix of measures and inconsistent application of survey items in election surveys consistent with the approaches found in Britain and the United States. Historically in Canada, senses of citizen duty to vote have been probed by the Canadian National Election Study (CNES) and Canadian Election Study (CES) and were not integrated in general attitudinal surveys such as the Statistics Canada Surveys of Participation. The Canadian Election Studies included duty items in only a few election surveys until the 2000 federal election, since which time they have been regularly incorporated. As in British and American surveys the duty to vote is treated as one-dimensional in the Canadian versions, although a combination of direct and indirect statements have been used. The earliest item was the negative duty probe, So many other people vote in federal elections that it doesn't matter very much whether I vote or not. This statement appeared in the 1974, 1979, and 1980 CNES surveys. For whatever reason duty items disappeared from the questionnaire agenda after that point and did not reappear until declining voter turnout became a concern. ${ }^{10}$

The 2000 CES included three agree-disagree items, (1) It is the duty of every citizen to vote, (2) It is important to vote even if my party or candidate has no chance of winning, and (3)

\footnotetext{
10 I was not able to determine this through my research.
} 
If I did not vote, I would feel guilty. Since 2004 three variations of these questions have been included, probing whether respondents agree or disagree it is every citizen's duty to vote in a federal election, would feel guilty if they did not vote, and voted mainly because of a sense of duty, because of a party or candidate, or because they felt their vote could make a difference (refer to Table 3.2). The phrasings of these measures are consistent with the established definition of the civic duty norm - the notion that voting in elections is a moral obligation.

While variations of the latter two questions had appeared in previous surveys, the question probing feelings of guilt for not voting was first introduced in election surveys in the 2000 CES. The guilt themed statements were initially crafted and used by Blais and Young (1996) in their study of Canadian university students during the 1993 election and appeared in later surveys they conducted during the 1995 Quebec referendum and the 1996 British Columbia election (1999). This style of question was put together based on the conclusion that it is not rational to vote (as per rational choice theory), and probes the flip side of admitting it is a duty to vote by asking "people to acknowledge that by not voting they would be doing something wrong" (Blais, 2000:96). The guilt item made its debut after collective decision by the 2000 CES team that the available measures did not sufficiently probe why people decided to vote. Furthermore, these existing measures could not adequately account for the variance in the turnout decision (Blais, July 14, 2010; Nevitte, July 13, 2010).

Overall, probing duty in Canadian surveys was initially similar to the American experience, using only indirect, general, and negative statements. When turnout became a growing concern however, as it did in Britain, Canadian election research began to place a 
greater focus on the duty variable and its approach more closely mirrored the British one.11 Since then a mixture of (1) general, negative, indirect; (2) general, positive, direct; (3) personal, positive, indirect and direct; and (4) personal, negative, indirect statements have been used to measure and assess the strength of eligible electors' senses of civic duty to vote. The primary differences between the Canadian and British approaches, aside from the fact that duty has been probed more frequently in British surveys, include a more developed guilt item in the Canadian batteries and variance in the wording strategies used. For example, the CES uses a personal, positive, indirect statement whereas the BES does not. Likewise, the BES includes a general, positive, indirect phrase while that particular wording strategy is not found in any CES surveys. Again this disconnect in measurement speaks to the fact that there has been a lack of research surrounding duty and insufficient critical analysis of the concept. As a result no core determinants of duty have been established and measurement strategies have been somewhat scattered.

The analyses that have emerged from the CES discuss and draw upon duty to help explain the decline in federal voting turnout, which is in large part attributable to generational replacement. Overall, they conclude that young people are less likely than older electors to show attachment to the norm of voting as a civic duty and are therefore less likely to participate electorally. For example, an assessment of the 2000 Canadian federal election reveals an important difference between older and younger cohorts in their propensity to vote (Pammett and LeDuc, 2003). Researchers suggest the difference may be attributed to a diminishing sense of voting duty on the part of younger electors (Blais et al., 2002; Gidengil et al., 2003; Gidengil et al., 2004). Other analyses of the same election point out that young

\footnotetext{
11 Duty became a permanent fixture in the CES battery and a combination of wording strategies were used to measure duty.
} 
people are less likely to vote because of weaker senses of duty and the fact that they pay less attention to politics (Blais et al., 2004). In fact, Canadian researchers lament having not probed duty more actively in previous survey years since it may have shed light on trends in public perception of voting as an important duty of citizenship over time (Blais et al., 2004). Coverage of subsequent elections produces similar findings with respect to young people's senses of civic duty and equally ominous prospects for future turnout (Clarke et al., 2005:251). Overall, the concept of civic duty accounts for a sizable part of the difference in turnout between the young and old. This research suggests that like other young people, Canadian youth are less likely than their elders to perceive voting as a moral obligation (Blais et al., 2002:58)

\section{International comparative surveys}

Aside from these country studies, there are several multi-nation continuing surveys that have established a regular program of probing public attitudes and values over time, these include: the International Social Survey Program (ISSP), World Values Surveys (WVS), the European Social Survey (ESS), and the Eurobarometer (EB). Despite a rigorous research program however, there has been infrequent use of questions aimed at tapping senses of civic duty to vote, and no such instances in the WVS series. The rationale behind the infrequent inclusion of civic duty items is unclear, but it is likely to have been left out because electoral turnout was not a primary focus of these studies. Another reason may be that many of these surveys have chosen to pay closer attention to other dimensions of a citizen's civic duty that are not related to elections and voting. The EB for example, probes respondents' moral duty to help, duty to ensure through tax and pension payments that elderly people have a "decent" living standard, duty to protect the environment, national pride as a duty, among other items. 
Some versions also implicitly probe whether respondents' feel a sense of duty to be involved in politics and current affairs ${ }^{12}$ There is one instance where the duty to vote was probed in a 1999 version of the survey, albeit as a response option and not an individual question.

Respondents were asked to list the two main reasons they voted in the European

Parliamentary elections and I consider voting a civic duty and vote in every election, be it local, national or European was a potential response option.

By comparison, the ISSP and ESS assess civic duty as a potential component of good citizenship, which can include volunteering, community involvement and other ethical considerations such as purchasing or boycotting certain consumer products. Within this survey framework a dutiful respondent in an electoral context perceives voting in elections as being very important. The ESS item, for example, asks respondents To be a good citizen, how important would you say it is for a person to...vote in elections? It is interesting that these questions refer to the importance of voting, rather than whether there is a feeling of duty to vote more directly. Much like the approach used in the early American surveys the strategy used by the ISSP and ESS also suggests that indirect items, which probe the importance of casting a ballot, can be good indicators of citizen duty.

Analysis of the ESS identifies that a sense of duty to vote in national elections is regarded among Europeans as constituting the one of the most important qualities of a good citizen. Though Americans do not share all of the same priorities of good citizenship, they too perceive voting as a civic virtue (European Social Survey, 2008:14). Research on ISSP data also confirms that voting in elections constitutes an important component of public activity in the eyes of Europeans (Pammett, 2009). Aside from a few analyses however, there is not a lot

\footnotetext{
12 The question reads "People should involve themselves more in politics and current affairs" from Special EUROBAROMETER 225 “Social values, Science \& Technology” (see European Commission, 2005).
} 
of literature that discusses the duty to vote. This is likely a consequence of the infrequency with which the concept is measured in these multi-nation surveys. Again, it is curious why civic duty to vote items have not been given greater prominence in these surveys especially considering its explanatory insight as a key motivation for voting. Researchers not being overly concerned with turnout and instead valuing other items is perhaps the best explanation for their absence.

\section{Conclusion}

From the above analysis a few things are clear. First, the civic duty to vote has not been treated as a central concept in survey research despite its explanatory power in models of turnout. It has been measured infrequently and inconsistently. Furthermore, the concept of duty that relates to elections and voting has not been entirely theoretically explored and there is a lack of research and critical analysis on the concept. The fact that no core determinants of duty have been established has resulted in the creation of a hodge-podge of survey items and no steadfast recipe to assess whether electors attach an intrinsic value to voting. Another consequence has been that items used to gauge senses of duty are not fully theoretically connected to one another. Finally, the conception that can be teased out of existing research and measures is one-dimensional given that all questions are designed to load on the same factor. There has been no consideration that the duty to vote may have other dimensions or facets that remain untapped and could perhaps help to better explain changes in the patterns of turnout. Developing a more refined duty framework is an important step toward ensuring consistent and perhaps more frequent future measurement. Prior to considering other elements or dimensions of duty, however, it is important to review the levels of duty observed 
and any trends noted over time based on the existing operational definition and available measures.

Research and data analyses that have emerged from British, American, and Canadian election surveys and other attitudinal questionnaires suggest that young people are less likely to perceive voting in elections as a civic duty and are more inclined to think of electoral participation as a choice. While civic duty has typically grown stronger with age it seems that lifecycle effects cannot account for the weakening senses of duty among younger cohorts and that the causes are generational in nature. In fact, senses of traditional duty appear to be declining further within each new cohort of the electorate. These age relationships show us that the traditional virtue of citizen duty is demographically phasing itself out of these polities. Taking into account the strong correlation between civic duty and voting, and the trend of voter decline among young people, the simultaneous pattern of weakening senses of citizen duty is particularly worrisome for the future health of electoral democracy.

More broadly, research suggests that young Canadians today are different from older generations because they have different issue priorities, different values, and different conceptions of civic duty and other aspects of citizenship (Turcotte, 2007). While the literature has focused on uncovering these differences in issue priorities (Gidengil et al., 2005; Pammett and LeDuc, 2004; Turcotte, 2005; 2007), differences in values (Inglehart, 1997; Nevitte, 1996), and differences in perceptions of what it means to be a citizen (Dalton, 2008; Pammett, 2009) there has been little to no concentration on the evolution of ideas about the civic duty to vote in the minds of young people, despite the fact that it is suggested that ideals of civic duty have changed (Dalton, 2008; Turcotte, 2007). It may be that traditional senses of duty are declining among the young or perhaps the feelings about the portion of duty that 
relates to elections is changing. There may also be other dimensions of duty that have been overlooked much like other political attitudes such as efficacy. ${ }^{13}$

Overall, there are a number of reasons that warrant a reconsideration of the concept of duty. This does not necessarily mean it has to be completely reconceptualized, but enough doubts have been raised about the nature of it that it should be rethought. The following chapter examines comparable data from Canadian, American, and British election surveys to assess any patterns or trends in responses to duty items over time. It is important to examine levels of traditional civic duty and assess its impact, if any, on electoral participation to clearly understand the explanatory value it possesses with regards to explaining voting behaviour, particularly among the youngest members of the electorate.

${ }^{13}$ Efficacy too was initially treated and measured in voting surveys as a one-dimensional construct and later found to contain two components - internal and external efficacy (Morrell, 2003). 


\section{Chapter 4 : Trends in the civic duty to vote over time}

\section{Introduction}

This chapter highlights patterns or trends in responses to duty items over time by looking at applicable survey data from American, British, and Canadian national election studies. Based on responses to traditional duty measures in all recent years for which data is available, the goal of this section is to establish the current picture of civic duty and its relationship with electoral participation. Specifically, this includes an examination of levels of traditional civic duty in these countries in recent years and whether a decline is evident. It also looks at whether there is an age relationship with the traditional operationalization of civic duty and finally, the degree to which civic duty has impacted voting in elections. Upon outlining levels of duty under the current approach to measurement the subsequent chapter proceeds by exploring whether conceptions of civic duty may be changing, particularly among young electors, by analyzing responses obtained from a unique qualitative data set.

\section{Trends and patterns in duty over time}

Although there is no longitudinal data that gauges the variation in civic duty to vote over time, it is useful to look at what cross-sectional measures tell us about the strength and weakness of senses of duty and their relationship with the act of voting. Relying on national election study data from Canada and Britain this portion briefly assesses whether the traditional civic duty to vote is declining over time. It also explores whether there is an age relationship with electoral duty, which refers to whether electors of a certain age group are more likely to report being 'more dutiful' than those from other cohorts. Finally, it evaluates the impact of civic duty on the decision to vote in those studies. Unfortunately, it is not possible to make the same comparisons over time with American data because duty was only 
evaluated in their national election surveys until the early 1990's. Though it did resurface in 2008 , there is no reliable data to provide for an assessment of patterns and/or trends of duty among the American electorate. ${ }^{14}$

Looking first to assess whether there has been a decline in reported duty over time, the Canadian and British surveys show different results. Examining all eligible electors the British data neatly outlines a decline, whereas the Canadian figures indicate mixed results, suggesting perhaps a slight increase in reported electoral duty. The Canadian findings are interesting because they are inconsistent with other reports that senses of duty are declining among the Canadian public (for example, Pammett and LeDuc, 2003). It is difficult, however, to rely on this data to make firm assessments of changes to patterns of duty over time since there are not many duty questions in the first place, and even fewer are repeated on a regular basis to allow for direct comparisons. In some years although question wordings are identical, different response categories make evaluations challenging. ${ }^{15}$ Therefore, while data suggests that senses of duty may be increasing slightly among the Canadian electorate, this could be more a result of data that is incomparable than an accurate assessment of public opinion. The fact that voter turnout has continued to decline in Canadian federal elections and has been established as having such a close and interrelated relationship with duty suggests that these findings are likely unreliable or that there is more to the story. Part of the explanation may be that low senses of traditional civic duty are prevalent among nonvoters, who are underrepresented in these datasets. Furthermore, many electors are likely to over-report

\footnotetext{
${ }^{14}$ As noted in the third chapter, the rationale for dropping the duty variable from surveys is not entirely clear but may have had something to do with repeatedly high reported levels of the civic duty to vote and quality issues with measurement scales.

${ }^{15}$ For example, in 2000 the response options given were strongly agree, agree, disagree, and strongly disagree. From 2004 onwards the scale has included strongly agree, somewhat agree, somewhat disagree, and strongly disagree. Although similar, respondents may attach different connotations to these response options and they can produce different results than might otherwise have been achieved.
} 
having voted in election surveys because electoral participation is seen as socially desirable.

\section{Canada}

Looking first at cross-tabulations from Canadian election studies in which duty was measured, we see a mixed pattern and possible increase. Figure 4.1, for example, shows the percentage of those that strongly identified with the best traditional duty question or statement posed in each survey year ${ }^{16}$; this includes the statement, So many other people vote in federal elections that it doesn't matter very much whether I vote or not in 1974 and 1979, It is the duty of every citizen to vote in 2000 , and It is every citizen's duty to vote in federal elections in 2004, 2006 and 2008. Responses to these questions suggest that reported levels of the civic duty to vote may be increasing. To assess this more thoroughly, it is useful to also look at reported duty by voting behaviour over time and reported duty by age over time.

Graphing the percentage high in traditional duty ${ }^{17}$ using the same survey measures from year to year ${ }^{18}$ reveals a clear relationship between age and respondent likelihood of reporting a sense of duty, and this pattern is consistent throughout a majority of the data (see Figure 4.2). This supports the conclusion that young people tend to identify less with traditional duty than their older counterparts. Mean scores from CES questions, It is every citizen's duty to vote in federal elections and If you didn't vote in a federal election would you personally feel very guilty, somewhat guilty, or not guilty at all? in 2004, 2006, and 2008 (the only years in which direct comparisons are possible) also support the conclusion that there is

\footnotetext{
16 The 'best' measure for each election year was selected based on how well electors identified with the traditional duty statements. A statement that seemed to resonate with the most prospective voters was selected for use. In some years the statements chosen are better than others, this is because more recent election surveys offered more variety in terms of duty measures, whereas older datasets often had less items to choose from. 17 Percentage high in traditional duty refers to the percentage of respondents that report high duty because they either 'strongly agree' with a positively phrased duty question or 'strongly disagree' with a negatively worded item. Depending on the composition of the question strong agreement can signify high duty or low duty and that is why the term 'percentage high in traditional duty' is used.

18 If possible, the 'best' duty item was selected.
} 
an age relationship with the traditional operationalization of civic duty.

\section{Figure 4.1 ${ }^{19}$ : Percentage high in traditional duty for best questions in Canadian surveys}

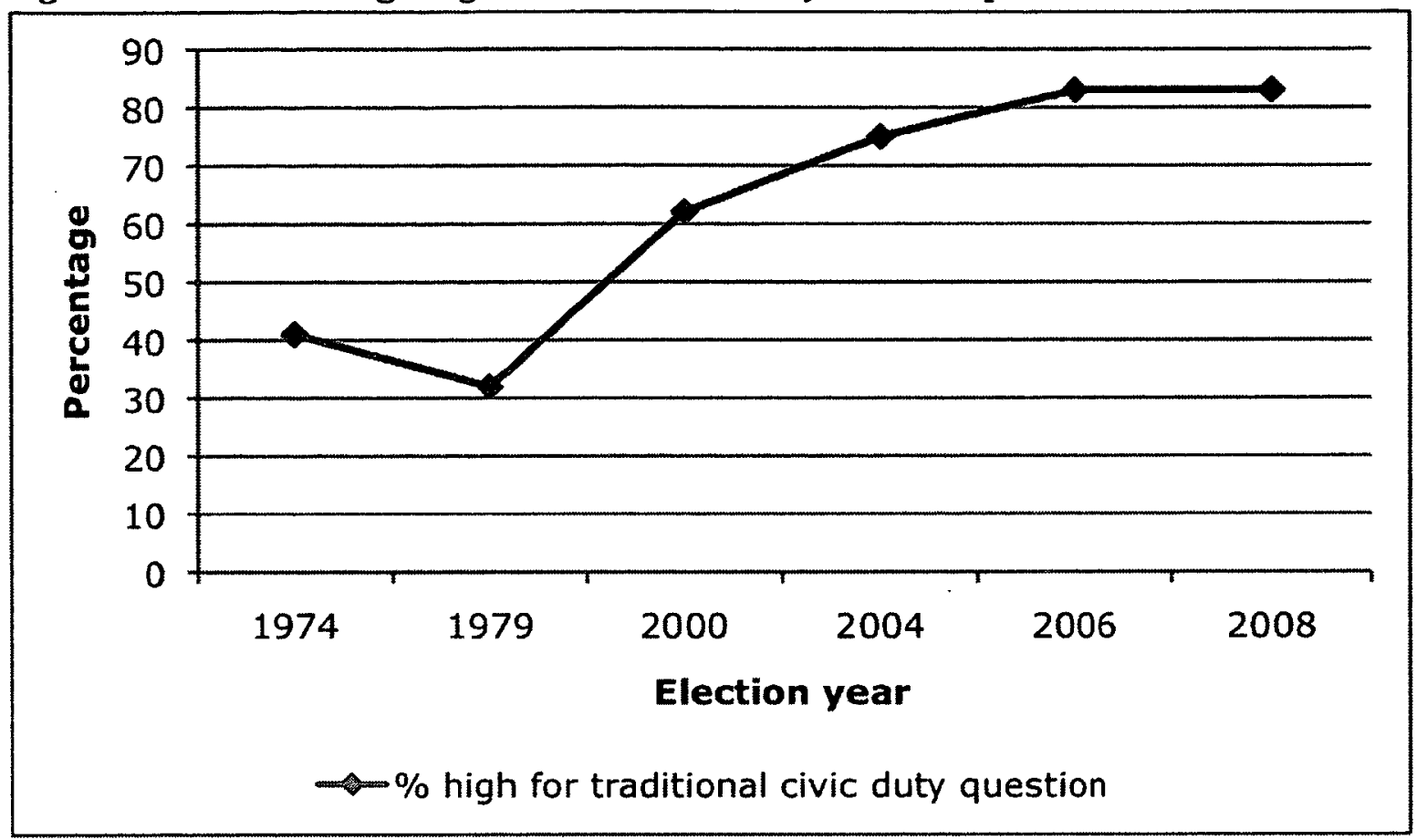

Source: Canadian Election Studies 1974-2008

The strength of a respondent's sense of duty seems to increase with age, at least as we extrapolate from the behaviour of different age cohorts in cross-sectional surveys. This premise has been documented in other studies (see Blais, 2000; Pammett and LeDuc, 2003) and corresponds with the life-cycle theory of voting, which posits that as young people settle down, marry, and pay taxes their inclination to participate rises (Wolfinger and Rosenstone, 1980). Although the 2000 CES is not directly comparable given a slightly different question wording (It is the duty of every citizen to vote) it too highlights the finding that young

\footnotetext{
19 This figure graphs the percentage of respondents who indicated they 'strongly disagree' with the statement 'So many other people vote in federal elections that it doesn't matter very much whether I vote or not' in 1974 and 1979 , and 'strongly agree' with the statements 'It is the duty of every citizen to vote' in 2000 and 'It is every citizen's duty to vote in federal elections' in 2004, 2006 and 2008. Each statement is different and therefore not directly comparable, but each of these can be considered to be the best traditional duty measure from each survey year based on response patterns.
} 
Canadians generally report weaker senses of civic duty than older electors.

Figure 4.2: Percentage high of traditional duty by age in Canada

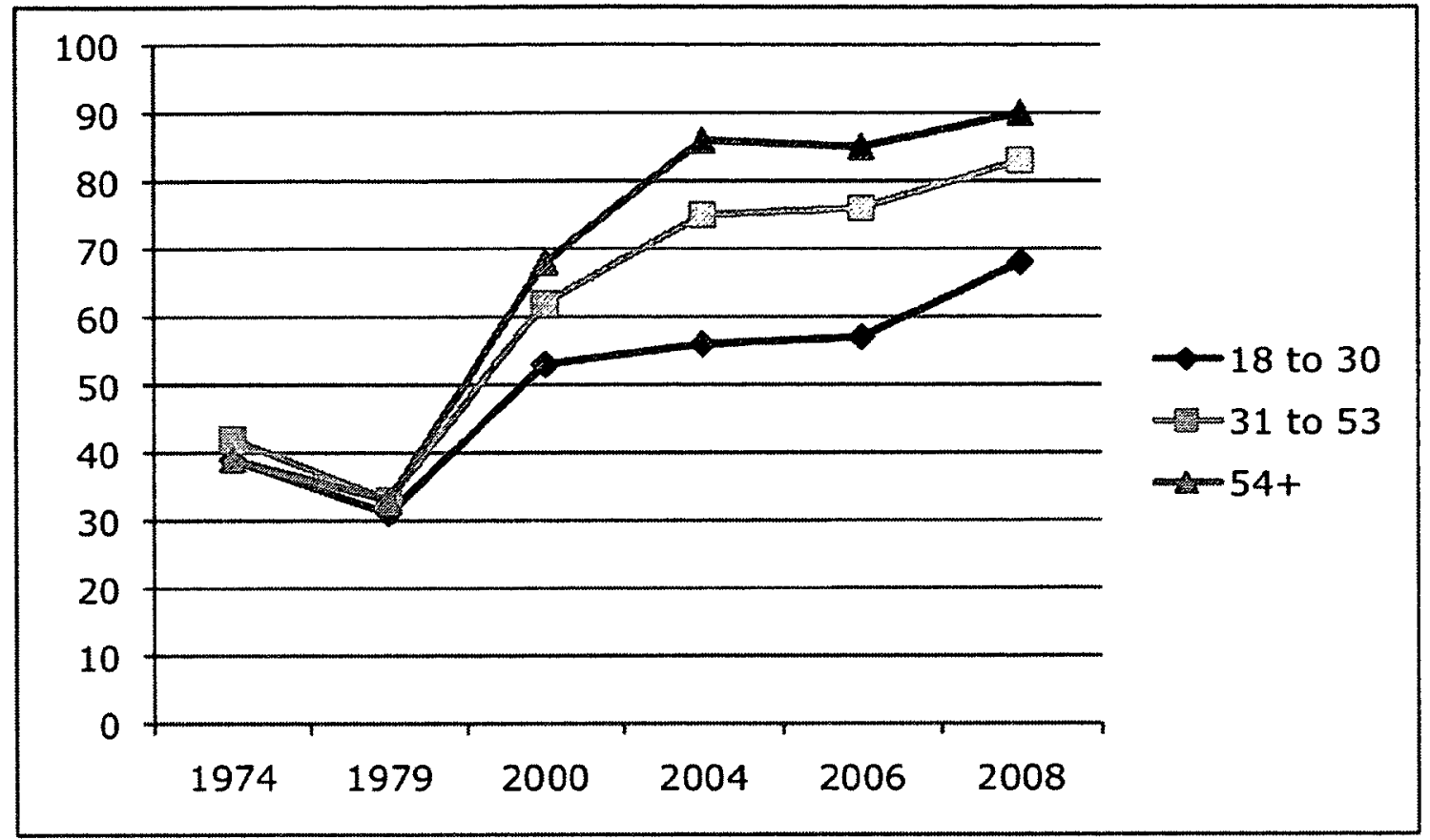

Source: Canadian Election Studies 1974-2008

Turning to voting behaviour and percentage high in traditional duty among voters and non-voters ${ }^{20}$ we see that there is a connection between those that report voting and stronger senses of duty (see Figure 4.3). Similarly, those expressing weaker senses of traditional duty are more likely to be non-voters. Much like Figures 4.1 and 4.2, there seems to be an increase in agreement with the traditional duty measure over time among voters and non-voters alike. This may be an effect of over-reporting because saying one is likely to vote or believes voting to be important is perceived by many as a socially desirable answer (Holbrook and Krosnick, 2010). The increase in agreement over time on the part of non-voters in particular could be a result of their interpretation of the question. It may be that many non-voters believe they have a duty to consider voting, but not necessarily commit to participate. Again however, the

\footnotetext{
${ }^{20}$ The same measures are used in each election year.
} 
results of this analysis should be taken with a grain of salt given the inconsistency of the questions and data available.

Table 4.1: Mean scores by age from Canadian surveys

\begin{tabular}{|}
$\begin{array}{c}\text { It is the duty of every } \\
\text { citizen to vote }\end{array}$ & \multicolumn{6}{c|}{$\begin{array}{l}\text { It is every citizen's duty to vote in federal } \\
\text { elections* }\end{array}$} \\
\begin{tabular}{|l|l|l|l|l|l|l|l|l|}
\hline Year & $2000^{* *}$ & 2004 & 2006 & 2008 \\
\hline Age group & Mean & SD & Mean & SD & Mean & SD & Mean & SD \\
\hline 18 to 30 & 1.6 & 0.7 & 1.7 & 0.9 & 1.5 & 0.7 & 1.5 & 0.8 \\
\hline 31 to 53 & 1.5 & 0.7 & 1.3 & 0.7 & 1.3 & 0.5 & 1.2 & 0.6 \\
\hline $54+$ & 1.4 & 0.6 & 1.2 & 0.5 & 1.2 & 0.4 & 1.1 & 0.5 \\
\hline
\end{tabular}
\end{tabular}

*This question was asked on a 4-point scale whereby a score of 1.0 signifies strong agreement and a score of 4.0 represents disagreement.

**Note this question is not directly comparable given the different wording.

Source: Canadian Election Studies 2000-2008

Table 4.2: Mean scores by age from Canadian surveys

\begin{tabular}{|c|c|c|c|c|c|c|}
\hline \multicolumn{7}{|c|}{$\begin{array}{l}\text { If you didn tote in a federalelection would you personally } \\
\text { feel very guilty, somewhat guilty or not guilty at all? } 21 \text {. }\end{array}$} \\
\hline Year & \multicolumn{2}{|c|}{2004} & \multicolumn{2}{|c|}{2006} & \multicolumn{2}{|c|}{2008} \\
\hline Age group & Mean & SD & Mean & SD & Mean & SD \\
\hline 18 to 30 & 2.2 & 0.7 & 2.1 & 0.7 & 2.2 & 0.7 \\
\hline 31 to 53 & 2.0 & 0.7 & 1.9. & 0.7 & 2.0 & 0.8 \\
\hline $54+$ & 1.8 & 0.8 & 17.7 & 0.7 & 18 & 0.8 \\
\hline
\end{tabular}

"This question was asked on a 3-point scale whereby a score of 1.0 signifies feeling 'very guilty' about not voting agreement and a value of 3.0 stands for feeling 'not guilty at all'.

Source: Canadian Election Studies 2000-2008

Moving on to assess whether and how much civic duty has impacted voting in these election years, Kendall's tau-c measure of association is used because it provides the direction of the relationship and is the appropriate test for the number of categories examined here. ${ }^{22}$ Correlating key civic duty questions with the vote variable from each survey year reveals a modest correlation between reporting a civic duty to participate electorally and voting

\footnotetext{
21 There was a differently worded 'guilt' styled statement asked in the $2000 \mathrm{CES}$, but it is not directly comparable because it was posed on a 4-point scale.

22 Tau-c is best used for rectangular tables, when the variables being analyzed have a different number of categories. Tau-b measure of association also provides the direction, but is best suited for analyses where the number of categories is the same and the table is square.
} 
behaviour. Though the relationship appears slightly stronger in some years than others, overall the trend indicates an association between the duty and vote variables. This suggests, as the literature points out, that those with a stronger sense of reported duty are also more likely to cast a ballot on election day (see Blais, 2000; Blais and Achen, 2010; Clarke et al., 2002; Pammett and LeDuc, 2003; Riker and Ordeshook, 1968). The results from the 1979 and 1974 survey years are negative because the question is worded negatively and therefore in these instances reporting 'strong disagreement' with the statement indicates a robust sense of civic duty.

Even though Canadian survey data does not offer clear support for a decline in duty, we do know that rates of participation on the whole are declining, particularly among the youngest segment of the electorate. The lack of a clear decline in identification with traditional duty may be a result of inconsistent question sequences over time. It may also be that the relationship between voting and civic duty is changing or evolving and that current measures are not capturing the connection between the two as well as they could be. Perhaps respondents are interpreting the importance of duty as more a duty to consider participation that to outright commit to electoral involvement. Furthermore, the fact that there is an age relationship with traditional civic duty illustrates that young people more weakly associate with the notion that elections demand a vote every time and therefore have other thoughts and beliefs about the ethic of participation during election time. 
Figure 4.3: Percentage high in traditional duty by voting behaviour in Canadian surveys

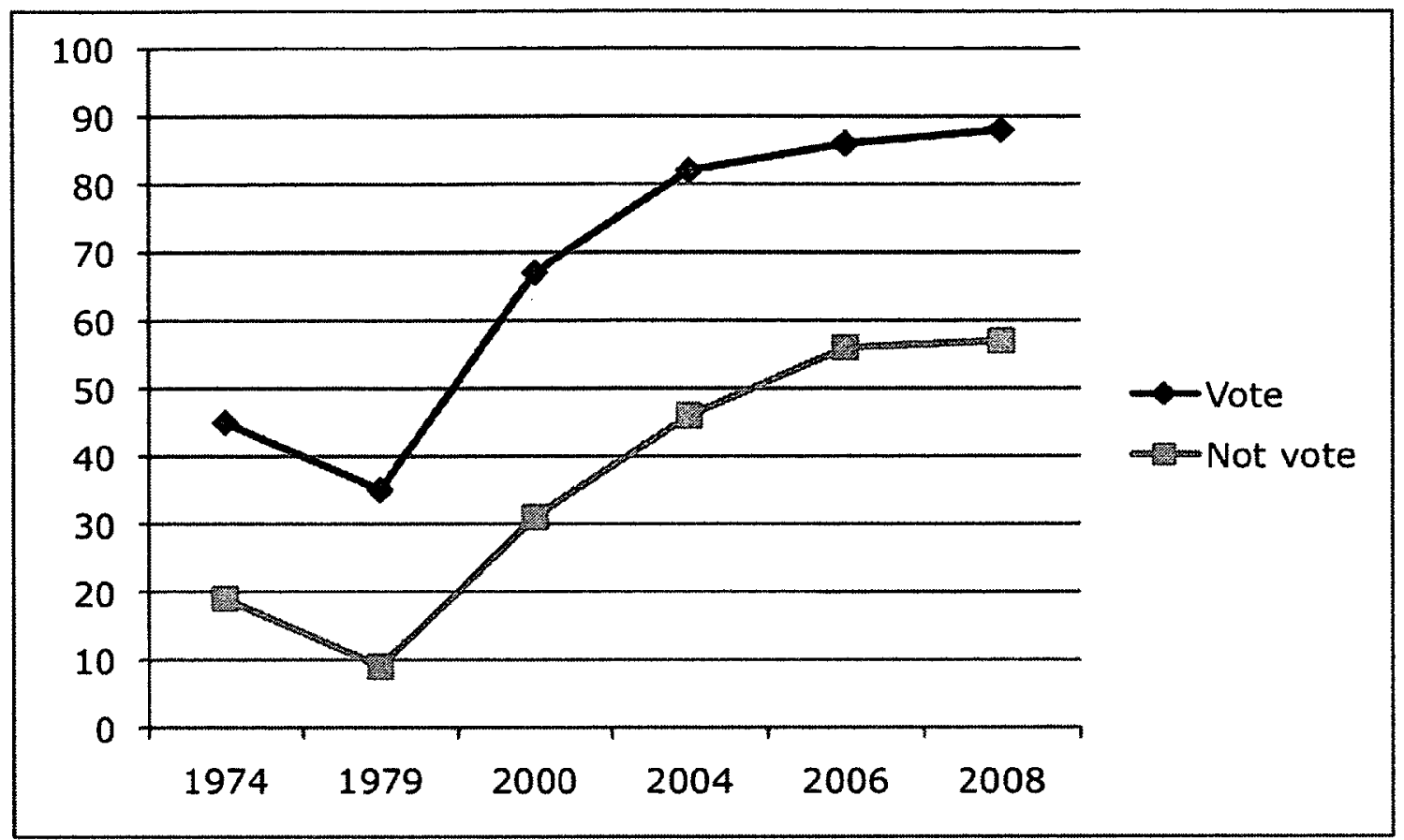

Source: Canadian Election Studies 1974-2008

Table 4.3: Correlation of traditional civic duty with the vote in Canadian election surveys $^{23}$

\begin{tabular}{|c|c|c|c|c|}
\hline Survey Year \& Question(s) & Vote & Not Vote & Kendalls & Sig. \\
\hline \multicolumn{5}{|c|}{ 2008 } \\
\hline $\begin{array}{l}\text { It is every citizen's duty to vote in } \\
\text { federal elections. }\end{array}$ & 2141 & 317 & .145 & .000 \\
\hline $\begin{array}{l}\text { If you didn't vote in an election would } \\
\text { you personally feel very guilty, } \\
\text { somewhat guilty, or not guilty at all? }\end{array}$ & 2125 & 313 & .205 & .000 \\
\hline \multicolumn{5}{|c|}{$20066^{2}$} \\
\hline $\begin{array}{l}\text { It is every citizen's duty to vote in } \\
\text { federal elections. }\end{array}$ & 2908 & 302 & .170 & .000 \\
\hline $\begin{array}{l}\text { If you didn't vote in an election would } \\
\text { you personally feel very guilty, } \\
\text { somewhat guilty, or not guilty at all? }\end{array}$ & 2894 & 305 & .142 & .000 \\
\hline \multicolumn{5}{|c|}{2004} \\
\hline $\begin{array}{l}\text { It is every citizen's duty to vote in } \\
\text { federal elections. }\end{array}$ & 2711 & 403 & .178 & .000 \\
\hline
\end{tabular}

${ }^{23}$ For all analyses missing data was excluded and appropriate national weights were applied. 


\begin{tabular}{|l|l|l|l|l|}
\hline $\begin{array}{l}\text { If you didn't vote in an election would } \\
\text { you personally feel very guilty, } \\
\text { somewhat guilty, or not guilty at all? }\end{array}$ & 2719 & 418 & .198 & .000 \\
\hline 2000 & \multicolumn{5}{|l|}{} & & \\
\hline It is the duty of every citizen to vote. & 1335 & 175 & .173 & .000 \\
\hline If I did not vote, I would feel guilty. & 1306 & 172 & .196 & .000 \\
\hline 1979 & 109 & -.141 & .000 \\
\hline $\begin{array}{l}\text { So many other people vote in federal } \\
\text { elections that it doesn't matter very } \\
\text { much whether I vote or not. }\end{array}$ & 1019 & 163 & -.117 & .000 \\
\hline $\begin{array}{l}1974 \\
\begin{array}{l}\text { So many other people vote in federal } \\
\text { elections that it doesn't matter very } \\
\text { much whether I vote or not. }\end{array}\end{array}$ 968 & 163 & & \\
\hline
\end{tabular}

Source: Canadian Election Studies 1974-2008

\section{Britain}

Data from British Election Studies, by contrast, illustrates a much clearer picture of declining senses of duty, which corresponds with falling levels of electoral participation. This pattern is substantiated in other studies that examine civic duty data from the BES (see Curtice and Park, 2010). Looking at the percentage high in traditional duty of the best questions over time suggests a majority of the drop has occurred in more recent years, although the questions asked before 2001 differ slightly and therefore are not directly comparable (see Figure 4.4). ${ }^{24}$ Looking at a larger pool of data collected by the BES between 1987 and 2009 offers further support for the finding that senses of civic duty to vote have been declining among British electors, particularly since 2005. Figure 4.5 for example, illustrates that over about a 20-year period the likelihood of agreeing that, It is everyone's duty

\footnotetext{
24 In the 1987, 1992, and 1997 surveys respondents were asked which statement they most closely identified with, one of which included It is everyone's duty to vote. In 2001, 2005, and 2010 they were asked to indicate agreement on a 5-point scale with the statement, It is every citizen's duty to vote in an election.
} 
to vote in an election decreased by 20 percent. ${ }^{25}$ As identification with duty has slowly fallen, there has been a corresponding rise in the number of respondents who report feeling that $I t$ is not really worth voting. This supports the conclusion that British electors increasingly identify less with the traditional conceptualization of the civic duty to vote.

Figure 4.4: Percentage high in traditional duty for best questions in British surveys

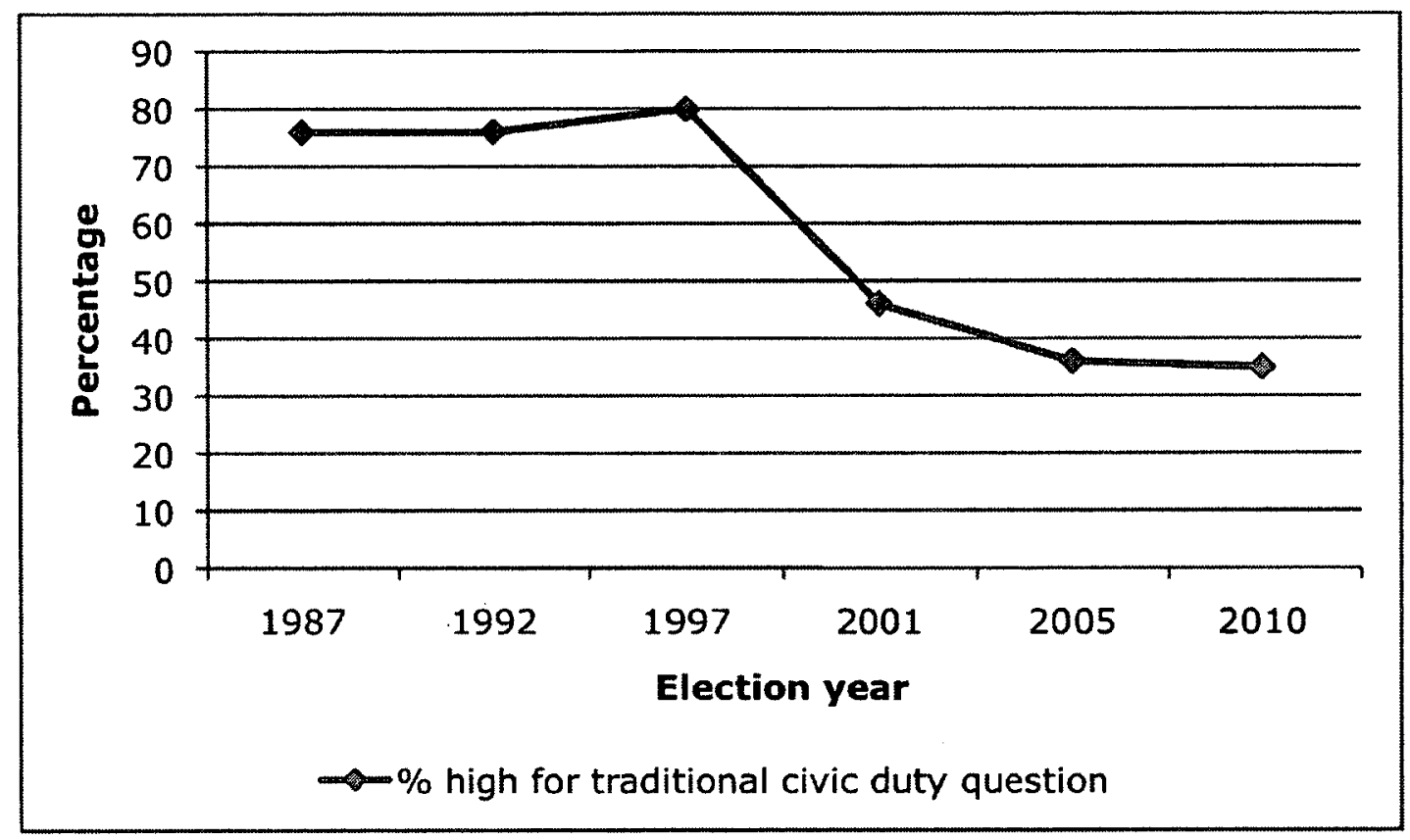

Source: British Election Studies 1987- 2010

Much like the Canadian case, British data also indicates a clear connection between traditional civic duty and age, providing support for the finding that respondents are more likely to be dutiful as they age and less likely to identify with the civic duty to vote in their younger years of electoral eligibility. Mean scores by age for comparable duty questions from 2001, 2005 and 2010 highlight the age relationship with the civic duty concept (see Tables 4.4 and 4.5). On the whole then, Canadian and British data suggest that young people are less

${ }^{25}$ Specifically, respondents were asked to choose one of the following statements when asked which most closely corresponds with their feelings about a general election. Response options include: 'It is not really worth voting', 'People should only vote if they care who wins', and 'It is everyone's duty to vote'. 
Figure 4.5: Civic duty responses in British surveys, 1991-2009

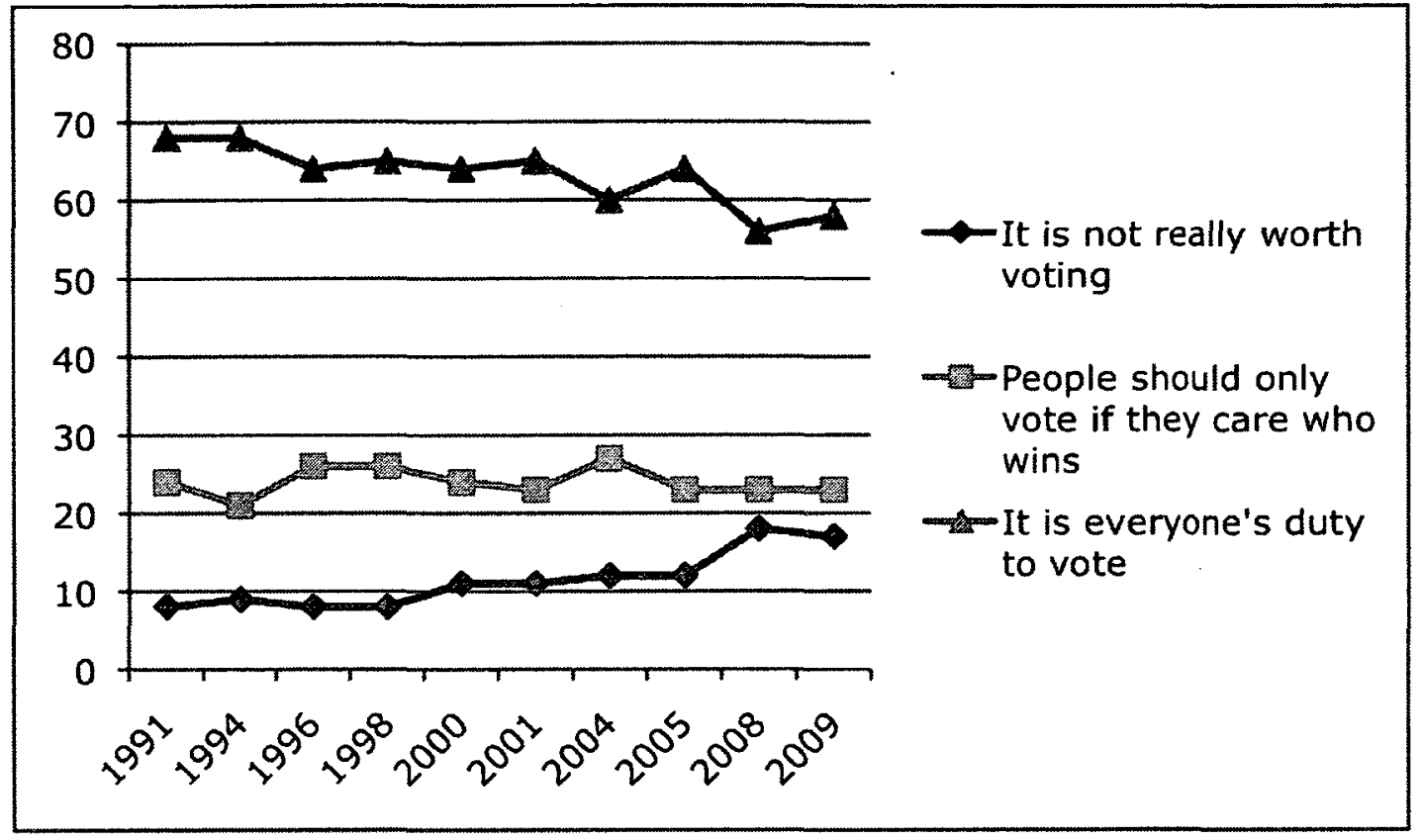

Source: Data taken from Curtice and Park, 2010 (British Election Study)

Table 4.4: Mean scores by age from British surveys

\begin{tabular}{|c|c|c|c|c|c|c|}
\hline \multicolumn{7}{|c|}{ It is every citizen's duty to vote man election. } \\
\hline Year & \multicolumn{2}{|c|}{2001} & \multicolumn{2}{|c|}{2005} & \multicolumn{2}{|c|}{2010} \\
\hline Age group & Mean & SD & Mean & $\mathrm{SD}$ & Mean & SD \\
\hline 18 to 30 & 2.8 & 1.08 & 2.53 & 1.12 & 2.53 & 1.14 \\
\hline 31 to 53 & 1.96. & 1.03 & 2.14 & 1.07 & 2.18 & 1.10 \\
\hline $54+$ & 1. 57 & 0.83 & 1.22 & 0.88 & 1.85 & 0.98 \\
\hline
\end{tabular}

*This question was asked on a 5-point scale whereby a score of 1.0 signifies strong agreement and a score of 5.0 represents disagreement.

Source: British Election Studies 2001- 2010

Table 4.5: Mean scores by age from British surveys

\begin{tabular}{|c|c|c|c|c|c|c|}
\hline \multirow{3}{*}{$\begin{array}{l}\text { woula fe } \\
\text { Year } \\
\text { Age group }\end{array}$} & y gui & 12 & ntvot & & ral & \\
\hline & \multicolumn{2}{|l|}{2001} & \multicolumn{2}{|c|}{2005} & \multicolumn{2}{|l|}{2010} \\
\hline & Mean & SD & Mean & SD & Mean & SD \\
\hline 18 to 30 & 3.28 & 1.27 & 3.27 & 1.15 & 3.28 & 1.20 \\
\hline 31 to 53 & 2.67 & 1.29 & 2.72 & 1.19 & 2.76 & 1.29 \\
\hline $54+$ & 2.14 & 1.22 & 2.58 & 1.21 & 2.26 & 1.28 \\
\hline
\end{tabular}

*This question was asked on a 5-point scale whereby a score of 1.0 signifies strong duty by indicating 'strong agreement' and a value of 5.0 represents no feelings of a moral obligation to participate in a general election. Source: British Election Studies 2001-2010 
likely to identify with the traditional conception of civic duty. While not all data points to a decline among the group it is clear that young electors have alternate feelings about the obligation to participate in an election or their level of identification with traditional items would be greater.

British data also reveals a connection between voting behaviour and civic duty. The percentage high in traditional duty for the best measure posed in each election year provides additional support for a relation between voting and a strong sense of the civic duty to vote (see Figure 4.6). Similarly, those less committed to voting report weaker senses of electoral obligation. Interestingly, both reported voters and non-voters have noted a decrease in their strength of civic duty over time, suggesting that today's British citizens no longer have the same powerful identification with the traditional operationalization of duty. It could be that perhaps electors' perception of a citizen's duty in an election has changed and that the feeling that an election demands a vote every time is no longer as powerful.

Finally, evaluating the impact of civic duty on voting behaviour in applicable election years using Kendall's tau-c suggests slightly stronger correlations between civic duty and the decision to cast a ballot than the Canadian case. Again, the association is slightly greater depending on the election year, but on the whole there is support for a correlation between electoral duty and whether a respondent voted. Those with weaker senses of duty are less likely to have voted, whereas those with stronger senses of electoral obligation are more likely to have cast a ballot during the election period.

Generally, the British survey results illustrate a clear decline in perceived electoral duty among both reported voters and non-voters. Though Canadian data presents a slightly different picture, it is important to remember that voter turnout has declined in spite of this. 
So, if levels of duty are really increasing among the eligible electorate there is still something to be explained regarding the relationship between voting behaviour and feelings that participating in elections is obligatory. These mixed results coupled with the fact that turnout in national elections has noted a steady decline over the past couple of decades, merits revisiting the traditional conceptualization of civic duty and how it is measured in public opinion surveys. Evidence of a clear age relationship with the duty variable and the fact that a large portion of voter decline is confined to the youngest segment of electorate makes focusing on exploring young people's perceptions especially necessary. Finally, this analysis tells us that, decline or no decline, there is a correlation between the reported vote and civic duty in the cases of both countries. This casts doubt on the Canadian findings, which show an increase in duty and also highlight the importance of revisiting how we think about and measure feelings of obligation to vote during election time.

Figure 4.6: Percentage high for traditional duty by voting behaviour in British surveys

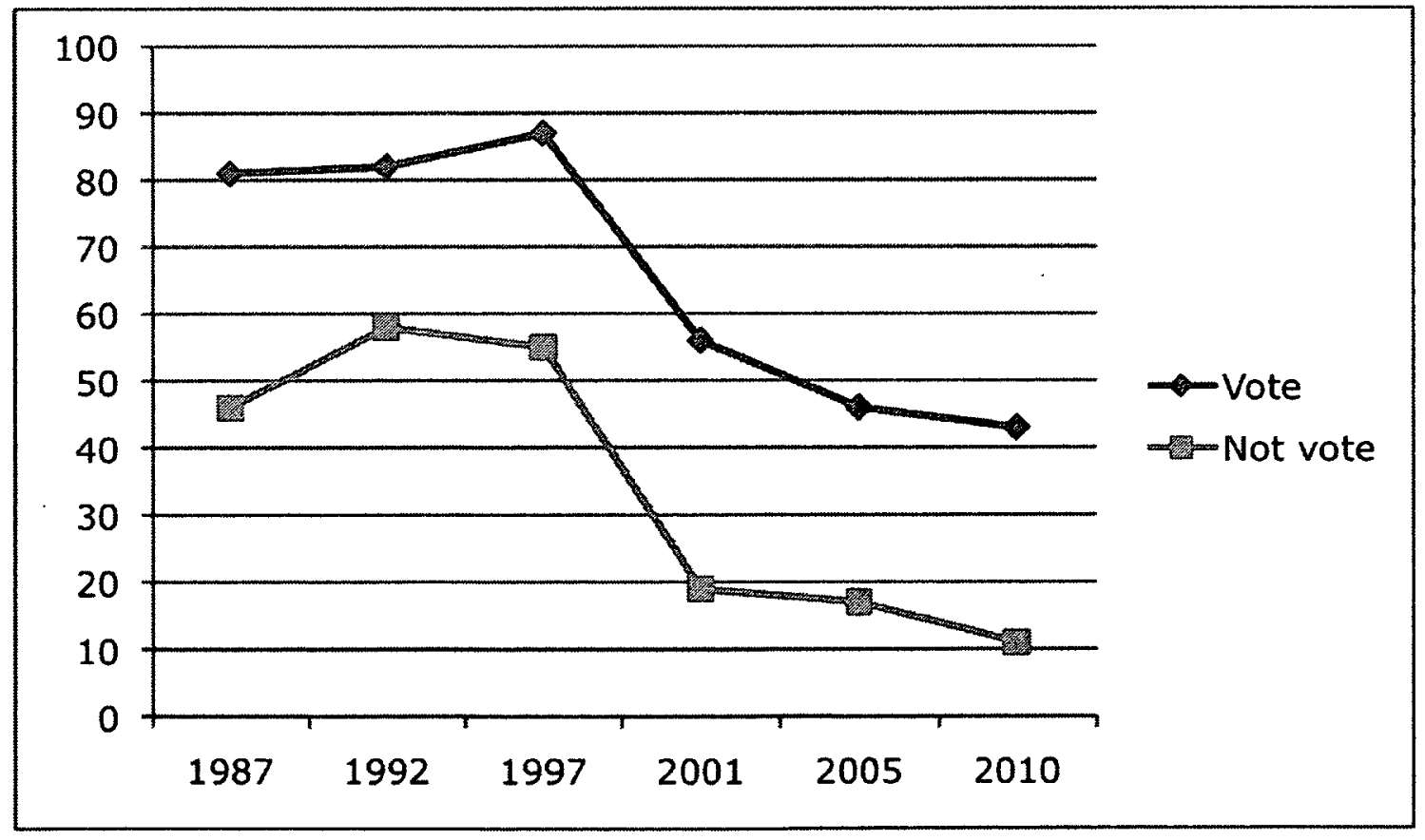

Source: Source: British Election Studies 1987-2010 
Table 4.6: Correlation of civic duty with the vote in British election surveys ${ }^{26}$

\begin{tabular}{|l|l|l|l|l|}
\hline Survey Year \& Question(s) & Vote & Not Vote & $\begin{array}{l}\text { Kendall's } \\
\text { Tau-c }\end{array}$ & Sig. \\
\hline $2009-2010$ & 1198 & 295 & .300 & .000 \\
\hline $\begin{array}{l}\text { It is every citizen's duty to vote in an } \\
\text { election. }\end{array}$ & 1200 & 287 & .309 & .000 \\
\hline $\begin{array}{l}\text { I would feel very guilty if I didn't vote } \\
\text { in a general election. }\end{array}$ & \multicolumn{5}{|l|}{} & .000 \\
\hline $\begin{array}{l}\text { It is every citizen's duty to vote in an } \\
\text { election. }\end{array}$ & 2181 & 792 & .316 & .000 \\
\hline $\begin{array}{l}\text { I would feel very guilty if I didn't vote } \\
\text { in a general election. }\end{array}$ & 2180 & 784 & .362 & .000 \\
\hline $\begin{array}{l}\text { 2001 } \\
\text { It is every citizen's duty to vote in an } \\
\text { election. }\end{array}$ & 2136 & 879 & .383 & .000 \\
\hline $\begin{array}{l}\text { I would feel very guilty if I didn't vote } \\
\text { in a general election. }\end{array}$ & 2137 & 880 & .436 & \\
\hline
\end{tabular}

Source: British Election Studies 2001-2010

The fact that researchers have not reevaluated this concept is not overly surprising given that survey items are typically carried over from election to election for purposes of comparison over time. For example, discussing the methodology of studying public opinion Niemi (1986) warns researchers not to "change question wording" or "change questionnaire content." While there seems to be some debate regarding the usefulness of changing survey measures, if they are no longer as effective at tapping an attitude or value as they have been historically, looking at refining or revising an existing measure could prove a very helpful exercise. In their article, "The Past and Future of the Canadian Election Study" Johnston and Blais (2008:4) discuss the importance of balancing "continuity with change". While older data

\footnotetext{
${ }^{26}$ It was not possible to evaluate the duty measures from 1987 and 1992 given the scale that was used $(1=I t$ 's not really worth voting; 2 = People should only vote if they care who wins; $3=$ It is everyone's duty to vote).

Similarly, questions from the 1997 campaign panel survey followed the same strategy. The cross-section survey from the same year offered two response options $(1=$ People need not vote unless they really care who wins; $2=$ Or, is it everyone's duty to vote), but again the scale differs from the items included in Table 4.6. Also, please note that for all of these calculations missing data was excluded and appropriate national weights were applied.
} 
remain relevant, social changes and the relevance of issues warrants revisiting and renewing survey instrumentation. Also, the fact that duty measures have been applied in an inconsistent manner and not necessarily repeated in all survey years provides additional support for a reevaluation.

\section{Conclusion}

The above analysis of traditional civic duty measures over time captures a very small part of the story of how young people in particular feel about citizen responsibilities during an election and the ethics of participation. To shed more light on this and assess whether there are other untapped dimensions of the duty to vote, the following chapter examines qualitative data that was obtained from a larger study conducted via Facebook during the 2008 federal election campaign where respondents were asked key questions about how they perceive of Canadian citizenship and what it means to be a citizen in an election campaign. ${ }^{27}$ Responses are analyzed to assess whether there appear to be alternate dimensions of electoral duty that are distinct from the traditional perception. Exploring new facets of the notion of citizen obligation in an electoral context may help shed light on young people's weak senses of traditional duty and hence their willingness to abstain from voting.

\footnotetext{
27 Carleton Professor Jon Pammett, University of Toronto Professor Lawrence LeDuc, one of his graduate
} students, Heather Bastedo, and myself conducted this study. 


\section{Chapter 5 : New conceptions of duty: the 2008 Facebook study}

\section{Introduction}

This chapter outlines a study of young people that was conducted via Facebook in conjunction with the 2008 Canadian Federal Election campaign to probe their attitudes and feelings about Canadian citizenship and, more specifically, their perceptions of what it means to be a citizen in an election campaign (Goodman et al., 2011) 28 . Participants were asked a variety of questions about engagement, responsibility, conceptions of citizenship, what it means to be a citizen during an election, and other items related to the specific topics and issues associated with the 2008 election. Those questions related to perceptions of citizenship and feelings regarding a citizen's role during an election are the focus of this section and the basis for reformulating how we think about the civic duty to vote in elections. The rich data obtained from these responses forms the foundation for alternate conceptions of the civic duty to vote-indeed, this was a major purpose of undertaking it. Exploring new facets of the notion of citizen obligation in an electoral context may help shed light on young people's apparently weakening senses of traditional duty and hence their willingness to abstain from voting. Why use a qualitative Facebook research design?

Most data addressing orientations toward voting is collected using quantitative surveys, using the many question types explored in Chapter Three. While quantitative items are essential, the nature and style of these questions do not allow researchers to collect additional explanatory insight into the voting behaviour of citizens or their perceptions of

\footnotetext{
28 Please note that some of the text in this chapter was written by me for the article "Young Canadians in the 2008 Federal Election Campaign: Using Facebook to Probe Perceptions of Citizenship and Participation" published in the Canadian Journal of Political Science in December 2011. The same sample of qualitative data was used as the basis for that article and is examined in a slightly different context for this thesis.
} 
citizenship duties during an election. Quantitative question sequences also prohibit thoughtful comparison of voters, non-voters, and electors that report more mixed patterns of voting engagement. Instead, they force electors to report being engaged or not engaged, dutiful or not dutiful, attentive or non-attentive. Thus, in the process of establishing new quantitative measures, qualitative research plays an essential part.

A main qualitative approach, the traditional focus group method, typically takes place in laboratory-type settings that may not be wholly comfortable for respondents and therefore are not ideal for obtaining candid responses, particularly from young people (LeDuc, Pammett, and Bastedo, 2008). In hopes of obtaining more genuine and reflective answers, Facebook was used to conduct a series of 'virtual' focus groups, given that it is an online forum where young people regularly congregate to share information and ideas and as such is a place in which they many of them feel comfortable.

Additional research benefits of using Facebook include the fact that participants are able to contribute or engage in the group any time of day, access it from multiple locations, incur lower research costs than traditional focus groups, provide a written log of the entire discussion (eliminating the need for transcripts), and give an opportunity for easy follow-up or clarification questions if required. Finally, although participants were self-selected, which is a limitation, it is likely that a broader group of young people were attracted to this study because it was carried out via Facebook as opposed to a different type of research project where participants are required to sign up or recruited over the telephone. Other limitations are the fact that as an Internet application Facebook typically attracts people with better access to socio-economic resources and likely those who are report higher education levels. Overall however, the Facebook design allowed for all the benefits of traditional qualitative 
methods with some added advantages. The quality and richness of the responses obtained from this study suggest that Facebook is a useful tool for conducting qualitative research.

\section{Specific study dynamics}

The study ran for a total of four weeks during the 2008 federal election campaign, which included the three weeks before election day and the week following. ${ }^{29}$ Ads were posted in the Marketplace ${ }^{30}$ section of the Facebook website calling for young people aged 18 to 26 from the Ottawa and Toronto areas and promising $\$ 50$ payment for completing four weeks of closed and open-ended questions relating to politics and the federal election in private Facebook groups. Potential participants were required to complete an initial questionnaire that sought to assess their level of interest in politics, intention to vote and, if eligible, past voting record. ${ }^{31}$ Based on these responses participants were arranged into three groups organized by low, moderate, and high levels of reported engagement and interest. We intentionally grouped people with similar response scores to avoid cross-respondent influence in the discussion groups and in hopes of minimizing over-reporting. ${ }^{32}$

The first group contained participants who reported higher levels of engagement and indicated they would be likely to vote. The second consisted of those who expressed minimal interest and self-identified as being unlikely to cast a ballot. Finally, those who reported mixed or inconsistent patterns of engagement, irregular participation history, and uncertainty

${ }^{29}$ Ethics approval for the 2008 Facebook study were applied for and obtained through the University of Toronto, who was a partner in the project.

30 Marketplace is a section of the Facebook website that allows users to post free classified ads either listing items available or indicating items wanted. There is a multitude of categories some of which include cars, jobs, and housing.

31 Participants that reported having a political science background were excluded. Others were left out because they did not fall within the desired age group. We also had more females than males respond to the ad and had to exclude some in an effort to balance the groups by gender. Initially there were 37 participants, but only 28 responded to the questions for all four weeks of the study. Groups were capped at a maximum of 15 participants. 32 While it may not be possible to fully eliminate these effects it was hoped that putting participants with likeminded individuals would encourage honest responses. The fact that many young people easily wrote about their lack of participation suggests that this technique was successful. 
about voting were placed into the third group. While we attempted to balance the groups by gender and education, there were more females than males and on the whole participants reported higher levels of education than the general population. ${ }^{33}$ Another limitation includes the fact that no comparisons with other cohorts are possible given that the sample was focused on young people.

At the beginning of every week two sets of questions were posted for participants. Open-ended questions were pasted in the group discussion forums and complementary closeended questions were sent to respondents by private message. This dual approach allowed for group members to interact and reflect on each other's thoughts and comments in their assigned forum, but also provided confidentiality for other, more sensitive, questions. The nature of Facebook allowed respondents to make a contribution at any time and also provided time for reflection and thought. Finally, the forum provided a useful means of posing followup questions, which were sometimes required to gain greater clarity for certain responses. Once the study was complete, the data was organized by constructing a number of measures. Specifically related to this thesis, measures regarding the meaning of citizenship and the role of a citizen in an election context were composed. Data was then organized and plotted along the $\mathrm{X}$ axes of matrices. The corresponding $\mathrm{Y}$ axes represents voting intention. Participants are plotted along the $\mathrm{Y}$-axis from a 5-point scale that is compiled based on reported voting behaviour in the 2004 and 2006 federal elections, the 2007 Ontario provincial election, intention to vote in the 2008 federal election, and whether participants

\footnotetext{
33 The initial survey asked respondents to indicate their highest level of education. It is not surprising that overall respondents report a higher level of education than the general population given that Facebook was originally designed as social connection tool for University students. Social networking sites also require access to resources such as a computer and the Internet and as a consequence may not be as accessible to people with lower socio-economic means.
} 
actually cast a ballot in $2008 .^{34}$

The scales used to construct the conceptions of citizenship and citizen's role matrices followed a similar process. The conception of citizenship variable was compiled using responses from two open-ended questions that probed respondent perceptions about what it means to be a Canadian citizen today. Based on their content responses were coded and given a value between 1 and 4 . These numbers were then added and divided by 2 to acquire an overall value for each participant. The citizen's role variable was computed based on responses to three closed-ended questions and one open-ended question that probed how respondents believed citizens should act in an election campaign. Scores for each question were added and divided by 4 to produce a value that could be plotted along the $\mathrm{X}$-axis. The specific questions used in the composition of both matrices can be found in the Appendices. ${ }^{35}$

\section{Conceptions of citizenship}

Chapter One and Chapter Two highlighted the interrelationship between citizenship and civic duty and pointed to the research finding that orientations toward engagement are by and large representative of a person's conception of citizenship (Pammett, 2009; TheissMorse, 1993). The value of citizenship norms in accounting for and determining the scope and depth of a person's propensity to participate is a useful place to start when seeking to shed

\footnotetext{
${ }^{34}$ For each election, respondents were given a score of 1 if they reported voting, a 0 if they reported not voting, and an $\mathrm{n}$ if they were not eligible. Scores were tallied based on the number of times participants were entitled to vote and this number was divided by 5 to produce a score out of 1 . All scores are plotted along the $Y$ axis between the values of 0 and 1 . A value of 0 represents a very weak or non-existent intention to vote, while a score of 1 signifies a strong intention to do so.

${ }^{35}$ With respect to conceptions of citizenship, the coding of responses was based on their richness and whether participants identified citizenship as being something multi-faceted and nuanced, a seemingly thicker conception, or as something that is one-dimensional and only designates a status and rights, characteristics associated with a thin conception. Coding of responses to a citizen's role considered whether a respondent perceived a citizen as having duties during an election campaign (no role constitutes a perception of no duties whereas feelings of obligation to vote or to vote, stay informed, discuss politics, and actively encourage others to participate represented fuller roles) and whether a citizen had any duties in addition to voting (such as keeping politically informed, paying attention to the campaign, discussing politics with others, etc.)
} 
light on the changing nature of civic obligation in an election context. Respondents were asked to describe what it means to be a Canadian citizen today and probed further as to whether they conceived of citizenship broadly, including items such as responsibility to the community, diversity, or more narrowly as merely a legal status that implies rights. Overall, the data reveals two broad conceptions of what it means to be a citizen. Some respondents express relatively one-dimensional conceptions of citizenship, describing it as a contract of rights conceived of in legalistic terms. Whereas other young people communicate more multidimensional conceptions, in which citizenship has not only legalistic elements, but also components involving duties on the part of the citizen. A few conceptions are richer and depict citizenship in very "thick" and more comprehensive terms.

The distinction between thick and thin conceptions of citizenship is well established in the literature. While some conceptions can be relatively narrow and thin, others by comparison are much more robust and thick. According to Tilly (1996) thin citizenship "entails a few transactions, rights and obligations," whereas thick citizenship "occupies a significant share of all transactions, rights and obligations sustained by state agents and people living under their jurisdiction" (8). Bubeck (1995) develops a similar typology, noting that thin citizenship can be characterized as passive and rights privileged, places responsibility with the state, perceives citizenship as a purely public status with legal duties, and sees freedom through choice. Thick citizenship, by contrast, is classified by its active nature and focuses on rights and responsibilities as mutually supportive, assigns responsibility to the community and not necessarily the state, recognizes citizenship as something that can be both private and public and that has moral obligations as well as legal ones, and views freedom through civic virtue. Linking these different conceptions to voting 
behaviour is a useful way of gaining explanatory insight into the relationship between citizenship norms and the motivation to participate electorally.

Data suggests that the presence and intensity of attachment to broader citizenship norms and the degree of fullness in a respondent's conception of citizenship is linked to voting orientation (explored more fully in Figure 5.1). For example, almost all reported nonvoters articulate one-dimensional or thin conceptions of citizenship, which mostly excludes any feelings of emotional attachment to being a citizen. Although several non-voters (e.g. Molly, Ben, Amy, and Jennifer) express some emotion in their comments, and acknowledge dimensions of citizenship beyond a legal status and entitlements to rights and privileges, these remarks do not more fully explore what this might involve. By comparison, reported voters describe either one-dimensional or multi-dimensional conceptions of what it means to be a citizen. These descriptions illustrate varying degrees of richness and commitment to citizenship in Canada.

Closer examination of comments reveals variations within one-dimensional or thin and multi-dimensional or thick conceptions of citizenship (see Figure 5.1). While not always visually obvious, there are small clusters of participants whose responses correspond closely and that present slightly different images or interpretations of what it means to be a Canadian citizen. In the lower left quadrant of the matrix for example, although respondents describe one-dimensional accounts of citizenship there are three different variations within this pattern. While one group reports being unsure of what citizenship means beyond status and rights (bottom, far left), another views citizenship as a type of status and nothing more (middle, left). Finally, a third group expressed recognition of rights and limited citizen responsibilities (bottom left, closer to the middle). 
Those with very weak intentions to vote are found closer to the left (e.g. Jacob, John, Samantha) and report notions of citizenship that are strictly rights-based. These young people also express uncertainty surrounding what else citizenship might involve besides the designation of rights. Many of the responses are accompanied by expressions like "I don't really know" or "I am not sure." John highlights the observations of the group when commenting, "A Canadian citizen, to me, refers to someone who resides in Canada. Outside of that, I don't really know what being a citizen would mean." Likewise, Samantha, a 23 year-old university student from Toronto also remarks, "I'm not really sure. To me a Canadian citizen is just someone who was born/lives here." These descriptions reflect a one-dimensional view of citizenship and doubt over what else the concept might involve. These young people focus on rights in their responses and do not identify further components or responsibilities that may be associated with Canadian citizenship. There is no association or relationship drawn between participation, public life, or citizen obligations.

Moving up slightly in the bottom left quadrant participants (e.g. Kim, Carissa, Aisha) continue to identify citizenship as a legal status, but exhibit no uncertainty surrounding what else citizenship might include. This cluster of young people is clear that the extension of citizenship bestows residents with rights and privileges and like other members of this quadrant excludes mention of any expectation of citizen action in return. For example, Aisha from Ottawa says, "I would describe a Canadian citizen to be someone who legally has Canadian citizenship lo ${ }^{36}$. I don't see any other way around it or any other types of descriptions..." Kim, a 20 year-old university student, expresses a similar attitude noting that, "a Canadian citizen is

36 "Lol" (laughing out loud) is a slang term young people use commonly in writing or text messages. It signifies that something is humorous. 
one who lives and works in Canada." These participants are more confident in their ability to define citizenship as a type of status with legal rights, but their depictions continue to focus on the individual and his or her legal contract with the state. These accounts of citizenship do not include recognition or acknowledgement of the importance of community, no sense of obligation, and no inclusion of any broader nuances regarding what it means to be a citizen.

\section{Figure 5.1: Conceptions of citizenship and orientations to voting}

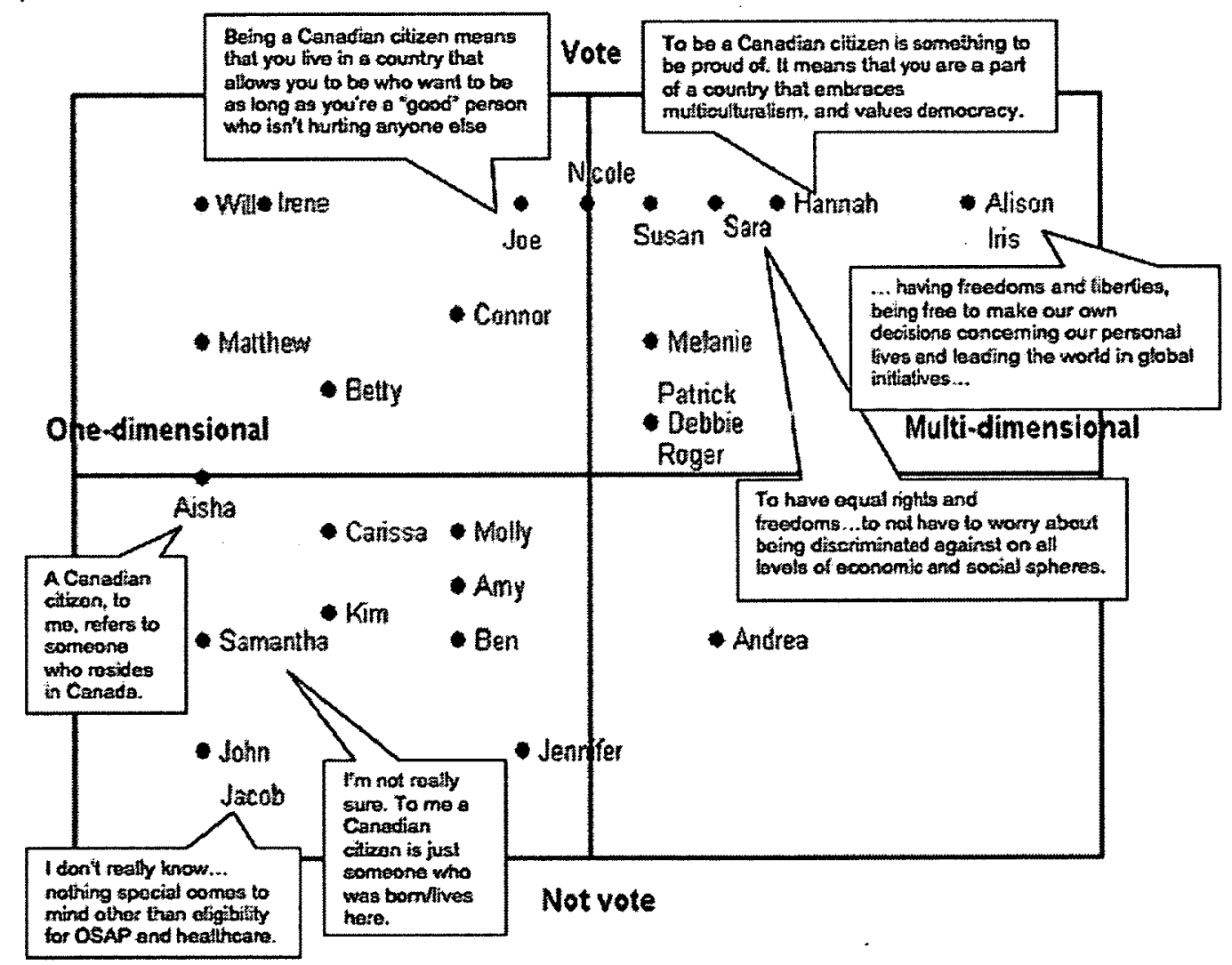

Finally, moving toward the right slightly, those closest to the centre line (e.g. Ben,

Molly, Amy, Jennifer) begin to acknowledge elements of citizenship beyond references to legal status. For example, Ben, a 25 year-old college student from Toronto comments, "A Canadian citizen is someone who has citizenship in this country, to be lucky and fortunate to live a country where you can practice your religion, and embrace your sexual preference without fear." Molly, 
who is plotted above Ben, remarks, "Being a citizen in Canada means following the laws set in place to ensure the safety of other citizens, and to respect said citizens despite any differences that there may be." Although these comments do not reveal an enhanced awareness of obligation, the conceptions of citizenship Ben and Molly describe are slightly more complex and are not quite as narrow as the other accounts of citizenship expressed by the bottom lefthand group.

Young people with higher voting intention, by comparison, characterize the upper lefthand quadrant. For the most part there is a continuation of the rights-based vision of citizenship, although respondents closer to the right (e.g. Connor, Joe, Irene, Nicole, and Betty) begin to offer additional gradations within their comments that demonstrate a belief that there is more to being a Canadian citizen than merely living and working within the nation. Some accounts imply an appreciation for citizenship by explaining that Canadian citizenship is a 'good thing'. While this group does not identify specific citizen responsibilities to the state, there is recognition that some sort of commitment to the community is important, even if this is expressed by just "being a good person". The closer participants are placed to the centre, the more nuanced their responses. ${ }^{37}$

Moving over to the top right hand quadrant of the matrix there are two other variations or sub-conceptions of citizenship, both recognizing that the notion of citizenship encompasses more than one dimension. One group of respondents (e.g. Roger, Patrick and Melanie) characterize citizenship as a multi-faceted concept that should be appreciated, but laments that it is not defined more broadly by the general public. These young people suggest

37 Though there is some uncertainty present in these responses, suggesting respondents may also believe there is more to citizenship than they are able to recount, this group of young people offers more detailed accounts of citizenship in spite of this. 
a tone of moral authority in their responses, specifically in reference to others not behaving as responsible citizens or the failure of others to recognize what is great about being a citizen of Canada. Roger offers a candid example when commenting:

Unfortunately, being a citizen of Canada today just means holding a piece of paper that tells you can legally be here and work here. Many... take it for granted...It's

saddening...Being a Canadian citizen (and living here) means it is your civic duty to take part in politics of this country, shape it and defend Canada first...

Melanie, a 21 year-old university student from Ottawa expresses a similar sentiment in her remarks:

...In my opinion citizenship doesn't really mean anything anymore. It means you live in a country and you have certain rights that everyone takes for granted, which has led to a DANGEROUSLY apathetic voting populace. I find that people would much rather turn a blind eye, and manage to epitomize the notion of ignorance being bliss, and then blaming their problems on others, when one of the most fundamental aspects of being a citizen is taking part in...the political sphere.

Although these respondents identify citizenship as encompassing additional dimensions beyond rights, they express negative judgments regarding the public's perception of citizenship and practical actions as citizens. This group of young people presents two approaches to being a citizen - a general definition that they believe is commonly accepted and practiced by others and their own personal conception, which is broader and specifically recognizes the duty to vote. Patrick, a biology student from Hamilton, essentially refers to the distinction between 'active' versus 'passive' citizenship, explaining that a passive citizen meets the minimum requirements of citizenship such as abiding by laws, "[having] basic rights, [and] treating Canada just as a piece of land they happen to live on" whereas a more active citizen seeks to play a role in the community and "want[s] to be involved and committed to society, and therefore, involved and committed to democracy." Patrick's position considers that young people like himself, Melanie, and Roger see the validity of both conceptions of 
citizenship, but mourn the fact that many of their fellow citizens support the more limited definition. As a consequence of their perceptions of a widely accepted thin definition of citizenship among other young people, they themselves largely define it in those terms.

Sara, Hannah, Alison, Susan and Iris convey the same message more positively, describing citizenship as a multifaceted concept for others. In fact, the farther to the right participants are plotted on the quadrant the broader the conceptions become, and this seems to correspond with intention to vote. Those respondents plotted at the far right of the matrix conceive of citizenship most broadly, their explanations acknowledging various combinations of norms, values, ideology, national identity, national culture, national institutions, rights, freedoms and the importance of community as components of citizenship. In terms of Canadian citizenship more specifically, responses mention community, identity, protection of diversity, and liberal values. Hannah, for example, highlights dimensions beyond rights when remarking, "be[ing] a Canadian Citizen...means that you are a part of a country that embraces multiculturalism, and values democracy." Iris, a Marketing student from Toronto, offers an even broader account:

To be a Canadian citizen...include: being a peace-keeping nation, having freedoms and liberties, being free to make our own decisions concerning our personal lives... and leading the world in global initiatives such as ending poverty and the environment. I think a true Canadian who lives and breathes these values should vote in the election...

The pattern of responsibility and broader conceptions of citizenship are likely closely linked and reflective of one another. The greater value respondents see in participation, the stronger their sense of obligation toward it and correspondingly, the greater emphasis placed on voting. Both variations in the right hand quadrant highlight the importance of citizen responsibilities and there is some emphasis that giving back and contributing to society in 
other ways is also a central dimension of citizenship. All of these respondents report a strong intention to vote, which is not surprising given their broader understanding of citizenship and reported commitment to the importance of citizen duty.

Looking at the matrix as a whole, the variation within the responses points to multiple conceptions of citizenship. Young people are certainly not a homogenous group with respect to how they conceive of citizenship and additional research confirms this is also characteristic of their level and scope of engagement. Furthermore, there appears to be an interesting connection with vote intention here, which suggests that young people's patterns of engagement may be partially reflective of their conceptions of citizenship. Generally, young people who characterize citizenship one-dimensionally can be voters, but non-voters rarely posses richer conceptions of citizenship. By comparison, those who conceive of a thicker, fuller version of what it means to be a citizen are more likely to be motivated to participate electorally. This may be a consequence of the fact that participants with more nuanced accounts recognize that the flip side of the rights citizenship bestows includes duties on the part of the citizen. The next section more fully explores these young people's feelings toward civic duty in an election context to further clarify how youth are thinking about citizen action in elections, if at all.

\section{A citizen's role in an election}

Following questions probing conceptions of citizenship respondents were asked specifically how they felt a citizen should act during an election campaign as well as other complementary questions about electoral involvement and good citizenship (see Appendices). Overall, mixed responses provide a clear indication that young people are not a homogenous group with respect to their perceptions of electoral obligation. This finding suggests it may be 
problematic to refer to the entire cohort of young people as "political dropouts" or "engaged citizens" because their level and scope of perceived participation is diverse. Responses about electoral duty also closely echoed sentiments regarding conceptions of citizenship, indicating that young people conceive of citizen obligation in an election two-dimensionally. The first reflects the traditional duty we commonly associate as being "civic duty" and can be classified as the responsibilities of the ideal citizen. The second image, by comparison, describes a more practical, real-life citizen who adheres to a very different set of expectations during an election. Ideal type responses are replete with recognition of the normative self-benefit of citizens voting, being informed, and involved during an election. On the other hand, the more practical view of citizenship in an election recognizes that citizens may choose not to be involved for various reasons. In fact, an overwhelming majority of participants expressed the belief that very little, if anything is actually required of the citizen during an election (see Figure 5.2, left side of the matrix). While most young people recognize both of these dimensions, they express that ideal-type responsibilities are not feasible expectations in today's society.

Interestingly, many of the young people expressing the practical citizen view are nonvoters themselves. Many also articulate shame when rationalizing who should participate and justifying their own patterns of participation, or lack thereof. The overall message among these respondents is that while it is good to vote, it is not always necessary. In support of this position, they draw upon reasons why they, themselves, did not vote. Some non-voters express regret that they do not know enough to make an informed choice, while others blame politicians, pointing to the unprofessional or combative nature of politics to rationalize their 


\section{Figure 5.2: A citizen's role during an election and orientations to voting}

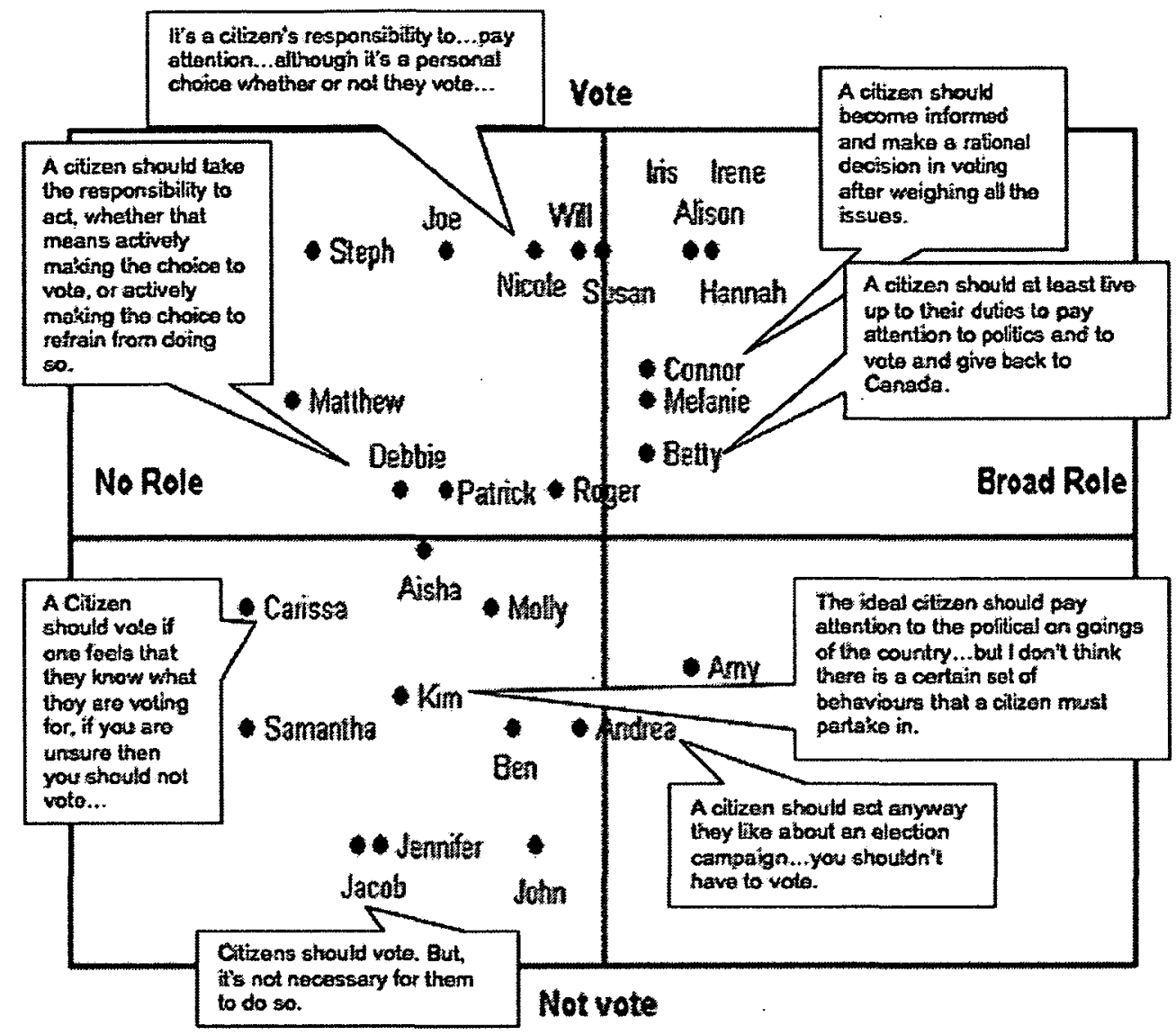

own lack of participation and responsibility. Though many respondents acknowledge ideal citizen duties, but do not actually expect anyone to fulfill these idyllic expectations, there is a small group of young people who report feeling that citizens are obliged to participate more fully. For the majority of youth however, contemporary duty can be best described as contingent or conditional, depending on circumstances, and in some cases not necessary. Specifically, aside from the traditional conception, two alternate conceptions of duty can be drawn from the responses and descriptions of the practical, real-life elector, one is conditional on information and knowledge while the other recognizes the rights dimension of voting ahead of the duty portion, noting that voting is simply not necessary. 
Looking more closely at patterns and responses depicted in the matrix, we see that non-voters closer to the far left of the matrix (e.g. Jacob, Jennifer, Kim, Carissa, Aisha and Samantha) report very weak, almost non-existent, senses of traditional duty and associate little value with voting, although they recognize that ideally citizens should vote. Some comments express that citizens should "pay attention to the political ongoings of the country" and others make the point that someone should only consider voting if "they know what they are voting for." If a potential voter is unsure however, then they "should not vote". Although these comments could be more explanatory, they imply that although citizens are not required to do anything in particular during an election, an ideal citizen would cast an informed ballot.

Those closer to the right, who are plotted at the bottom or top of the matrix (some voters and non-voters, such as Nicole, Joe, Molly, John, Ben, Patrick, Andrea, and Debbie), also acknowledge that citizens should actively take part and be involved in politics. These young people also talk about information, placing a greater emphasis on of the importance of paying attention and casting an informed vote. Overall however, they emphasize that a citizen's only responsibility during a campaign is to choose whether or not to vote.

Patrick, for example, highlights the notion of the ideal citizen and the expectation of being informed and voting when saying, "I believe that an ideal Canadian citizen would be upto-speed on current candidates, would have watched political debates, and made an informed vote based on his or her beliefs." Other comments, like those of Debbie and Joe stress the 'voting as a choice' nature of today's participation ethic. For example Debbie says, "A citizen should take the responsibility to act as they feel they must during a campaign, whether that means actively making the choice to vote, or actively making the choice to refrain from doing so." 
25 year-old Joe's comments also highlight this acceptance of not voting: "I think citizens have the right to act however they want in an election campaign. I mean voting would be the ultimate goal, but if someone feels they do not want to vote then I feel that is perfectly fine behaviour." According to this cluster of young people, voting is a choice and not a necessary duty. Responses reveal that while this group recognizes that 'ideally' a citizen should vote in elections, on a practical and personal level they have a relatively weak sense of obligation to participate. Since both voters and non-voters communicate similar conceptions of a citizen's role during an election campaign being 'optional', it is useful to examine other elements that might help explain what motivates both groups to abstain.

Both voters and non-voters report being "turned off" by politicians, given the unprofessional way they behave and the combative or negative nature of the campaign. However, voters seem to exhibit a sense of pride in their capacity to contribute despite this situation, whereas non-voters do not. For example, non-voter Samantha remarks, "I believe that a citizen should vote if one feels that they know what they are voting for; if you are unsure then you should not vote because that one vote could decide our future in the wrong way."

While she admits she wishes she knew more, she is not really interested, and rationalizes her lack of knowledge by referencing the conduct of parties and politicians:

"the candidates are just bashing each other every chance they get and they are only saying what we want to hear. It seems like whoever is elected never follows thru [sic] with their promises and we end up suffering in the end. In all honesty it reminds me of a high school popularity contest."

Similarly, a 24 year-old college student from Toronto, John, justifies his lack of voting by referring to the conduct of politicians:

According to TV, "We're better off with Harper", and something about how Jack Layton is good? I don't really like TV spots - they're so stupid, relying on shallow processing. The whole 
"Yeah, this person is a baby eater, I am pretty much awesome. Don't concern yourself over issues" thing just annoys me.

John offers the following response when asked about how a citizen should act during an election, "A citizen should pay attention to the election campaign (though, really, how many of us really do?), and should vote." Like others with weak intention to vote, John and Samantha recognize what citizens ought to do, but see real life citizen duty as minimal given either their lack of information and/or dissatisfaction with politicians' behaviour. John's comments in particular illustrate a 'why should I care' attitude with respect to obligation. Many of these young people also express little faith in their ability to make a difference. This may be an indication of low political efficacy, which has been found to be low when senses of civic duty are also weak (Turcotte, 2007). Overall, even though the non-voters recognize that they should participate, they place the impetus for change in the hands of the politicians.

Voters with weak but detectible senses of obligation (in the top of the upper left hand quadrant) also point to the conduct of politicians, but have greater faith in their personal capacity to have a say. They see themselves as having the potential to contribute. As 23 yearold Will remarks:

I see a lot of negative finger-pointing by all the parties. As well, most of the things each party says they will do just seem really dishonest. I mean, none of those things will ever actually get done; they're just ways to get more votes. I really don't like that, so I ignore those and look at the parties' history at getting things done.

Susan also comments, "Most of the campaign ads attack one another, and instead of focusing on important issues, situations are being brought up that have nothing to do with the current campaign" but she still believes she is "responsible for remaining informed on all of the issues and voting." Although these voters also express a lack of respect for government, they have a sense of confidence in their ability to contribute. 
Looking to the upper right hand quadrant of the matrix (e.g. Iris, Alison, Hannah, Irene, Connor Betty and Melanie), a different picture of citizen duty emerges. This image is characterized by a much stronger sense of responsibility and also emphasizes the importance of information. These young people express that citizens not only have an obligation to vote, but to also cast an informed vote. Non-voters and voters with weaker senses of obligation also stressed the need to be informed and many explained that the act of informing oneself needed to come before voting, almost as a prerequisite duty. However, if for whatever reason it was not possible or desirable to be informed or follow the election then non-voting is the more responsible choice. This group by contrast, places a greater emphasis on voting as a key responsibility of citizenship but one in which being informed is part and parcel of this obligation. Responses suggest that merely voting is insufficient and that citizens have a moral responsibility to pay attention, be informed, and educate themselves. Some comments stress the importance of representation and voting as a means of 'giving back' and renewing democracy. While these young people also dislike government behaviour and campaign unprofessionalism, they express feelings of discontent or moral disdain toward uninformed voters. Aside from their more expansive senses of citizen duty, this group also reports stronger intentions to vote and define citizenship more broadly.

Like their compatriots, this cluster of young people recognizes both ideal and practical conceptions of citizenship, but their personal commitment to being a citizen is couched in a strong sense of obligation to live up to the expectations of ideal citizenship and the duties associated with it. For example, Alison's remarks highlight the importance of obligation and duty despite negative perceptions of politicians when commenting, "A citizen should be informed of their options before they vote in this election; During the campaign they should be 
open to all possibilities and not get swept away by the usual white-washing of parties." The importance these young people place on being politically informed is further highlighted by Melanie when she comments, "A citizen in a Utopia would be responsible for voting, and doing as much as they possibly can to make an EDUCATED vote. The key word being EDUCATED, not simply following what a bunch of people have told you, or voting based on a 3 minute clip on TV." To this group, the importance of voting is taken as a given, but being informed and making a responsible, knowledgeable choice takes precedence. They are not only critical of government, but also of the public and what they perceive to be a lackluster commitment to responsible citizenship. This suggests that for young people today being informed is a critical component and perhaps essential pre-requisite of voting. Those who define citizenship in more narrow terms are more likely to support non-voting and not being informed if it is not feasible, whereas those who articulate thicker versions of citizenship are more likely to subscribe to the belief that being informed is a necessary precondition of voting and a responsibility citizens must live up to.

Taking the data on citizenship and civic duty into consideration together, we see that this group of young people delineates two distinct images of what it means to be a citizen and what one ought to do during an election. The first image recognizes an ideal type of citizen, with normative implications regarding what a citizen should do during an election and the campaign leading up to it. The second image, by comparison, is a more practical conception that reflects the respondents' actual contribution during an election and/or their perceived responsibilities as a citizen. Within this more practical, 'real life' conception, there are many who believe citizens have little, if any, duty to participate. This indicates a normative acceptance of not participating, regardless of respondents' own activity. The strong presence 
of these two themes suggests that young people today conceive of citizenship and citizen duty in elections two-dimensionally - one dimension portrays the actions and expected behaviour of an ideal citizen, while the other explains the respondent's own reality or expectation of a citizen and attempts to justify his/her personal behaviour during an election. On the whole, these young people agree that, while voting is desirable, there are a number of reasons which make non-voting understandable or acceptable and that the choice to vote or not is in the hands of individual citizens.

\section{Conceptions that can be drawn from this}

Reviewing the data on conceptions of citizenship and citizen duty during an election campaign provides insight as to how young people think about the civic duty to vote. While there are many different accounts and perspectives proposed, overall there are a few overarching conceptions that can be teased out of the material. For one, although sparse, the notion of traditional duty and the principles associated with it are present in the responses of some participants. These young people talk about the moral importance of voting for the health of democracy and recognize participation in elections as a sign of respect for Canadian culture and the institution of citizenship. A much larger section of the group identifies the ideal of traditional civic duty, but observes that this norm is no longer a realistic expectation of citizens for various reasons. This suggests that while the traditional way of thinking about the civic duty to vote is still relevant and is an accurate reflection of how some young people think about participating in elections, there are also other, more pragmatic, ways that young people conceive of citizen responsibilities in an election context.

One of these other 'realistic' conceptions describes the duty to vote as a responsibility that is contingent upon information and knowledge. Young people express that being 
informed heightens one's duty to participate, whereas being uniformed lessens one's obligation to vote. Likewise, greater levels of political knowledge and information about the campaign mean that casting a ballot is more important and is more of a social expectation. By contrast, if little is known and no attention has been paid to the campaign many young people explain that it is more responsible to abstain. In this sense, there seems to be a duty to be informed that precedes voting, and if this requirement cannot be met then not voting is a perfectly acceptable and responsible action. Even those young people with stronger senses of citizen obligation in an election stressed the importance of information as a necessary precondition to voting. Exploring this conception further could help shed light on how the duty to vote is conceived of and practiced today.

Finally, a second realistic perspective recognizes voting in elections as something that is not necessary and focuses on the flip side of the duty to vote - its rights dimension. Young people point out that the right not to vote is equally important, if not more so, than the obligation to participate electorally. This conception also echoes the sentiments of the importance of information rationalization, noting that in certain instances it is not responsible to vote and so actively refraining from voting can sometimes be the better choice. If others are not voting they likely have good reasons for doing so and should not be sanctioned or looked down upon for not fulfilling an obligation of ideal citizenship. The perception is that these electors are merely exercising their right not to participate. Considering this, it may be that young people today do not focus on the duties of citizenship, especially voting, but instead view citizen action through a rights-based lens. ${ }^{38}$

It is important to make clear that this conception is not simply a rejection of traditional

\footnotetext{
${ }^{38}$ It is important to note that these two alternate conceptions are not mutually exclusive and some of the same young people describe both perspectives.
} 
duty, or the stark opposite of a feeling that voting in elections is an important citizen responsibility. These young people do not discard voting in elections as a moral obligation or an act required to maintain the health of democracy per se, but express greater identification with the rights portion of voting as an element of citizenship. Associating more closely with the rights portion of the act of voting rather than the obligation part is conceptually distinct. It signifies that these young people are more in tune with the individual benefits and rights citizenship bestows rather than the contribution elements (so far as electoral participation is concerned), which are closely tied to community involvement and giving back to renew the health of the polity. While many young people may reject the ideal of traditional duty in favour of other conceptions of participation, or none at all, disagreeing that voting in elections is a citizen duty and viewing the decision to cast a ballot as an important right of citizenship rather than a necessary obligation are different ways of perceiving and interpreting the connection between citizenship and voting in elections.

Finally, overall, findings suggest that a limited number of young people personally identify with the traditional conception of the civic duty to vote that their elders grew up believing. Instead, while many of them recognize this conception of duty as being textbook behaviour of an ideal citizen, they describe a different set of civic duty dimensions that apply to the practical, real-life citizen in an election. These include (1) duty being contingent upon information and knowledge, meaning the more a young person knows about politics or the election, the greater responsibility they have to vote (being uninformed, by comparison, makes it largely acceptable to not participate); and (2) voting as a right before a duty, where the focus is on the rights dimension of duty as opposed to the citizen responsibility of casting a ballot. Interestingly, these alternate conceptions involve rational calculations or thought on 
the part of young people, whereby voting or not voting becomes a choice that is made based on various calculations, instead of a foregone conclusion. This suggests that perhaps rational frameworks of voting behaviour have explanatory power in understanding motivations to participate electorally.

These findings also merit revisiting how we operationalize and measure the duty to vote. For some, the image of the ideal citizen in an election appears to be an apt reflection of the current popular conception of the duty to vote - a moral obligation to participate for the sake of democracy. However, when a practical citizen is faced with such a survey question he/she is forced to appear undutiful, even though there may be other elements or nuances to his/her perception and actions of electoral duty. Young, real life citizens recognize that electoral duty is important, but that realistic expectations are different. The next step is to capture the essence of these conceptions in survey questions and assess whether they stand up as accurate measures of possible other dimensions of the duty to vote.

\section{A third alternate conception}

Developing questions to capture new feelings of citizen obligation in an election led to many discussions with students in a first year political science seminar focusing on youth and political participation that I taught in 2010 . These discussions reinforced the validity of the alternate, realistic conceptions communicated in the 2008 Facebook study, and also suggested a third possible conception very closely aligned with the notion of contingency associated with the information interpretation of duty. Students suggested that information was not the only conditional element to consider when rationalizing whether or not to vote. They communicated an additional type of two-tier duty in which the responsibility to participate is largely contingent upon the importance or stakes of an election. 
This conception depicts voting in elections as something that is, again, not always necessary and is largely dependent on the stakes of an election. For example, in situations where an election is perceived as being more meaningful, addresses issues of particular importance or interest, is a close race, or is characterized by other variables that increase the perceived stakes of an election, young people express a greater duty to participate. According to this view, the greater the perceived stakes in an election, the more participation is necessitated. The duty to vote increases when an electoral contest is perceived as being important or meaningful and, by that same logic, is not obligatory in situations where elections are a foregone conclusion or when the ante is not considered high enough to merit casting a ballot. This point of view is consistent with the rationale that elections no longer demand a vote every time illustrated in the other alternate conceptions of the duty to vote. This conception is also very much based on rational calculations on the part of young people and although not clearly communicated in the Facebook study is worth examining to assess whether it has relevance when it comes to measuring and understanding citizen obligation in an election.

The argument that the size and nature of the stakes, particularly in policy terms, and other contextual elements such as electoral competiveness impact turnout is well argued by Mark Franklin (2004). Though Franklin shows that the character of elections affects the rational choice to take part, he does not explore this in the context of civic duty. It is not clear what impact contextual factors have on duty or in shaping senses of duty among newly eligible electors. These elements may have an important influence on the character and strength of a citizen's sense of electoral duty. While the assessment of conditional duty provided in this thesis does not examine the possible rational basis of this viewpoint directly, 
it can be viewed as consistent with that frame of reference.

Overall then, the 2008 Facebook study and discussions with students suggest four possible ways of thinking about the duty to vote in elections, which include:

(1) Traditional duty (voting as an innate responsibility of citizenship)

(2) Being informed (being informed heightens one's duty; being uninformed lessens ones obligation to vote)

(3) Voting as a right before a duty/ Not necessary (electors have the right to vote, which includes the right not to participate electorally. They should choose whatever is more responsible, whether that is voting or abstaining)

(4) Meaning, Importance or Closeness (a two-tier duty whereby people have a duty to vote in certain elections where the stakes are high, but not necessarily others)

Taking these alternative dimensions of duty into consideration, the next step in this research involved compiling questions that capture the essence of these points of view and that could be useful measures of these perspectives.

\section{New duty questions}

Critically examining the spirit behind each point of view led to developing a battery of survey items to probe these various conceptions. A majority of questions were designed based on a 5-point Likert scale and offered five response options, including: strongly agree, agree, neither agree nor disagree, disagree, and strongly agree. The Likert method is the "most favored attitude-measuring tool in use today" and was originally designed to ensure all questions or "items would measure the same thing" (McNabb, 2010:120; Oppenheim, 1992:195). Since the focus here is on the formulation of various statements that capture the essence of new duty conceptions and their evaluation as dimensions of civic duty, the choice 
of the Likert scale was a logical selection. This type of scale allowed for the collection of ordinal level data, which is required for factor analysis. Additionally, applying this scale consistently to all questions was important for the creation of comparative measures, also needed for factor analysis. Using the same scale to evaluate all the civic duty statements meant old duty items and new duty questions could be more accurately compared. Furthermore, offering varying levels of agreement or disagreement allow for more nuanced responses than simple yes and no options.

A 5-point scale was chosen over a 4-point scale so that respondents would not be forced to choose between positive and negative responses and could opt for a middle option. ${ }^{39}$ Offering a mid-point was not intended to give respondents a means of not choosing or expressing that they 'did not know', but rather to represent an actual scale point between agreement and disagreement. 5-point scales have been the choice for political scientists seeking to evaluate new dimensions of other political attitudes, such as efficacy (Niemi et al., 1991) and to verify operationalization and measurement of concepts like social capital (Lochner et al., 1999). Scales with a mid-point have also been used to gauge duty items in many of the surveys explored in this thesis.

In terms of question selection, most of the questions for the traditional conception of duty were taken from previous Canadian, British, and American election studies that have proven over time to be good measures of the civic duty to vote. ${ }^{40} \mathrm{~A}$ fourth, newly created item

\footnotetext{
${ }^{39}$ There is debate as to whether a 4-point scale or 5-point index is preferential. Some say that using a 4-point index over-scales the answers while using a 5-point scale can exacerbate social desirability bias. There is also evidence that the inclusion or exclusion of a mid-point can generate result distortions. Garland (1991:70) concludes for example, that the decision to use a mid-point is "largely one of individual researcher preference." ${ }^{40} \mathrm{It}$ is evident that these questions are good measures of the traditional duty to vote because conducting a factor analysis reveals that those particular questions all load highly together. The fact that they correlate well with each other is a good indication that they measure the same underlying dimension.
} 
was added to see if feelings of good citizenship correlated well with the traditional 'vote for the sake of it' mentality of civic duty in an election.

Second, questions that addressed information sought to probe two positions - one that being well informed or knowledgeable heightens a citizen's duty to participate electorally, and two, that lacking information about the election means voting is largely irresponsible and should be avoided. Although questions did not specifically state what being informed entails (e.g. perhaps it means paying attention to the campaign or candidate platforms, or just being generally knowledgeable about politics) they tried to broadly pick up on the notion that information is an important pre-requisite to voting and that the level and scope of information an individual possesses has an important impact on the direction of their electoral citizen responsibility - whether voting is a duty or abstaining is a more responsible choice.

The third sub-set of items sought to assess whether young people think of voting in elections as being a right, a duty, or both, and if so, which they most identify with. It also included a question to highlight the attitude Facebook participants communicated that voting in every election is not always necessary. While voting may be a duty, or may have been regarded as such in the past, in modern society it is more of a choice and not an expectation of each election.

Finally, the fourth grouping gets at the notion that the strength of a citizen's responsibility to participate in an election is contingent upon the stakes of that particular contest. Items specifically probe whether young people feel their duty to vote increases when important issues are being addressed, when there is enhanced competition and the outcome is likely to be close, and more generally when the stakes are high. Overall, the wording of 
these measures reflects the three different classifications or types of duty questions detailed in Chapter Three, which includes personal and general, positive and negative, and, direct and indirect style statements.

Again, although elements of the questions in this fourth grouping represent various characteristics of elections that may well impact the rational choice to participate (Franklin, 2004) these questions were not specifically designed with a rational framework in mind. The focus in designing these statements was to best replicate and capture the sentiments expressed by young people about how they perceive citizen duty at election time. If these feelings lead to statements that reflect a particular voting framework or lend support for a specific model, that finding was to come organically as the research exercise unfolded.

\section{Table 5.1: First round of duty questions}

\section{Traditional duty}

1. I have a duty to vote in every élection even if I'm busy or not very interested.

ii. I woúld be seriously neglecting my duty as a citizen if l didn't vote.

iii. I would feel very guilty if I did not vote in a general election.

iv. Although voting may not be necessary to be a good person, a good citizen votes all the time.

\section{(2) Being informed.}

i. People who are informed about politics have a greater responsibility to vote than those who know little or nothing.

ii Casting an uninformed vote is irresponsible.

iii. If you don't know much, you should vote anyway.

(3) Voting as a rigl before a duity

i. Voting in elections is more a right than it is a responsibility.

ii. An ideal citizen votes in all elections, but realistically citizens today do not have to.

iii. Voting in elections is as much a responsibility as it is a right. iv. Which statement do you most identify with: (1) It is my right to vote; (2) It is my duty to vote; (3) It is both my right and duty to vote. ${ }^{41}$

4) Meaning Importance, Gloseness

i. The more important the issues in an election, the greater the duty of a citizen to vote.

41 Due to the nature of this question an accurate factor analysis was not possible and therefore it does not appear in the factor loading tables in the following chapter. 
ii. Given the fact that there is only so much the average person can do, citizens only really need to vote in elections where the stakes are high.

iii. It is important to vote in some elections, but not necessarily all of them.

iv. It is important to vote in elections when the outcome is likely to be close. ${ }^{42}$

All of these duty statements, new and old, were evaluated and then refined by conducting two pre-tests. The final items were administered in a Canada-wide survey of all ages with an oversample of young people. Chapter Six examines the factor analyses of these new duty items and illustrates how these questions were improved and refined to better reflect young people's conceptions of civic duty today. Chapter Seven follows by providing a thorough analysis of how these senses of duty impact voting behaviour and evaluates whether they correlate with other political attitudes such as political interest, efficacy, and trust.

42 Two other questions were also included to try and capture the distinctions between the ideal and practical citizen many participants expressed in the 2008 Facebook study and that were also echoed in my first year class. These include: Given the fact that there is only so much the average person can do, expecting them to cast a ballot in every election is not practical; and, Voting all the time is ideal, but not practical because people are busy and have things to do. 


\section{Chapter 6 : Construction and Performance of new civic duty factors}

\section{Introduction}

The goal of this chapter is to illustrate the development of questions designed to capture the alternate dimensions of the civic duty to vote that emerged from participant responses in the 2008 Facebook study and other preparatory work described in previous chapters, and to explain the rationale behind their disposal or survival as useful measures of those sets of attitudes. The chapter begins by detailing the methodology of the data sets used in the quantitative portion of this project. It then provides an analytical overview of the factor analyses and construction process used to devise questions that represent the new dimensions of the civic duty to vote in elections. Specifically, this section outlines the refinement of the new duty measures, which took place by conducting two small-scale pretests. These phrases are then evaluated in a national survey of Canadians that includes a special oversample of young people, to assess how well the phrases depict these new conceptions of duty and whether they are an accurate representation of the beliefs of both young electors and the larger population of potential voters. Throughout, the findings from the new questions are compared to those obtained from the traditional operationalization of duty that relates to elections.

\section{Methodology}

The Data Collection branch of Delvinia, a Toronto-based company, gathered the primary data for this portion of the thesis. Prior to submitting the survey questions to Delvinia however, two pre-tests were conducted to ensure that the survey items were indeed good measures of the previously outlined conceptions of the duty to vote. This section 
outlines the methodology of the pre-tests and the final survey before presenting the results and analysis of the data in the next portion of the chapter.

The first pre-test was conducted as part of a classroom exercise to stimulate discussion about civic duty and what it means both theoretically and practically. In total it involved 111 Carleton undergraduates, each of whom completed the survey in class from March 22, 2010 to March 30, 2010 and were made aware of the nature of the research. All of these participants were enrolled in Political Science or Communications courses at Carleton and only those surveys completed by students aged 18 to 26 years were coded and input into the SPSS database. This particular age group was selected because the 2008 Facebook study also focused on probing thoughts from young people, aged 18 to 26. Choosing a different group of young people of the same age group made it useful to evaluate the questions that emerged from the Facebook responses and assess whether respondents identified with the statements. Although classroom discussion resulted as a consequence of the exercise, all surveys were completed anonymously. The overall goal of this pre-test was to get a sense of how young people responded to these duty measures and to offer feedback as to how they might be improved or clarified.

The second pre-test involved a more refined set of questions based on the response patterns and reactions from the students. This pre-test was conducted using the Google survey tool and advertised through a link from my personal Facebook page. This was a convenience sample, participants were self-selected (voluntarily), and each survey was completed anonymously as part of Google's survey platform. A total of 97 people completed the survey between August 13, 2010 and August 26, 2010. The survey link explained the nature of the test, the reasons for the data collection and its use, and that participation was 
anonymous. Participants ranged in age from 18 to 61 years; though anyone eligible to vote was encouraged to participate. The only required question fields were age and gender - all others were optional.

The survey link was accessible 24 hours a day while it was posted, and completed surveys were instantaneously time-stamped and posted to a Google spreadsheet, which included all responses. ${ }^{43}$ Google survey is a useful data collection tool because it is accessible, anonymous, and inputs responses directly into a spreadsheet that can be easily converted into a dataset if the appropriate variable coding is programmed. ${ }^{44}$

The mean age of the participants from this sample is 28 years and the average level of reported education is 'community college' or 'some university'. 54 percent of the sample is male, and the rest female. While not random or representative of the population as a whole, this sample provided a broader cross-section of Canadian electors than the first and allowed for additional explanatory insight as to whether or not the newly developed measures are indeed useful assessments of the civic duty to vote.

Following these exercises those questions suggested by factor analyses to be the best measures of each sub-conception of duty were passed along to Delvinia to include as part of a larger study on Internet voting and public attitudes. This survey was distributed to Delvinia Data Collection's AskingCanadians ${ }^{\top M}$ panel. ${ }^{45}$ The panel is a group of more than 160,000 people from across Canada of the age of majority who complete surveys in exchange for Hudson Bay Company reward points, Aeroplan Miles, or other incentives such as entries into

\footnotetext{
43 Surveys are posted anonymously to a spreadsheet by the Google server. Therefore, there is no way of tracing responses back to participants.

44 The data from this survey was transferred directly into an SPSS spreadsheet.

45 More detailed information about the AskingCanadians ${ }^{\mathrm{Tm}}$ panel can be found in the Appendices.
} 
draws and contests. While not random and representative of the entire population per se, this survey sample is random and representative of the AskingCanadians ${ }^{\mathrm{rm}}$ panel and the demographic characteristics of the sample align with the percentages in Statistics Canada surveys. ${ }^{46}$

The survey was conducted from September 7, 2010 to September 13, 2010 online through the AskingCanadians ${ }^{\mathrm{TM}}$ forum and a total of 1132 respondents completed the questionnaire. All questions required a response to receive the incentive or reward and all participant identities remained anonymous. Delvinia only discloses aggregate data and does not publicize or distribute personal identifying information. ${ }^{47}$ To ensure appropriate statistical analysis could be conducted on the portion of the sample from those aged 18 to 26 an oversample of that group was collected (a total of 256 respondents). ${ }^{48}$ Respondents ranged in age from 18 to 88 , with an average age of 43 . Levels of education varied from no schooling to professional degrees, with a mean education level of 'some university.' The sample was approximately 51 per cent female and 48 per cent male. ${ }^{49}$

\section{Analysis and presentation of factors:}

\section{First pretest with 111 Carleton undergraduate students aged 18 to 26}

Conducting a simple factor analysis using the first round of duty questions, compiled as a result of the qualitative data obtained from the 2008 Facebook study, produced five

\footnotetext{
46 It should be noted that although Delvinia strived to ensure the sample is representative of the population, there were no respondents from the Northwest Territories, Nunavut, or the Yukon. Percentages of respondents from the provinces are closely aligned with the true percentages in the general population.

${ }^{47}$ The complete Delvinia privacy policy can be accessed via this link: https://www.askingcanadians.com/communities/default.aspx?p=p430686807\&n=\%280\%3a0$452574110 \% 230,+690 \% 29$

48 This oversample allows for analysis to be conducted within a $+/-5$ percent margin of error. Appropriate weights are applied throughout the statistical analysis in this thesis to ensure the sample reflects national population statistics in Canada given the fact that there is an oversample.

${ }^{49}$ Additional demographic information regarding the Delvinia sample can be provided upon request.
} 
factors instead of the expected four. Each factor has distinct questions that load highly, although some items load on more than one dimension (see Table 6.1). This suggests that there may be more to a particular conception than is currently captured here or that the question may be a useful measure of multiple factors. Another possibility is that the question is not targeted enough to be an accurate gauge of the intended dimension of duty.

As expected 'traditional civic duty' emerged as the strongest factor with the traditional election survey questions producing the most consistent and robust factor loadings. The one additional measure composed for this thesis, Although voting may not be necessary to be a good person, a good citizen votes all the time, also loads highly (.744) and appears to be a good assessor of the belief that voting is an important obligation of citizenship that electors should fulfill.

Table 6.1: Factor Analysis Pretest 1: Carleton undergraduate students aged 18 to 26

\begin{tabular}{|c|c|c|c|c|c|}
\hline Question/ Measure & Factorinter & etafions and & adings 50 & & \\
\hline (n) & Trivic duty & $\begin{array}{l}\text { Meaning } \\
\text { mportance) } \\
\text { moseness }\end{array}$ & $\begin{array}{l}\text { Woting as a } \\
\text { right before } \\
\text { a duty }\end{array}$ & $\begin{array}{l}\text { Being } \\
\text { informed }\end{array}$ & Being \\
\hline $\begin{array}{l}\text { I have a duty to vote } \\
\text { in every election even } \\
\text { if I'm busy or not very } \\
\text { interested }\end{array}$ & .790 & -.092 & -.285 & -.081 & -.103 \\
\hline $\begin{array}{l}\text { I would be seriously } \\
\text { neglecting my duty as } \\
\text { a citizen if I did not } \\
\text { vote }\end{array}$ & .804 & -.209 & -.144 & .000 & .051 \\
\hline $\begin{array}{l}\text { I would feel very } \\
\text { guilty if I did not vote } \\
\text { in a general election. }\end{array}$ & .786 & -.289 & -.168 & -.084 & .020 \\
\hline $\begin{array}{l}\text { Although voting may } \\
\text { not be necessary to be }\end{array}$ & .744 & -.088 & .101 & .198 & -.088 \\
\hline
\end{tabular}

${ }^{50}$ This factor analysis was conducted using the principal components method and the varimax rotation. These figures are based on eigenvalues greater than 1 . 


\begin{tabular}{|c|c|c|c|c|c|}
\hline \multicolumn{6}{|l|}{$\begin{array}{l}\text { a good person, a good } \\
\text { citizen votes all the } \\
\text { time. }\end{array}$} \\
\hline $\begin{array}{l}\text { Voting in elections is } \\
\text { as much a } \\
\text { responsibility as it is a } \\
\text { right. }\end{array}$ & .561 & .164 & -.343 & .231 & -.198 \\
\hline $\begin{array}{l}\text { The more important } \\
\text { the issues in an } \\
\text { election, the greater } \\
\text { the duty of a citizen to } \\
\text { vote. }\end{array}$ & .117 & .601 & -.016 & .335 & -.161 \\
\hline $\begin{array}{l}\text { Given the fact that } \\
\text { there is only so much } \\
\text { the average person } \\
\text { can do, citizens only } \\
\text { really need to vote in } \\
\text { elections where the } \\
\text { stakes are high. }\end{array}$ & -.264 & .492 & .284 & .272 & -.067 \\
\hline $\begin{array}{l}\text { It is important to vote } \\
\text { in some elections, but } \\
\text { not necessarily all of } \\
\text { them. }\end{array}$ & -.497 & .682 & .161 & .107 & .002 \\
\hline $\begin{array}{l}\text { It is important to vote } \\
\text { in elections when the } \\
\text { outcome is likely to be } \\
\text { close. }\end{array}$ & .009 & .806 & -.016 & -.260 & .159 \\
\hline $\begin{array}{l}\text { Voting all the time is } \\
\text { ideal, but not practical } \\
\text { because people are } \\
\text { busy and have things } \\
\text { to do. }\end{array}$ & -.407 & .410 & .322 & .271 & .091 \\
\hline $\begin{array}{l}\text { Given the fact that } \\
\text { there is only so much } \\
\text { the average person } \\
\text { can do, expecting } \\
\text { them to cast a ballot } \\
\text { in every election is } \\
\text { not practical. }\end{array}$ & -.458 & .494 & .306 & .093 & .160 \\
\hline $\begin{array}{l}\text { Voting in elections is } \\
\text { more a right than it is } \\
\text { a responsibility. }\end{array}$ & -.094 & .134 & .803 & -.259 & .109 \\
\hline $\begin{array}{l}\text { An ideal citizen votes } \\
\text { in all elections, but } \\
\text { realistically citizens }\end{array}$ & -.206 & .134 & .701 & .433 & -.175 \\
\hline
\end{tabular}




\begin{tabular}{|l|l|l|l|l|l|}
\hline today do not have to. & & & & & \\
\hline $\begin{array}{l}\text { People who are } \\
\text { informed about } \\
\text { politics have a greater } \\
\text { responsibility to vote } \\
\text { than those who know } \\
\text { little or nothing. }\end{array}$ & .064 & .091 & -.086 & .670 & .208 \\
\hline $\begin{array}{l}\text { If you don't know } \\
\text { much, you should vote } \\
\text { anyway. }\end{array}$ & .546 & -.049 & -.126 & -.394 & -.526 \\
\hline $\begin{array}{l}\text { Casting an } \\
\text { uninformed vote is } \\
\text { irresponsible. }\end{array}$ & .070 & .024 & -.012 & .101 & .826 \\
\hline
\end{tabular}

*Note that 34.4 percent of the variance is explained by traditional civic duty, 10.7 percent by the meaning, importance, closeness factor, 7.4 by the voting as a right before a duty factor, 6.3 by being informed factors, and 5.7 of the total variance can be accounted for by the factor titled, being uninformed.

The statement, Voting in elections is as much a responsibility as it is a right loads moderately high (.561) on this factor. While it is not as high a factor loading as the questions actually intended to gauge the concept of traditional duty, the fact that it loads on this dimension is not surprising given that it focuses on the importance of voting as a responsibility of citizenship. Although it was proposed to evaluate the notion of voting as a right before a duty (designed to evaluate whether young people are more likely to identify voting as a right, a duty, or both) the concentration on responsibility as much as rights makes it better suited for this traditional dimension. Again, the goal of the questions is not to reflect the opposite of traditional duty. Rather, it is to express a perception that more strongly associates with voting as a right of citizenship instead of its duty element.

Finally, other statements designed to reflect the 'meaning, importance, closeness' dimension load negatively on this factor. Specifically, the two questions that address the notion of voting not being practical given busy schedules or the daily expectations of life are 
placed here. ${ }^{51}$ This line of thinking is in direct opposition to the belief that elections demand a vote every time or that people are expected to participate electorally for 'the sake of it' so it is logical that they loaded in this category. The fact that these two statements produce moderate factor scores on both the 'traditional duty' and the 'meaning, importance, closeness' dimensions, albeit in opposite directions, is an indication that they could be better refined to get at the belief that one's motivation to vote escalates when an election has a special meaning, is considered important, or due to a close race among candidates.

The second factor, 'meaning, importance, closeness', is best characterized by those statements that directly address voting being more important when the outcome is likely to be close and the more important the issues in an election, both of which load fairly high. However, the question, Given the fact that there is only so much the average person can do, citizens only really need to vote in elections where the stakes are high produces a much lower factor score than expected (.492). It was anticipated that this item would load strongly because in the 2008 Facebook study many young people communicated feeling that a sense of duty to vote was imposed in situations where an election was perceived as being particularly important for one reason or another. The wording 'high stakes' was intended to capture this sentiment. 52

Finally, the statement It is important to vote in some elections, but not necessarily all of them produces a fairly high loading (.682) on this factor suggesting it is a reasonably good

\footnotetext{
${ }^{51}$ These statements include, Voting all the time is ideal, but not practical because people are busy and have things to do and Given the fact that there is only so much the average person can do, expecting them to cast a ballot in every election is not practical.

52 To better get at these feelings in the next pre-test, the first part of the statement that refers to what 'average people can do' is removed since it can be perceived as addressing another aspect of electoral motivation, which focuses on a lower sense of civic responsibility in elections among citizens that are considered 'average'. Its removal is also helpful to better capture the belief that an enhanced sense of electoral obligation emerges when the perceived stakes of an electoral contest are greater for one reason or another.
} 
measure of this dimension. While this question does not directly ask respondents whether the meaning, importance, or closeness of an election(s) heightens their sense of duty and thereby encourages their vote, it generally addresses the notion that it may not be important to vote in all elections and it is certainly not equally important to participate in every binding election. Instead, it recognizes that voting can be considered obligatory in certain elections, but not necessarily all of them.

'Voting as a right before a duty' emerges as the third factor, with two questions presenting as good indicators of this dimension - Voting in elections is more a right than it is a responsibility and An ideal citizen votes in all elections, but realistically citizens today do not have to. ${ }^{53}$ As noted above, the other statement that was intended to load here actually fits better with the traditional duty conception. The output of this factor suggested that additional development and refinement of questions was necessary to better reflect and get at the nature of this dimension. Although two statements load highly here, one is more focused on probing the belief that the rights portion of voting in elections supersedes the duty part, while the other addresses the notion of voting not being necessary for everyday or average citizens. This is an important theme identified in the 2008 Facebook responses, but it is not an apt reflection of the belief that the right to vote and to choose whether to do so is a more powerful consideration than the moral obligation to participate.

Moving on to the fourth factor, 'being informed', we see that the statement, An ideal citizen votes in all elections, but realistically citizens today do not have to also loads moderately in this category. Although there is no mention of information in this phrase the underlying logic is similar in that both kinds of statements recognize that a certain type of citizen, either

\footnotetext{
53 The fourth question gave multiple response options and therefore was not suitable for factor analysis. For exact wording of questions please see Chapter Five.
} 
an informed or ideal elector, is bound by a stronger sense of electoral duty than others. However, since the intent of this dimension was to focus on the 'being informed' aspect it was concluded this question needed further development to better get at the belief that information enhances a feeling of duty. Only one statement seems to represent this factor well notionally and loads fairly high, People who are informed about politics have a greater responsibility to vote than those who know little or nothing. This test revealed that the development of additional statements probing this conception were needed to better understand and evaluate if this should be considered an alternative dimension of the duty to vote.

Finally, in addition to the four expected factors ('traditional civic duty', 'meaning, importance, closeness', 'voting as a right before a duty' and 'being informed') a fifth dimension emerges - the notion of being uninformed. Just as young people identify that those who are informed or have been paying attention to the campaign have a greater civic duty to participate because of their increased knowledge base, participation by those with little to no information about the candidates and issues can be considered irresponsible. While the belief that it is irresponsible to cast an uniformed vote came out in the 2008 Facebook study, it was not clear when constructing the first round of duty questions that being informed and the flip side of not knowing much might be two separate dimensions. While possessing the commodity of knowledge can intensify one's sense of citizen duty in an election, not being informed seems to minimize the moral obligation to participate and could even be considered irresponsible.

Though these questions are by far the weakest of the factors produced, the information factors highlight the presence of an important rationale and a differentiation 
between the impact of being informed on electoral motivation and the effect of not knowing much. However, given the fact that 'being uninformed' presented as the weakest factor and the limited number of questions that can be asked on the final survey, this fifth dimension of duty was not included in following tests.

\section{Refinement of dụty questions}

Taking these results into consideration revealed significant room for question refinement and the creation of additional statements that perhaps better capture the essence of these new dimensions of duty (see Table 6.2 for a list of all question changes). All the traditional duty questions were retained because they proved to be good measures of the concept. One small change was made to the duty statement not taken from previous election surveys to emphasize voting 'in every election' as someone with a strong sense of traditional duty would expect instead of 'all the time', which is slightly more ambiguous wording.

Four new statements were added to capture the dimension of duty that focuses on information as an element upon which voting is contingent. These statements are designed to reflect feelings that citizens have a responsibility to be informed first and then, once adequately fulfilling this obligation, cast a ballot. Furthermore, they are composed to capture the belief that possessing information or knowledge augments the sense of duty a potential voter feels or should feel to participate electorally. Instead of merely mentioning information, statements were broadened to include more variation, making reference to knowledge about politics, what is going on in an election, and being well informed generally. An additional statement was added that explicitly measured feeling a stronger obligation to vote when politically informed to assess whether a different wording resonates well with respondents, and if it loads equally high in subsequent factor analyses. While all previous questions 
designed for this factor were worded generally, the new sub-set of questions included two personal statements to see if first-person references impacted respondents' level of identification with these measures.

\section{Table 6.2: Second round of duty questions ${ }^{54}$}

(1) Traditional civic duty w/W

i. I have a duty to vote in every election even if l'm busy or not very interested.

ii. I would be seriously neglecting my duty as a citizen if I didn't vote.

iii. I would feel very guilty if I did not vote in a general election.

iv. Although voting may not be necessary to be a good person, a good citizen votes in every election.

(2) Being informed

i. People who are informed about politics have a greater responsibility to vote than those who know little or nothing.

ii. The more you know about politics, the greater your obligation to vote.

iii. If I know what is going on in an election I have a greater duty to vote than if I haven't been paying attention.

iv. If you are going to vote you have a responsibility to be well informed

v. I have a stronger obligation to vote when l am politically informed.

(3) Voting as a right thefore a dity

i. Voting in elections is more a right than it is a responsibility:

ii. An ideal citizen votes in all elections, but realistically citizens today do not have to.

iii. The freedom to choose whether or not to vote is more important than the duty to vote.

iv. Voting may be important, but sometimes it is too inconvenient.

(4) Meaning limportance Goseness

i. I have a greater duty to vote in elections where important issues are being addressed.

ii. It is more important to vote in elections where the stakes are considered high.

iii. It is important to vote in some elections, but not necessarily all of them.

iv. It is important to vote in elections where the outcome is likely to be close.

v. I have a greater duty to vote in elections where there are major differences between parties and candidates:

Two statements were added to gauge the conception of 'voting as a right before a duty'.

This wording was designed to get at the fact that voting is both a right and a duty, justifying a

\footnotetext{
${ }^{54}$ Changes to questions from the initial round have been demarcated using italics and underlining. Questions that are wholly new are italicized, whereas small wording changes are underlined.
} 
lack of participation in elections on the grounds that not-voting is as much a democratic right as is participating electorally. To try to capture this, the statement, The freedom to choose whether or not to vote is more important than the duty to vote was added. Furthermore, the measure Voting may be important, but sometimes it is too inconvenient was created to tap the associated feeling that a vote is not always required, expected, or necessary.

Finally, measures of the 'meaning, importance, closeness' factor were refined to produce three new statements. Whereas the previous four statements were all general in the nature of their wording, two personal style questions were added to evaluate if a more individual frame of reference has an impact on the factor output. While the 'important issues' and 'stakes are high' statements were altered to better get at the notion young people communicated, a question referencing major differences between parties and candidates was added as another element designed to capture the nature of this dimension of the duty to participate in elections.

The questions sought to capture and reflect a two-tier sense of duty, wherein the obligation to vote in elections is heightened based on an individual's perception of the presence of various contextual factors such as important issues, high stakes, a close race, or major differences between political parties and/or candidates. According to this view, it may be important to vote in certain elections because duty morally requires it in those instances, but in other elections, not voting is completely acceptable. These statements are notionally similar to the information measures because both posit that the feeling of duty to cast a vote varies in strength depending on other outside factors. If these certain features are in place electoral duty is intensified, but if, however, they are not, duty is diminished to the point where a vote in that particular election may not be perceived as an obligation whatsoever. 


\section{Second Pretest, 97 Google survey respondents, all ages}

Aside from the newly framed questions the second pretest was slightly different from the first given the nature of the sample surveyed. In addition to using a different methodology (Facebook recruitment and Google survey tool as opposed to hand-written surveys from University students) this sample included respondents of all ages (18 to 61 years) instead of only the younger segment of the electorate. The rationale behind the sample expansion was to see how other potential electors related to the new dimensions of duty. Since the goal of the final survey was to gauge opinions from prospective voters of all ages to be able to compare differences between the youngest cohorts of the electorate with older groups, examining responses from all age groups was a useful exercise in the pretest.

The results of the rotated component matrix produced five factors instead of the anticipated four (see Table 6.3). Traditional civic duty once again emerged as the most powerful factor with all items loading highly, except the statement Although voting may not be necessary to be a good person, a good citizen votes in every election, which produced a more moderate loading (.447). This result indicates that while all four are useful assessments of the traditional duty conception, the three measures commonly used in election surveys are the best way of probing the belief that voting is a moral obligation.

Three statements produced negative loadings on the traditional duty factor, indicating they capture the opposite feeling of voting for the 'sake of it'. It is important to vote in some elections, but not necessarily all of them and An ideal citizen votes in all elections, but realistically citizens today do not have to are particularly negative and do not seem to load highly on the factor categories for which they were designed, suggesting they should be dropped as measures from the battery of statements. Voting in elections is more a right than it 
is a responsibility also appeared here with a negative association. This is not surprising

because the rights dimension is the 'flip side' of any citizen duty (Pammett, 2009). However, it was expected that this statement would load on a factor of its own. The fact that it did not may be because it is a poor measure, which is probably not the case since it loaded highly in the first pretest, or because there are no other good questions that reflect this belief. ${ }^{55}$

Table 6.3: Factor Analysis Pretest 2: Google survey, all ages ${ }^{56}$

\begin{tabular}{|c|c|c|c|c|c|}
\hline Question M M easure & $\begin{array}{l}\text { Factor inter } \\
\text { craditional } \\
\text { civic duty }\end{array}$ & $\begin{array}{l}\text { Betations and } \\
\text { Being } \\
\text { informed }\end{array}$ & $\begin{array}{l}\text { oadings } \\
\text { Meaning } \\
\text { limportance, } \\
\text { closeness }\end{array}$ & Importance & Votingmot \\
\hline $\begin{array}{l}\text { I have a duty to vote } \\
\text { in every election even } \\
\text { if I'm busy or not very } \\
\text { interested. }\end{array}$ & .770 & -.225 & .135 & .278 & .065 \\
\hline $\begin{array}{l}\text { I would be seriously } \\
\text { neglecting my duty as } \\
\text { a citizen if I didn't } \\
\text { vote. }\end{array}$ & .788 & -.140 & .131 & .219 & .120 \\
\hline $\begin{array}{l}\text { I would feel very } \\
\text { guilty if I did not vote } \\
\text { in a general election. }\end{array}$ & .787 & -.093 & -.093 & .268 & -.027 \\
\hline $\begin{array}{l}\text { Although voting may } \\
\text { not be necessary to be } \\
\text { a good person, a good } \\
\text { citizen votes in every } \\
\text { election! }\end{array}$ & .447 & .082 & .221 & .611 & .140 \\
\hline $\begin{array}{l}\text { People who are } \\
\text { informed about } \\
\text { politics have a greater } \\
\text { responsibility to vote } \\
\text { than those who know } \\
\text { little or nothing. }\end{array}$ & -.221 & .775 & .140 & -.060 & .099 \\
\hline The more you know & -.155 & .841 & .260 & .020 & .056 \\
\hline
\end{tabular}

55 The statement, An ideal citizen votes in all elections, but realistically citizens today do not have to also loaded highly along with, Voting in elections is more a right than it is a responsibility in the first pretest, however they seem to get at different aspects of not-voting. It seemed a different statement that made explicit reference to rights would be a more appropriate match for the factor 'voting as a right before a duty'.

${ }^{56}$ This factor analysis was conducted using the principal components method and the varimax rotation. These figures are based on eigenvalues greater than 1. 


\begin{tabular}{|c|c|c|c|c|c|}
\hline $\begin{array}{l}\text { about politics, the } \\
\text { greater your } \\
\text { obligation to vote. }\end{array}$ & & & & & \\
\hline $\begin{array}{l}\text { If I know what is } \\
\text { going on in an } \\
\text { election I have a } \\
\text { greater duty to vote } \\
\text { than if I haven't been } \\
\text { paying attention. }\end{array}$ & -.022 & .867 & .117 & .168 & .082 \\
\hline $\begin{array}{l}\text { If you are going to } \\
\text { vote you have a } \\
\text { responsibility to be } \\
\text { well informed. }\end{array}$ & .035 & .240 & .244 & .667 & .076 \\
\hline $\begin{array}{l}\text { I have a stronger } \\
\text { obligation to vote } \\
\text { when I am politically } \\
\text { informed. }\end{array}$ & -.023 & .732 & .333 & .228 & - \\
\hline $\begin{array}{l}\text { I have a greater duty } \\
\text { to vote in elections } \\
\text { where important } \\
\text { issues are being } \\
\text { addressed. }\end{array}$ & -.097 & .509 & .549 & .079 & .081 \\
\hline $\begin{array}{l}\text { It is more important } \\
\text { to vote in elections } \\
\text { where the stakes are } \\
\text { considered high. }\end{array}$ & .052 & .381 & .771 & .136 & .011 \\
\hline $\begin{array}{l}\text { It is important to vote } \\
\text { in some elections, but } \\
\text { not necessarily all of } \\
\text { them. }\end{array}$ & -.657 & .143 & .052 & -.030 & .164 \\
\hline $\begin{array}{l}\text { It is important to vote } \\
\text { in elections where the } \\
\text { outcome is likely to be } \\
\text { close. }\end{array}$ & .237 & .112 & .673 & .409 & .206 \\
\hline $\begin{array}{l}\text { I have a greater duty } \\
\text { to vote in elections } \\
\text { where there are major } \\
\text { differences between } \\
\text { parties and } \\
\text { candidates. }\end{array}$ & -.142 & .329 & .714 & -.131 & -.075 \\
\hline $\begin{array}{l}\text { Voting in elections is } \\
\text { more a right than it is } \\
\text { a responsibility. }\end{array}$ & -.419 & .003 & -.071 & .103 & -.650 \\
\hline $\begin{array}{l}\text { An ideal citizen votes } \\
\text { in all elections, but }\end{array}$ & -.610 & -.155 & .346 & .349 & -.089 \\
\hline
\end{tabular}




\begin{tabular}{|l|l|l|l|l|l|}
\hline $\begin{array}{l}\text { realistically citizens } \\
\text { today do not have to. }\end{array}$ & & & & & \\
\hline $\begin{array}{l}\text { The freedom to } \\
\text { choose whether or } \\
\text { not to vote is more } \\
\text { important than the } \\
\text { duty to vote. }\end{array}$ &.- .397 & -.023 & .258 &. .656 & .077 \\
\hline $\begin{array}{l}\text { Voting may be } \\
\text { important, but } \\
\text { sometimes it is too } \\
\text { inconvenient. }\end{array}$ &.- .352 & .108 & -.002 & .229 & .746 \\
\hline
\end{tabular}

*Note that 26.9 percent of the total variance can be explained by traditional duty, 22 percent by being informed factor, 7.1 percent by meaning, importance, closeness factor, 6.3 percent by the importance of voting factor, and 5.8 percent can be accounted for by the voting not necessary factor.

With a grouping of new statements, 'being informed' comes out as the second factor. This is hopeful, given the popular expression of these types of statements in the Facebook study. Four of the five load highly with the exception of If you are going to vote you have a responsibility to be well informed. This statement differs slightly from the others because it assumes voting first and along with that the enhanced responsibility of being well informed. It asserts that any vote should be one that is adequately informed. The others, however, focus on information and knowledge as commodities that, if possessed, augment one's obligation to participate electorally. Interestingly, the measure I have a greater duty to vote in elections where important issues are being addressed also loads moderately high within this factor (.509) as well as the grouping for which it was intended (.549). It could be that this question does not effectively tap the 'meaning, importance, closeness' conception as well as intended, or because it adopts a similar logic to the statement, 'I have a stronger duty to vote when...' Furthermore, respondents may perceive issues as a type of information. When these issues are considered important and are known (assuming the elector is sufficiently informed to know about the issues and their salience) the subjective obligation to participate in elections 
increases. ${ }^{57}$

Four of the five statements composed to gauge the factor 'meaning, importance, closeness' load reasonably high in this category (.549 to .771$)$. The one exception is the statement, It is important to vote in some elections, but not necessarily all of them, which, as explained, loaded negatively in the 'traditional civic duty' factor. Based on these figures it was best to continue using the three statements with the highest loadings and include these in the final survey battery.

Two other, unexpected, factors emerged in this pretest, neither of them accurately capturing the notion of 'voting as a right before a duty' the way it had been communicated in the qualitative commentary from the 2008 Facebook study. The fourth factor incorporates a combination of statements that all possess various links to the importance of voting. ${ }^{58}$ The phrase, The freedom to choose whether or not to vote is more important than the duty to vote fares negatively here, indicating that the duty to vote is considered important. This factor is likely very similar to the 'traditional civic duty' factor and a closer look at how well these statements load in that grouping supports this assertion.

The fifth and weakest factor we can call 'voting not necessary' because only the statement Voting may be important, but sometimes it is too inconvenient loaded positively (.746) here. The measure, Voting in elections is more a right than it is a responsibility produces a negative score $(-.650)$ the same way it did with respect to 'traditional civic duty'. This result suggests that these respondents are not thinking about the rights or duty aspects of voting in

\footnotetext{
${ }^{57}$ Given that this statement loaded well on both factors it is going to be removed from the final round of duty questions.

58 Statements include, Although voting may not be necessary to be a good person, a good citizen votes in every election, If you are going to vote you have a responsibility to be well informed, and It is important to vote in elections where the outcome is likely to be close.
} 
elections. Instead, they recognize voting as being important but something that may not be possible given the greater significance of other daily tasks.

It is clear from the factors produced that the notion of 'voting as a right before a duty' was not being adequately captured despite its strong presence in responses among the 2008 Facebook study participants. This could be because the questions designed require further development and are not accurately getting at the heart of these young people's rationale for not participating or perhaps the conception communicated is different than the one being interpreted by the researcher. In the end, based on the fact that there was strong expression of the feeling that 'people should have the right not to vote' and should be able to choose whichever action they feel is more responsible, be it voting or abstaining, a set of questions probing this conception was retained in the final survey.

\section{Final selection of duty questions}

The selection of questions for the survey with the larger, cross-Canada sample was based upon the results and development from the two pretests. Retention or refinement of the statements occurred based on the strength of their factor loadings and whether they seemed to represent a particular notion well, loading positively and strongly in only one category. Three statements were chosen for each factor, except for 'voting as a right before a duty', which proved difficult to capture. As a result one phrase was added, I have a right not to vote along with Voting in elections is more a right than it is a responsibility (which loaded highly in the first pretest). Although this additional statement was not officially tested it seemed to be the most direct choice of words to encapsulate the belief that the rights portion of voting in elections is more powerful than the perception that it is a citizen's obligation to vote, and that electors should be able to make the choice of whether to vote or not vote based 
on what they feel is most responsible. If an elector chooses not to vote, $\mathrm{s} / \mathrm{he}$ has a right to do so and that decision should not be regarded with disapproval. This was expected to be the weakest of the four factors based on previous tests, but it was hoped that in combination with these statements it would do a better job of assessing the feeling of voting as a right first.

The other three factors, 'traditional civic duty', 'being informed', and 'meaning, importance, closeness' are represented by the statements that performed best in the factor analyses. Those that were dropped were eliminated because they did not load as highly and as such were taken as not being 'the best' measures of that dimension of the duty to vote, because they loaded on multiple factors, or because they did not produce a significant factor score, suggesting they are not a useful probe of the desired conception (see Table 6.4 for a list of questions).

\section{Table 6.4: Final round of duty questions}

\begin{tabular}{l} 
(1) T have a duty to vote in every election even if I'm busy or not very interested. \\
i.. I would be seriously neglecting my duty as a citizen if I didn't vote. \\
iii. I would feel very guilty if I did not vote in a general election. \\
(2) Being informed \\
i. People who are informed about politics have a greater responsibility to vote than \\
those who know little or nothing. \\
ii. The more you know about politics, the greater your obligation to vote \\
iii. If I know what is' going on in an election 1 have a greater duty to vote than if I \\
haven't been paying attention. \\
(3) Meaning Importance. Gloseness \\
i. It is more important for people to vote in elections where the stakes are \\
considered high. \\
\hline ii. It is important to vote in elections where the outcome is likely to be close. \\
\hline iii. I have a greater duty to vote in elections where there are major differences \\
between parties and candidates. \\
(4) Voting as aright before a duty \\
i. Voting in elections is more a right than it is a responsibility. \\
\hline ii. I have a right not to vote. \\
\hline
\end{tabular}




\section{Delvinia national survey}

The factor analysis based on the AskingCanadians ${ }^{\mathrm{TM}}$ sample of 1132 respondents

produced three distinct factors, which can be termed 'conditional duty', 'traditional civic duty' and 'voting as a right before a duty'. ${ }^{59}$ Interestingly, though 'traditional civic duty' questions loaded highly (as expected), the conception emerged as the second factor, suggesting the first factor may actually be the more powerful of the two. This is significant because not only do all the factor results suggest the presence of alternate dimensions of the civic duty to vote, but this final analysis also implies that one of the new dimensions of duty might actually be more potent than the sense of moral obligation many have come to associate as synonymous with the civic duty to vote.

The first dimension, 'conditional duty', combined the previous factors 'being informed' and 'meaning, importance, closeness'. The combination of these two aspects was unexpected, but upon closer examination is not surprising given that the rationale behind participating in each set of circumstances is dependent on the presence of outside factors that can heighten or lessen an elector's obligation to participate. This perspective does not just consider voting important for the sake of it, but rather implies a more rational calculation on the part of the elector based on a combination of factors.

According to this view, the duty to vote in elections is contingent upon various contextual elements or the degree of knowledge/information an elector possesses. This perception of voting does not demand a vote in every election, but rather recognizes the obligation to vote as being stronger under various circumstances. This could be because there is a significant meaning (high stakes), importance (such as large differences between parties

59 Performing a regular varimax factor analysis produced two factors - conditional duty being the most powerful and traditional duty second. Forcing a third factor allowed for the conception of voting as a right before a duty. 
and/or candidates), or closeness of the race associated with a particular election. With

respect to information, possessing political knowledge, being informed politically, or having

paid attention to the campaign enhance one's responsibility to participate electorally.

Table 6.5: Factor Analysis Delvinia national survey60

\begin{tabular}{|c|c|c|c|}
\hline Question Measure & $\begin{array}{l}\text { Factor loading } \\
\text { conditional } \\
\text { duty }\end{array}$ & civaditional & $\begin{array}{l}\text { Yoting as a } \\
\text { mightivefore } \\
\text { a duty }\end{array}$ \\
\hline $\begin{array}{l}\text { The more you know about politics the } \\
\text { greater your obligation to vote. }\end{array}$ & .728 & .129 & -.016 \\
\hline $\begin{array}{l}\text { If I know what it going on in an election I } \\
\text { have a greater duty to vote than if I have } \\
\text { not been paying attention. }\end{array}$ & .768 & .023 & .043 \\
\hline $\begin{array}{l}\text { People who are informed about politics } \\
\text { have a greater responsibility to vote than } \\
\text { those who know little or nothing. }\end{array}$ & .754 & -.028 & .079 \\
\hline $\begin{array}{l}\text { It is more important to vote in elections } \\
\text { where the outcome is likely to be close. }\end{array}$ & .730 & .055 & .047 \\
\hline $\begin{array}{l}\text { I have a greater duty to vote in elections } \\
\text { when there are major differences between } \\
\text { parties and candidates. }\end{array}$ & .742 & .098 & .101 \\
\hline $\begin{array}{l}\text { It is more important for people to vote in } \\
\text { elections where the stakes are considered } \\
\text { high. }\end{array}$ & .714 & -.041 & .079 \\
\hline $\begin{array}{l}\text { I have a duty to vote in every election even } \\
\text { if I am busy or not very interested. }\end{array}$ & .047 & .862 & -.092 \\
\hline $\begin{array}{l}\text { I would be seriously neglecting my duty as } \\
\text { a citizen if I did not vote. }\end{array}$ & .058 & .886 & -.138 \\
\hline $\begin{array}{l}\text { I would feel very guilty if I did not vote in a } \\
\text { general election. }\end{array}$ & .041 & .836 & -.071 \\
\hline $\begin{array}{l}\text { Voting in elections is more a right than it is } \\
\text { a responsibility. }\end{array}$ & .246 & -.021 & .736 \\
\hline I have a right not to vote. & -.052 & -.237 & .733 \\
\hline
\end{tabular}

*In this final analysis 31.5 percent of the variance can be explained by conditional duty, 22.1 percent by traditional duty and 8.2 percent by voting as a right before a duty.

While the conception of traditional civic duty posits that the obligation to participate is

60 Please note that data was weighted appropriately to account for the oversample of young people. The weight has been applied in this factor output. This factor analysis uses the principal component method and varimax rotation. A fixed number of three factors was chosen. Without selecting the 'fixed' option the two most powerful factors emerge. 
equally important in all elections, this 'conditional' dimension reasons that while citizen obligation to vote in elections still exists, the strength of this obligation varied depending on various conditions. This does not necessarily dismiss the belief that voting in elections is $a$ moral obligation in which participation is valued for the health of democracy, but rather that certain people should have a greater commitment to contribute electorally depending on the nature of the election, how they perceive the election, and their level of political information and/or knowledge. The other side of this is that the less important the electoral race or the less one knows, the more socially acceptable it is to not vote. In addition, someone who is completely uninformed has little if any duty to cast a ballot. This rationale presumably has important implications for political participation and may perhaps be able to shed light on the political behaviour (particularly voting behaviour) of young people.

Aside from traditional duty, whose meaning and nature has been well explored throughout this thesis, 'voting as a right before a duty' finally materializes as an independent factor in this analysis, with both measures loading highly (.736 and .733 respectively).

Though this factor was forced, there seems to be some legitimacy to the perception that many electors identify with the rights dimension of voting more so than the civic duty to participate. These citizens believe that electors have the right to not participate as much as they have the right to engage electorally. With respect to duty, they reason that potential voters should make a responsible choice when it comes to deciding whether or not to vote. Depending on various circumstances, schedules, or life more generally, this could mean voting or abstaining in elections. 


\section{Conclusion}

While further examination of these factors is necessary before any broad conclusions can be drawn, this initial analysis provides strong evidence that the civic duty to vote in elections should be conceptualized multi-dimensionally and not solely in terms of the existing one-dimensional perception, which takes civic duty as a moral obligation in which participation is valued for the health of democracy. The fact that traditional civic duty and an elector's propensity to vote have been shown to have a powerful relationship and that the levels of both have noted a decline suggests not only that civic duty and its connection with voting may be changing, but also that the relationship between the two may have shifted in some capacity. This preliminary analysis indicates that there are different dimensions of duty and that perhaps the decision to vote today is more of a calculation based on various conditions than an outright expression of loyal citizenship. Furthermore, these factors suggest that the strength of citizen obligation that is, or should be, felt by a potential voter varies depending on a combination of circumstances. With respect to young people, if electors decide not to participate based on the interplay of factors with which they are presented, the message from the 2008 Facebook study is that their compatriots are not prepared to censure this decision and that non-voting is perfectly acceptable - an attitude in complete opposition to the traditional belief that duty is a moral citizen responsibility.

Having established that there are alternate components of the duty to vote in elections it is important to evaluate what these dimensions mean for political participation, particularly the notion of 'conditional duty' given how highly its statements load in the factor analysis. The next chapter looks more closely at the nature of the relationship between these new dimensions of duty and voting behaviour and compares them to the relationship between 
traditional civic duty and voting. Specifically, it assesses what these new duty dimensions relate to by exploring whether there is a connection with other political attitudes such as political interest, efficacy, and trust. Finally, it sheds light on the degree to which these new items can explain voting behaviour, particularly among the young. 


\section{Chapter 7 : The impact of civic duty on voting and other attitudes}

\section{Introduction}

The factor analyses performed in Chapter Six suggest that there are several dimensions of the civic duty to vote in elections. Given this finding it is important that its current operationalization be expanded to include these new items so that researchers are better able to understand and explain perceptions of civic duty among citizens and how these orientations affect their patterns of behaviour. To explore how these dimensions of new duty and traditional duty relate to voting behaviour this chapter provides an analysis of these items. Further analysis examines the relationship of both old and new dimensions of civic duty to other well-established political variables, which include political efficacy (both internal and external), trust, and interest. The overall goal is to assess the degree to which all of the dimensions of duty exert an impact on an elector's propensity to vote and the effect they have on other important variables that are typically indicative of a person's likelihood of participating electorally.

\section{The story of new duty}

To start, it is useful to examine the degree to which respondents agree with the various duty statements. Figure 7.1 adds the percentage of those who indicated they 'agree' or 'strongly agree' with the duty questions. It displays the percentage of agreement expressed by the entire sample (all ages) and offers a comparison with the youngest age cohort (those aged 18 to 26 ) and the eldest group (those aged 55 and older). As expected, those aged 18 to 26 identify less with the 'traditional duty' style phrases and exhibit slightly more agreement than 
the overall electorate (in most cases) ${ }^{61}$ with the new duty statements. Young people seem to associate best with statements that focus on voting as a right, suggesting that they are more likely to relate to the rights dimension of voting than the responsibility portion. Notably, there is overwhelming support among the youngest age bracket for the phrase I have a right not to vote. This level of agreement is indicative of the attitude that not voting is equally acceptable to casting a ballot and perhaps even preferred under certain circumstances.

One of these circumstances may be the feeling that being informed or knowledgeable about politics increases an elector's duty to vote, as expressed in the 2008 Facebook study (see Chapter Five). A greater proportion of young people agree with the information statements that comprise the 'conditional duty' dimension than the survey group as a whole. Notably, the young express the most support for the phrase People who are informed about politics have a greater responsibility to vote than those who know little or nothing. Identification with this statement reflects a belief that information is an important prerequisite to casting a ballot during an election. The fact that many young people do not have strong feelings of electoral obligation, which could typically act as an override (e.g. voting is important no matter what), may mean that feeling uninformed becomes a rationale for not participating and, in some cases, pushing the responsibility for voting on the shoulders of those who are deemed 'knowledgeable'.

\footnotetext{
61 I have a greater duty to vote when there are major differences between parties or candidates, is the one exception.
} 


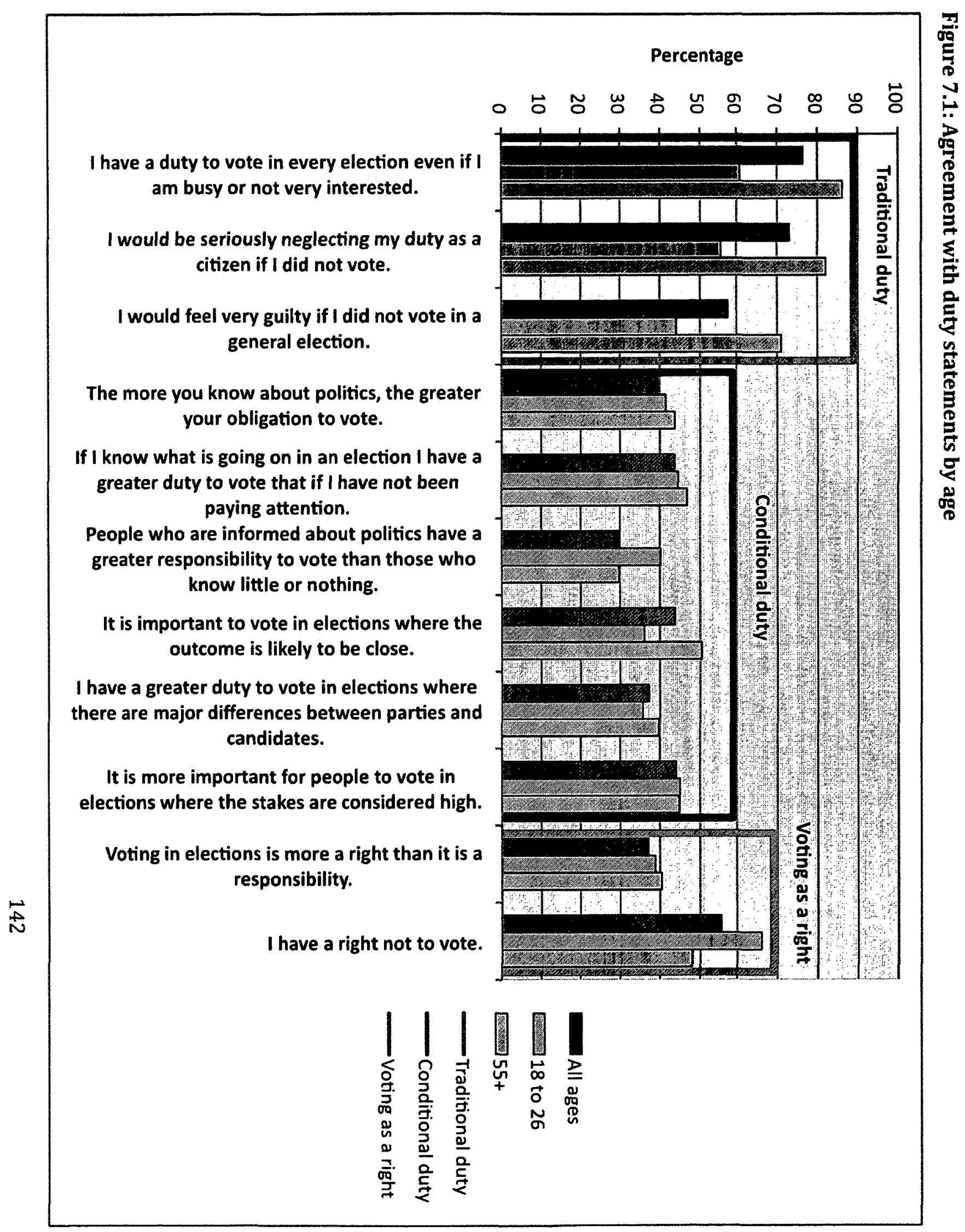


Looking at older electors, those aged 55 and older express strong agreement with traditional duty statements and less so with the phrase I have a right not to vote. These prospective voters identify more strongly with the notion of voting as a continual civic obligation and not one that changes based on the interplay of contextual factors. Their level of agreement with most 'conditional duty' statements may be explained by the fact that though they feel they have a duty to vote in every election, this duty can nevertheless be heightened under various circumstances. Therefore, from the vantage point of older electors, though it is important to vote in every election regardless of circumstances, certain conditions make the motivation to vote additionally compelling. The difference, then, between old and young potential voters seems to be that older electors take voting as their baseline, while younger people take not voting or a neutral position as their basic standard of participation in elections. Both groups feel the need to vote can be augmented from time to time, but the basic level of expectation is distinctive - an obligation to vote for older citizens translates into nothing more than some thoughtful consideration of voting for the young.

Examining agreement with duty statements by voting behaviour (see Figure 7.2) presents some interesting findings. Nonvoters of all ages are the most likely to agree with the phrase I have a right not to vote, but a large group of young voters (aged 18 to 26) also identify with the statement. The fact that young people agree so readily with this measure offers support for the rationale observed in the Facebook study that young voters are not prepared to censure their peers for failing to participate electorally.

Second, looking at levels of agreement with the 'conditional duty' dimension we see that with the exception of It is important to vote in elections where the outcome is likely to be close, which attracts more support from older electors, these statements are more appealing 
to the young. Furthermore, young voters and non-voters are closer in agreement with statements that reflect the new dimensions of duty than voters and non-voters of all ages, who in fact report greater agreement with traditional duty. While there is not overwhelming support for these new measures in the same sense as traditional duty probes, there is sufficient agreement to draw the conclusion that many of these statements resonate with the younger demographic and may help explain and account for their patterns of electoral participation.

Finally, this figure reinforces the notion that old and young prospective voters have different basic standards of participation that determine the scope of their involvement. While traditional duty phrases clearly draw voters and the notion of voting as a right attracts non-voters, measures of conditional duty appeal quite comparably to both those who participate and abstain. This suggests that there are varying degrees of duty amongst both types of electors. Many voters take casting a ballot as their participation minimum, but recognize that the duty to participate can be heightened based on the context of the race or other variables. Non-voters, by comparison, accept not voting as commonplace unless certain conditions exist, such as being informed, which augment the feeling that voting is obligatory under circumstances where it might be considered more rational. There are simply more young people who identify with these latter measures. As a consequence, there are more young non-voters who adopt this line of reasoning in considering electoral participation and likewise, many young voters who accept this rationale for the non-participation of their peers. Moving past agreement, it is useful to assess to what degree these dimensions of duty are correlated with voting. 


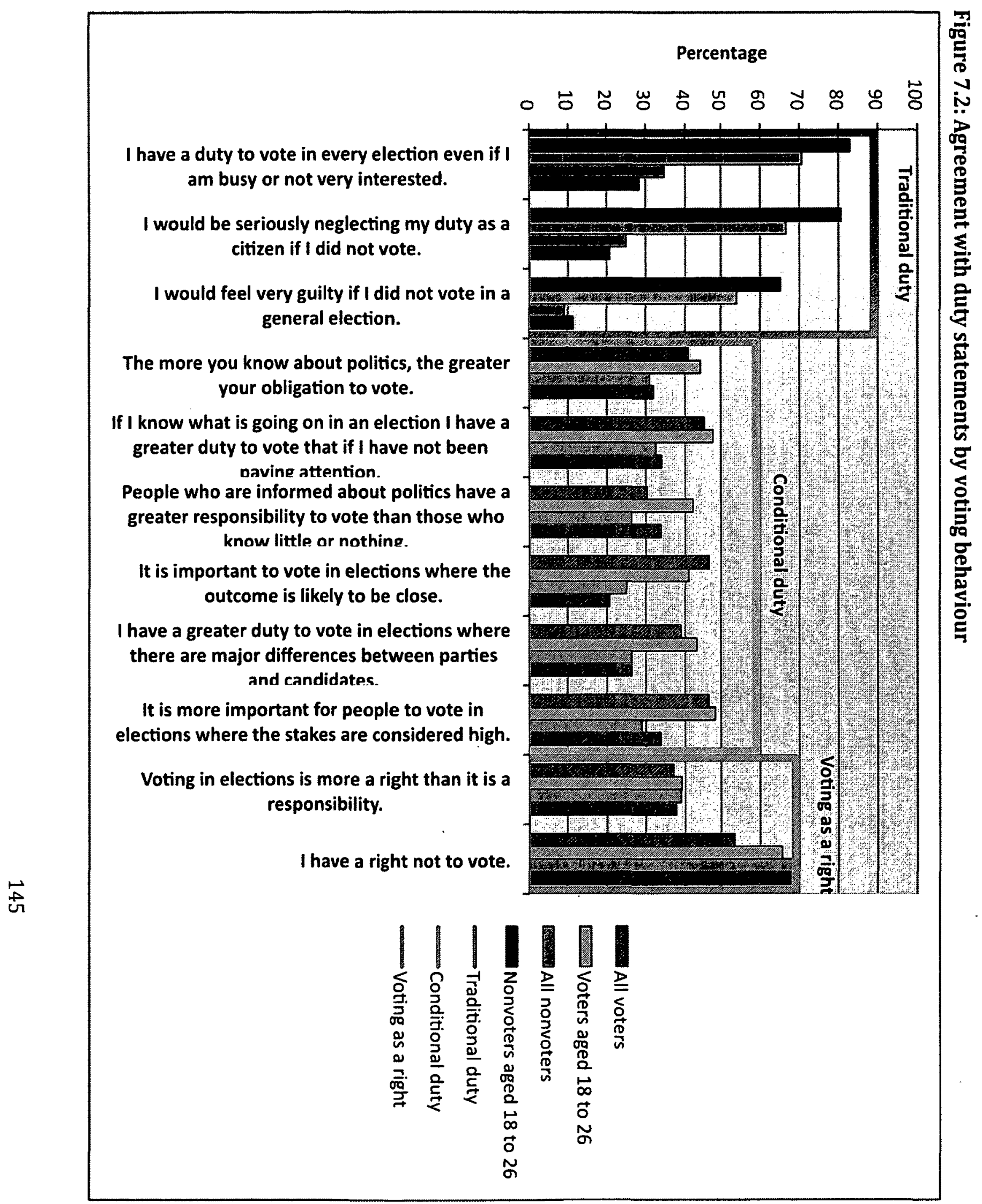




\section{New duty's relationship with voting}

Examining the relationship these new duty dimensions have with reported voting in federal elections ${ }^{62}$ illustrates the strong correlation between traditional duty and the vote (see Table 7.1). These scores provide evidence that this group of Canadians is similar to previous samples taken by national election studies, which also highlight the connection between the traditional obligatory feeling to cast a ballot and voting. This reinforces that electors who are more likely to identify with phrases that reflect a belief in a citizen duty to participate in elections are also more likely to vote. Many of the questions that represent the new dimensions of duty, however, do not exhibit a similar strong relationship with voting. Partial exceptions include the conditional duty 'meaning, importance, closeness' items $(.064, .045$, and .046$)$ and $I$ have a right not to vote $(-.124)$, although these show weak or very weak connections.

The fact that there are not many powerful significant correlations between the survey items representing the new dimensions of electoral civic duty and voting suggests that many electors who identify with these new duty statements have mixed participation records since otherwise strong or weak histories would show positive or negative relationships. Mixed participation records among older electors could be an indication that the trend of 'sometimes' participation is rooted in the values and attitudes of older generations and is becoming more visible and concentrated in the minds and actions of newly eligible electors.

\footnotetext{
62 Reported voting in the past federal election is used here because past voting behaviour in national election(s) was used in the national election surveys, whose data was presented and analyzed in Chapter Four.
} 
Table 7.1: Correlations (tau-c) of civic duty dimensions with reported voting in past federal elections for all electors, and for young and older age groups

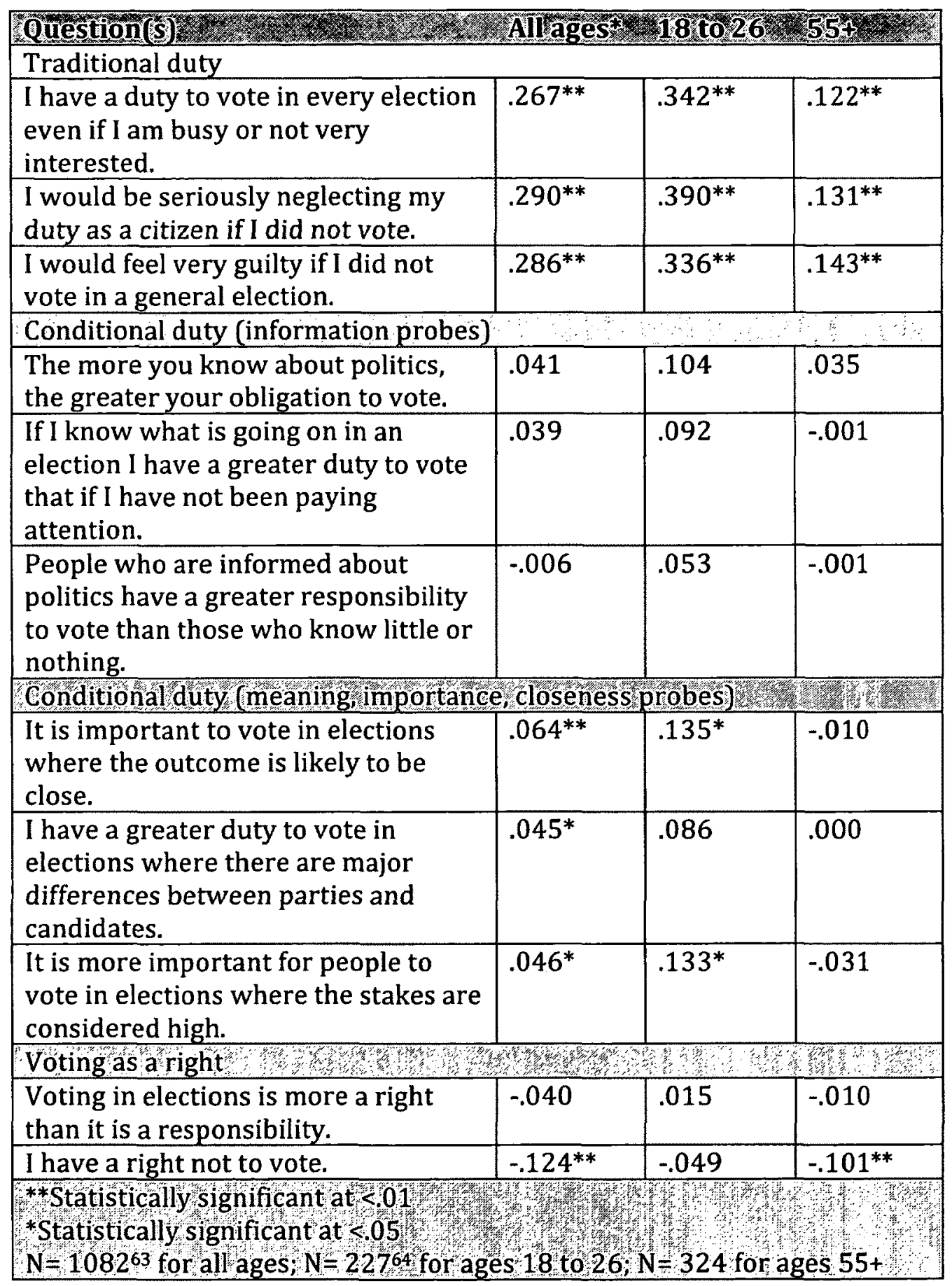

${ }^{63}$ The $\mathrm{N}$ varies by question between 1080 and 1082 respondents, depending on whether respondents were eligible or could not remember if they voted in the most recent federal election. Missing data is excluded. 
*Note that weight is applied to analysis of all ages to account for any effect from the oversample of young people and to ensure the sample is demographically balanced by age.

The correlations between voting and the meaning, importance, closeness component of conditional duty may be the partial effect of these statements winning agreement from traditional voters. Traditional voters presumably interpret voting in any election as being important, as this follows from having a traditional sense of electoral obligation and a close race scenario or higher perceived stakes are no exception. These statements more closely resemble the traditional duty phrases than the conditional duty information probes. The information focused statements, by contrast, put the onus on the individual elector and emphasize that under various conditions, where information or knowledge is enhanced, a greater degree of importance or sense of obligation should be associated with voting. This feeling is evoked through phrasing such as: 'greater duty to vote' and 'greater responsibility to vote'.

By comparison, the meaning, importance, closeness phrases address mostly contextual factors that an individual cannot necessarily control. Furthermore, the one item that explicitly uses the 'I have a greater duty to vote' wording shows the weakest correlation for all age groups and is the only statement from that section that is not significant among the younger age group. Statements that emphasize 'voting is more important' or 'duty heightening' under certain conditions may be relevant, but get away from the notion that a vote is required in every election regardless of circumstance. ${ }^{65}$

The connection with the statement, I have a right not to vote, by comparison, is a

64 The total oversample of young people is 25618 to 26 year olds, however only 227 sets of responses qualify in this case because 29 survey participants either did not remember whether they had voted or not in the previous federal election or failed to participate because they were not eligible. Missing data is excluded. 
negative one. This illustrates that as support for the right not to vote increases in intensity the likelihood of voting lowers correspondingly. Therefore, those who agree with this phrase are more likely to abstain on election day. This relationship suggests that an increasing number of electors look to the rights aspect of voting to rationalize their abstention during election time.

\section{Young people, new duty and voting}

Looking more specifically at correlations among young electors, a slightly different picture unfolds. For the most part relationships between duty statements and the vote that emerge for all ages are replicated among the young, except that they present more strongly for this group. It is interesting that young people who associate with traditional civic duty items have a greater propensity to participate electorally than all eligible electors and especially those potential voters aged 55 and older. Yet, there is much less agreement with traditional duty statements among the young than the older cohorts. Part of this may be because few young non-voters report identification with phrases that reflects a belief in voting as a moral obligation; although not many more older non-voters express support for these types of statements, either.

Another explanation is that many more of the young people who identify with traditional duty are more likely to be surefire voters whereas older electors may agree that they have a duty to vote, but not all of them manage to get to the polls all the time or as often as they would like. There may be less young people who associate with traditional duty, but a good portion of those who express support for this belief report acting out on it. This suggests that youth who are engaged are truly engaged, but there are less of them. While many young electors are abstaining from voting in elections, fewer members of the age group express identification with sentiments of traditional duty. The ones that do indicate support have a 
greater likelihood of casting a ballot.66

Moving on to the conditional duty statements, while there are not many significant correlations, the values are stronger for the young than the entire sample and much stronger than the tau-c values for the eldest cohorts. This suggests that this conception may be more relevant for younger electors. Another explanation for the limited number of significant associations between voting and the conditional duty items may be the pattern of mixed voting records echoed above. The fact that there are few meaningful relationships between the new duty dimensions and voting is consistent with patterns of sporadic voting behaviour addressed by these new conceptions. For example, if young people did not vote the analysis would show a negative relationship. Likewise, robust voting records would be accompanied by positive, meaningful relationships. A mixed and relatively inconsistent voting record, or the presence of varied intentions to participate, by contrast, are expected to yield no clear overall connection. Examining voting records, past and future, among young, older, and all electors, additionally emphasizes mixed records of participation among all age groups, though young people appear the least committed.

Compiling data from six questions on whether respondents had voted in the most recent federal, provincial or municipal elections and whether they planned to do so in the forthcoming federal, provincial or municipal elections allows for the creation of a voting index. Vote scores are added and tallied on a scale from zero to six. A six qualifies as 'strong vote' 67 (the respondent reported voting in every eligible election), whereas a score of zero

\footnotetext{
${ }^{66}$ Another consideration may be the sample size. An oversample of young people may lend itself to the production of stronger correlations because it is a more accurate representation of that segment of the population. That said, there is a good amount of older electors as well.

${ }^{67}$ All vote responses were coded a value of 1 and non-vote responses a value of 0 . Adding the responses of six voting behaviour questions together allowed for a maximum value of 6 and a minimum value of 0 . The lower the total number the less committed a person's voting record. Similarly, a high value represents a robust history of and intention to participate electorally.
} 
constitutes 'no vote' (the participant abstained in every eligible election). ${ }^{68}$ Figure 7.3 illustrates that electors of all ages show patterns of inconsistency with respect to their electoral participation, but those aged 18 to 26 are the least likely to report committed voting records. This variance implies that there are more factors at play that influence a young elector's propensity to cast a ballot and the electoral motivations of all electors. The mixed patterns suggest that while voting is not out of the picture completely it is by no means a certainty.

Finally, the fact that the phrase I have a right not to vote exhibits a negative significant relationship with voting when assessing all electors but not when looking specifically at young potential voters is likely the result of positive support among young people for the statement. It would seem that a substantial portion of young voters who strongly identify with the traditional duty dimension of voting in elections are equally cognizant of the other side of electoral duty, which is the right to participate or abstain. Agreement with this statement does not mean respondents are inclined to act out on their recognition of this right, but their identification with it allows them to not censure other young people who abstain electorally because of the belief that electors are entitled to refrain from voting as much as they are required to engage in elections.

Overall, traditional duty items exhibit the strongest association with voting among those aged 18 to 26 . There are fewer young people who express support for traditional duty phrases and who report loyal voting records. Youth who do express identification with these statements, by comparison, have a greater propensity to participate and come from a much a

\footnotetext{
${ }^{68}$ All missing data, such as cases where respondents were not eligible or could not remember whether they had participated were omitted from the analysis.
} 
Figure 7.3: Voting record by age

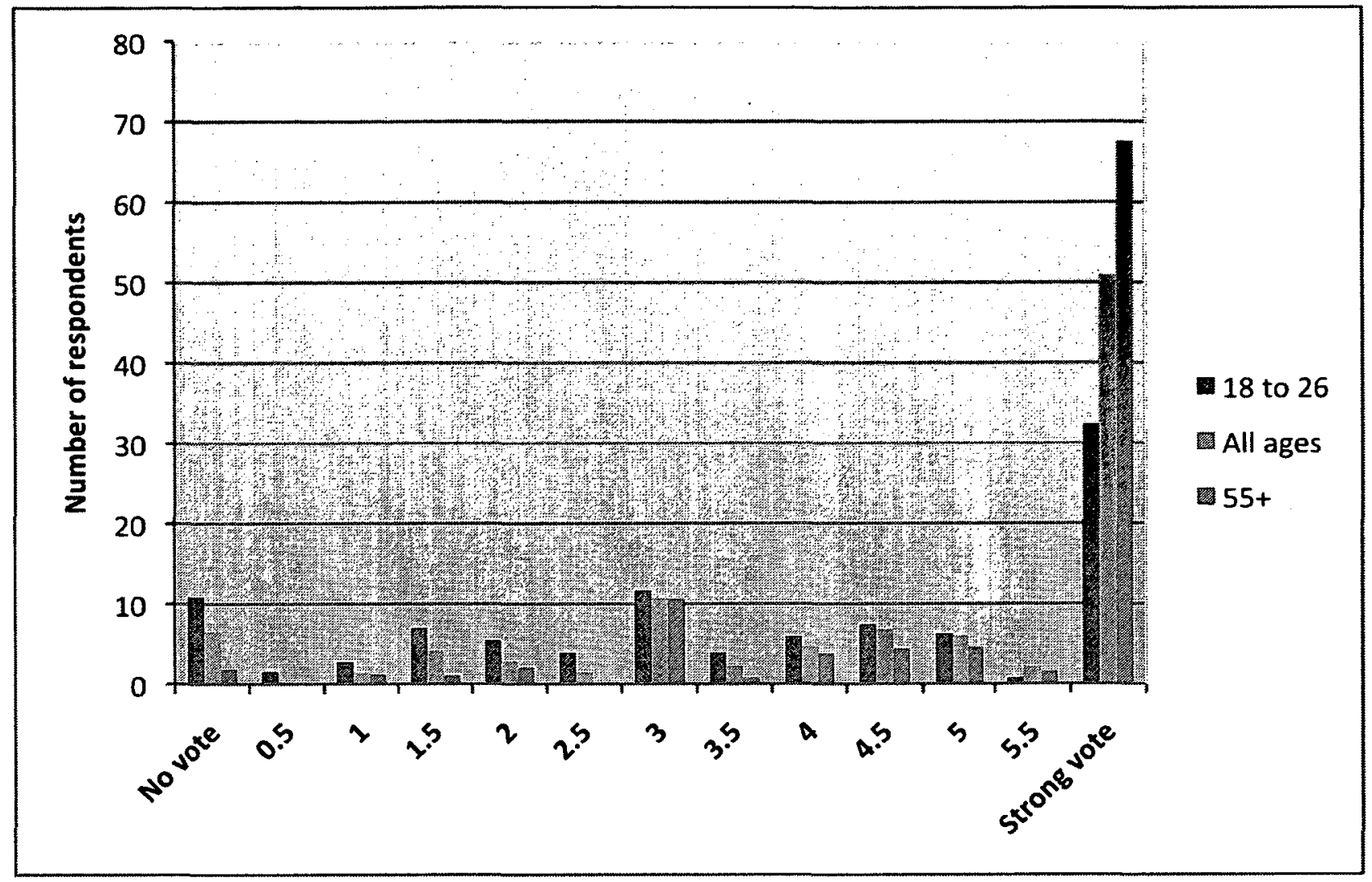

smaller pool of electors. The rest of the group, however, reports inconsistent voting histories and uncertain future plans to cast ballots. The fact that a majority of new duty items do not exhibit a close tie with voting is not surprising. Citizens who agree with these statements have a looser sense of electoral obligation. Instead of adhering to the doctrine that elections demand a vote at every occasion, these electors believe that the obligation to vote is made stronger by various contextual factors, which may not be present all the time. Based on this rationale, it would be expected for these measures to have a mixed relationship with voting. To learn more about what variables these new duty dimensions do relate to, it is useful to examine the degree of association they have with other dependent variables that are linked to voting behaviour, namely political trust, internal and external efficacy, and political interest. 


\section{The relationship of new duty dimensions with other dependent variables}

Evaluating civic duty dimensions with other dependent variables reveals some interesting correlations. Looking first at the entire sample we see that traditional duty exhibits a positive relationship with all four variables - political trust, internal efficacy, external efficacy and political interest. ${ }^{69}$ Traditional duty correlates strongly with internal efficacy and political interest, weakly with external efficacy and very weakly with political trust (see Table 7.2). Therefore, the more a respondent identifies with traditional civic duty the more likely that person is to believe that they can understand and have an impact on politics, and there is a greater likelihood that individual exhibits an interest in politics. These persons are also somewhat more likely to believe that the government is responsive to citizens and exhibit slightly elevated levels of trust than those who do not associate with the notion that voting in all elections is equally important and should be carried out as a duty of citizenship.

Looking at the 'conditional duty' dimension, which includes information and meaning, importance, closeness components we see a weak, positive correlation with the concepts of internal efficacy and political interest, and a negative relationship with external efficacy. There is no relationship between conditional duty and political trust when examining all age categories. These results suggest that someone who identifies with 'conditional duty' can be

\footnotetext{
${ }^{69}$ Measures for these variables were derived from various past election surveys (American, British and Canadian) that used them over time. Trust is measured by the statements, Most of the time we can trust people in government to do what is right and Most politicians are in politics only for what they can get out of it personally. Internal efficacy is gauged by the phrases, I consider myself well-qualified to participate in politics and I feel I have a pretty good understanding of the important political issues facing Canada. External efficacy is assessed via People like me don't have any say about what the government does and I don't think the government cares much what people like me think. Finally, political interest is measured by Generally speaking, how interested are you about what's going on in government and politics? Response options for these statements were on a 5-point Likert scale. For the first three variables this scale ranged from 'strongly agree' to 'strongly disagree.' For interest, response options varied from 'extremely interested' to 'not interested at all.' For a full outline of all questions asked please see the Appendices.
} 
characterized as being more likely to have a sense that they personally grasp and can influence politics and more likely to be interested in politics. Furthermore, those that subscribe to conditional duty are less likely to believe that political institutions are responsive to citizens. The fact that internal efficacy and political interest have a relationship of similar strength and direction with conditional duty is not surprising since research has linked the two concepts along with other variables such as political knowledge and engagement. Likewise, external efficacy has been linked to political trust (Sullivan and Riedel, 2001; Turcotte, 2007).

External efficacy's relationship with conditional duty is the opposite direction of its correlation with traditional duty, signaling that having faith in the responsiveness of political institutions may be a precursor to adopting the belief that it is an important obligation of citizenship to participate in every election. People with higher levels of external efficacy exhibit greater faith in the political system, which likely leads to stronger voter confidence and promotes their participation in the electoral process. Having less assurance that government is responsive, however, is an incentive to abstain and could help account for why those that identify with 'conditional duty' do not feel compelled to cast a ballot at every electoral opportunity. People who perceive a system as unreceptive are less likely to regularly participate in the processes that support the institutions which legitimize and uphold them.

Similarly, the 'voting as a right' dimension also shows a weak and negative relationship with external efficacy. There is no significant correlation with other variables. Respondents who identify with these statements are less likely to perceive the government as being receptive to citizens and, as a consequence, are less likely to see the value of electoral participation. Instead, this reduced confidence in the political system may help frame 'voting' 
as one of many democratic rights instead of as an important citizen obligation that maintains electoral democracy.

Table 7.2: Correlations (tau values*) of civic duty dimensions with trust, internal and external efficacy and interest for all electors

\begin{tabular}{|c|c|c|c|c|}
\hline Questoon $(S)$ & Tinst & $\begin{array}{l}\text { Tinternal } \\
\text { Effieacy }\end{array}$ & Exterial & Interest \\
\hline \multicolumn{5}{|l|}{ Traditional duty } \\
\hline $\begin{array}{l}\text { I have a duty to vote in every election } \\
\text { even if I am busy or not very } \\
\text { interested. }\end{array}$ & $.059^{*}$ & $.265^{* *}$ & $.144^{* *}$ & $.303^{* *}$ \\
\hline $\begin{array}{l}\text { I would be seriously neglecting my } \\
\text { duty as a citizen if I did not vote. }\end{array}$ & $.079^{* *}$ & $.290^{* *}$ & $.143^{* *}$ & $.322^{* *}$ \\
\hline $\begin{array}{l}\text { I would feel very guilty if I did not vote } \\
\text { in a general election. }\end{array}$ & $.118^{* *}$ & $.336^{* *}$ & $.120^{* *}$ & $.353^{* *}$ \\
\hline \multicolumn{5}{|c|}{ Conditional duty (information probes) } \\
\hline $\begin{array}{l}\text { The more you know about politics, the } \\
\text { greater your obligation to vote. }\end{array}$ & -.023 & $.137^{* *}$ & $-.073^{* *}$ & $.137^{* *}$ \\
\hline $\begin{array}{l}\text { If I know what is going on in an } \\
\text { election I have a greater duty to vote } \\
\text { than if I have not been paying } \\
\text { attention. }\end{array}$ & .001 & $.093^{* *}$ & $-.079 * *$ & $.089^{* *}$ \\
\hline $\begin{array}{l}\text { People who are informed about } \\
\text { politics have a greater responsibility to } \\
\text { vote than those who know little or } \\
\text { nothing. }\end{array}$ & .008 & $.072^{* * *}$ & $-.103^{* *}$ & .050 \\
\hline \multicolumn{5}{|c|}{ Conditional duty (meaning, importance, closeness probes) } \\
\hline $\begin{array}{l}\text { It is important to vote in elections } \\
\text { where the outcome is likely to be close. }\end{array}$ & -.037 & $.128^{* *}$ & $-.115^{* *}$ & $.094^{* *}$ \\
\hline $\begin{array}{l}\text { I have a greater duty to vote in } \\
\text { elections where there are major } \\
\text { differences between parties and } \\
\text { candidates. }\end{array}$ & .000 & $.109 * *$ & $-.103^{* *}$ & $.083^{* *}$ \\
\hline $\begin{array}{l}\text { It is more important for people to vote } \\
\text { in elections where the stakes are } \\
\text { considered high. }\end{array}$ & -.007 & $.076^{* *}$ & $-.115^{* *}$ & .022 \\
\hline \multicolumn{5}{|c|}{ Voting as a right } \\
\hline $\begin{array}{l}\text { Voting in elections is more a right than } \\
\text { it is a responsibility. }\end{array}$ & -.007 & $.003^{* *}$ & $-.121^{* *}$ & -.003 \\
\hline I have a right not to vote. & $-.087^{* *}$ & -.007 & $-.097^{* *}$ & -.040 \\
\hline${ }^{* *}$ Statistically significant at $<.01$ & & & & \\
\hline
\end{tabular}


*Statistically significant at $<.05$

$\mathrm{N}=1132^{70}$

*Note that for political trust, external efficacy and internal efficacy tau-c measure of association is used because for each of these variables two questions measuring their strength or weakness were asked of respondents. The responses to these questions were then added into one variable, resulting in a 10-point scale, instead of the original 5-point scale. Since the number of rows and columns are not the same tau-c is appropriate. Tau-b is used for political interest because it was evaluated on a 5-point scale and no other questions were added.

\section{Young people}

Conducting the same analysis among youth aged 18 to 26 we see that many of the significant relationships between these duty dimensions and the dependent variables share the same direction and strength as with the entire sample, and in most cases are more robust. (see Table 7.3). ${ }^{71}$ With respect to traditional duty, for example, those young people that harbour traditional feelings about the obligation to vote in elections are more likely to be interested in politics and have strong senses of internal efficacy. A weak positive correlation is also present between some measures of external efficacy and political trust, suggesting that as identification with traditional duty rises young people are more likely to have positive orientations toward the political system.

By comparison, young people who identify with the conditional duty dimensions are also politically interested and believe that they can have an impact, slightly more so than the sample as a whole. Furthermore, trust and external efficacy are significant for this group, showing negative relationships with conditional duty. These negative correlations are also more powerful for the young. This means that young people who share the sentiments of this dimension of duty are less trusting of political institutions and actors and have less faith in institutional responsiveness to citizens.

\footnotetext{
70 The $\mathrm{N}$ varies by question between 1128 and 1132 respondents, depending on whether several respondents omitted answering that particular question.

71 The only exception to this is the statement I would feel very guilty if I did not vote in a general election, which exhibits stronger relationships with the sample electorate as a whole than the younger oversample.
} 
Table 7.3: Correlations (tau values*) of all civic duty dimensions with trust, internal and external efficacy and interest for young people aged 18 to 26.

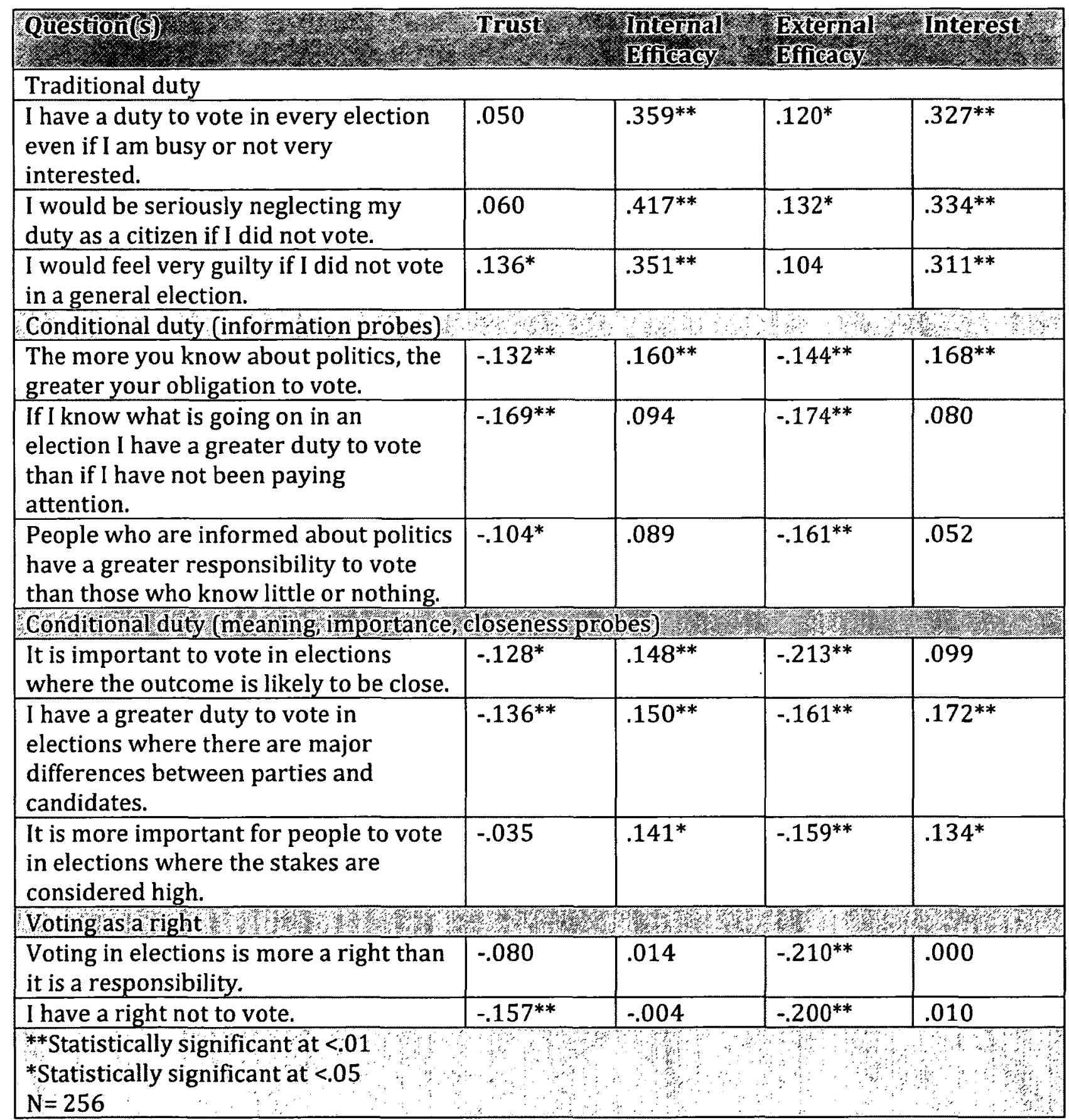

*Note that for political trust, external efficacy and internal efficacy tau-c measure of association is used because for each of these variables two questions measuring their strength or weakness were asked of respondents. The responses to these questions were then added into one variable, resulting in a 10-point scale, instead of the original 5-point scale. Since the number of rows and columns are not the same tau-c is appropriate. Tau-b is used for political interest because it was evaluated on a 5-point scale and no other questions were added. 
Looking at the results for this new dimension more closely, we see strength of the relationship conditional duty has with these political attitudes is similar for the information and the meaning, importance, closeness components; although, there are slightly more significant correlations among the meaning, importance, closeness statements. The primary difference between the results for young people when compared to the correlations for all electors is that trust exhibits a weak to moderate negative relationship among youth, but no clear connection for the entire sample. This signifies that the young people who identify with conditional duty are less trusting of government and politicians, which seems logical since young people are less likely to be motivated to engage in a system that supports and legitimizes the election of political representatives they do not trust.

External efficacy also exhibits a negative relationship, but it is more moderate in strength. This suggests that those young people who believe it is more important to vote under certain conditions have less conviction in the responsiveness of politicians, which may be why they are less likely to advocate voting every time, since voting is a measure of support for these political actors. These negative relationships highlight pessimistic feelings about the external political environment. This is in contrast to traditional duty, which is characterized by positive outside orientations.

Political interest and internal efficacy statements produce weak to moderate positive relationships with conditional duty phrases, suggesting a certain level of political interest among young people that feel this way and faith in their personal capacity to influence politics. A greater number of meaning, importance, closeness items demonstrate significance here. This may be because young people feel their chances of exerting an impact are greater under these conditions or that their vote will be more meaningful because of the importance they 
associate with a particular election. Interest also has an additional significant statement for this grouping. More exciting electoral circumstances could motivate greater interest. It could also be that these phrases get at a more powerful segment of conditional duty or that the wording is better at evoking the feeling of contingent voting in youth.

Overall, young people who believe that the obligation to vote is dependent upon having more information or knowledge, or the presence of certain contextual factors that make an election 'more important' are less trusting of politics, have less faith in the responsiveness of political institutions, exhibit more confidence in their own personal ability to have a say, and are more interested in politics.

Finally, looking at the 'voting as a right' statements, we see that external efficacy exhibits a moderate negative relationship, suggesting that those young electors who associate more with voting as a right instead of a duty have much less efficacy in the political institutions that support our system of government. I have a right not to vote is also negatively correlated with trust, implying that identification with this phrase is connected to lower levels of political trust. These correlations show negative orientations to the external political system, but without the same positive internal attitudes, such as internal efficacy and political interest, that are present in the analysis for traditional duty and conditional duty. Positive internal feelings appear to be a key difference in which new duty dimension electors identify with. Likewise, positive external orientations seem to be a leading factor that separates traditional feelings about duty with new ones.

\section{Traditional duty and conditional duty profiles}

Taking these results into account, let us compare a citizen with traditional duty beliefs with one who identifies with conditional duty. How does this picture change with age? It is 
useful to look at a graphic summary of the significant correlations to gain a better sense of the characteristics possessed by persons who relate to these conceptions. Examining eligible voters of all ages we see that someone with a belief in traditional duty votes, has positive orientations toward the political system. This person is typically politically interested and has faith in his/her personal capacity to have a say. To a slightly lesser degree, this elector is externally efficacious and has trust in the political system (see Figure 7.4). By comparison, a young person who identifies with traditional duty also votes, is politically interested and has an even stronger sense that they understand and can influence the political system. These young people are also characterized by their positive orientations of the political system, showing positive scores for external efficacy and trust.

An elector supporting the sentiments of conditional duty is interested in politics, has faith in his/her ability to understand and exert an influence on the political system, but has less confidence in the system itself (see Figure 7.5). Those that identify voting as being more important in a close race or because of important election issues are also more likely to vote. In contrast, young people subscribing to conditional duty have much less assurance that political institutions are responsive to citizens and are distrustful of political actors. They are likely interested in political developments and have a greater confidence in their abilities to understand and participate in politics. For these young people a vote is not assured, but is taken more as a choice or calculation to be evaluated based on the various circumstances at the time. Voting is considered helpful if an individual has the political knowledge or evaluates the election as being meaningful, but deciding to abstain because of a lack of campaign information or because there is not a major perceived difference between political parties or their candidates is perfectly acceptable. This conception is best distinguished from traditional 
duty by its negative perceptions of the external environment and political institutions. In this case the decision to vote may be dependent on information and external factors, but it is also likely a consequence of internal confidence and interest.

Finally, there are not as many significant connections with these political attitudes Figure 7.4: Correlations with Traditional duty by age

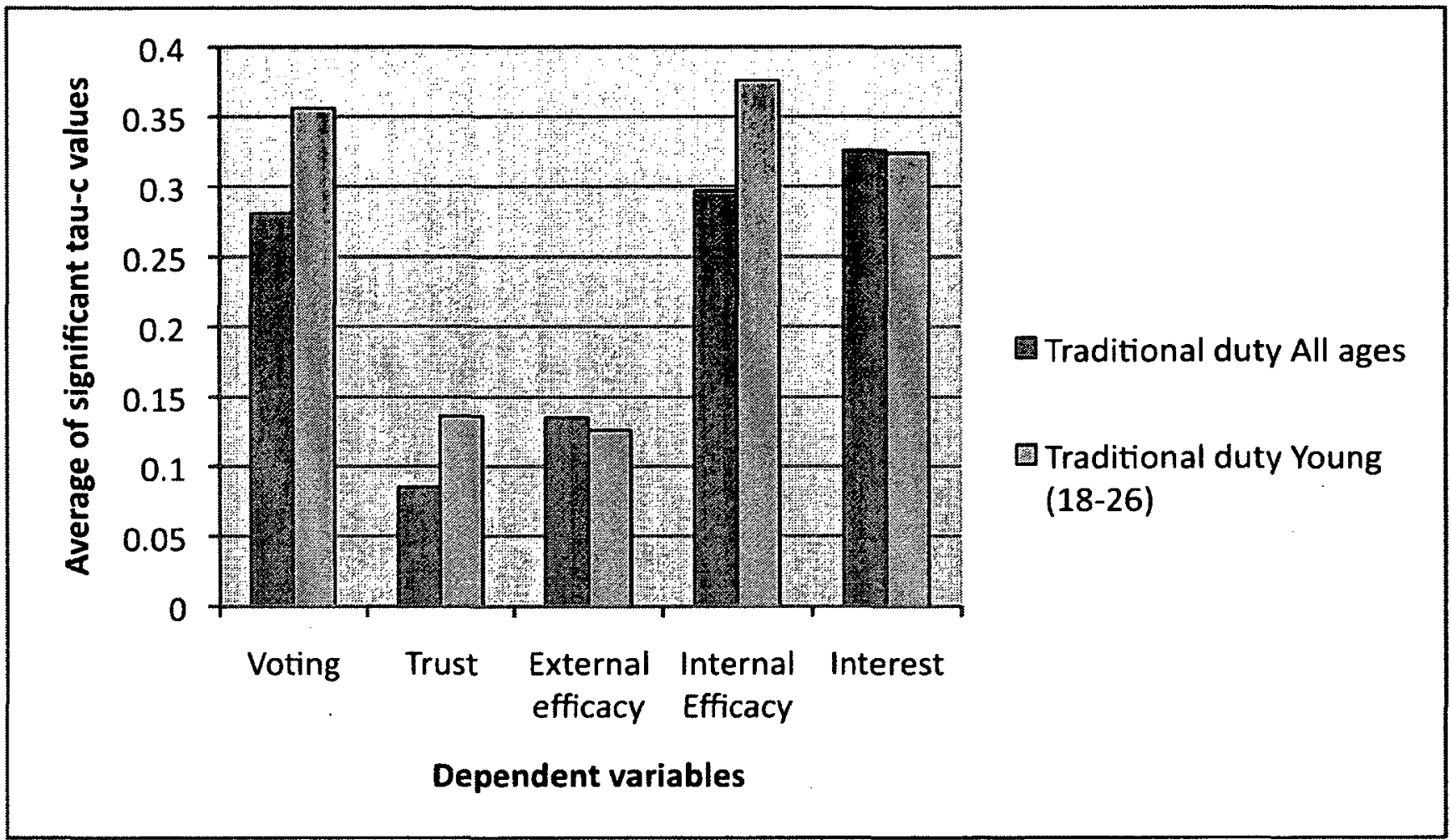

those who associate with the 'voting as a right' dimension as with the first two conceptions. This elector has slightly lower efficacy in the political system and somewhat lower trust as a result making him/her less likely to vote. A young person with this conception, however, perceives the system as being much less responsive and, accordingly, has less trust in political structures. In fact, this young elector has less faith in political institutions and less trust in politicians than the elector subscribing to conditional duty. Furthermore there is no meaningful relationship with political interest or internal efficacy among either group, 
Figure 7.5: Correlations with Conditional duty by age

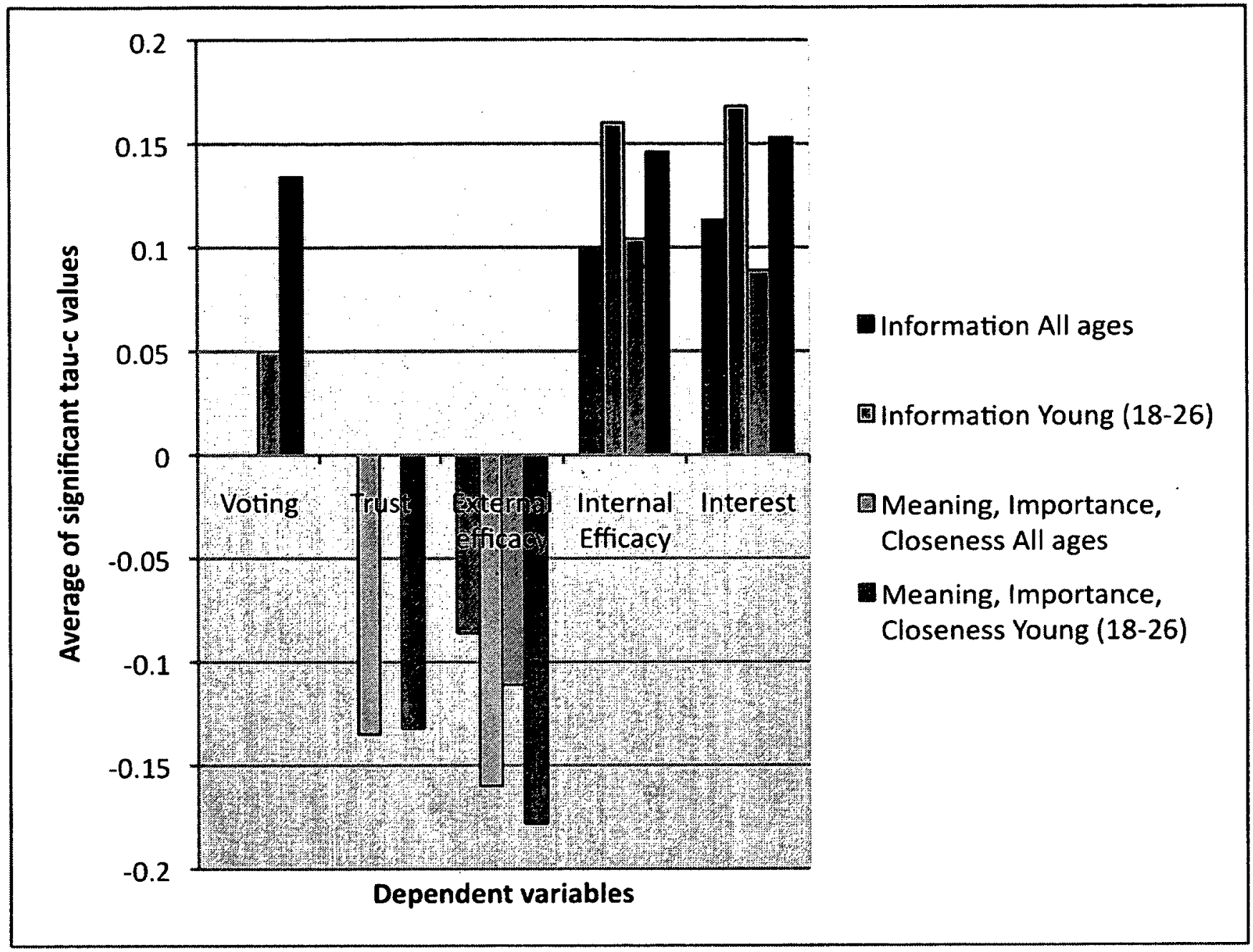

although these correlations are clearly negative for young people. This illustrates that these potential voters have no personal conviction or political curiosity to stimulate the internal motivation to participate regardless of these negative external perceptions. For this elector non-voting is a satisfactory response to a system that is unreceptive and dishonest. ${ }^{2}$ Analysis

Taken together, some interesting findings emerge from examining the correlations between the dimensions of civic duty to vote and political trust, interest, internal and external

\footnotetext{
72 No graphic display is presented for this conception because there are so few significant relationships between duty statements and these attitudinal variables.
} 
efficacy among the youngest electors. First, for the most part the trends in correlations detected when looking at the entire electorate are replicated among the young, only more strongly. If the portion of the electorate that relates to conditional duty has a negative sense of external efficacy, young people aged 18 to 26 are even less externally efficacious, suggesting a lower degree of faith in the receptiveness of politicians.

The fact that the relationships for almost all dimensions and all variables are more robust among the young is reminiscent of an assertion made by Chris Achen that young people are "the canary in the coal mine" when it comes to electoral participation (2009:17). Applying Tingsten's law of dispersion to voter turnout in Canada and the US, Achen makes the case that the youngest electors (aged 18 to 24 ) are the most volatile electoral cohort "nearly always respond[ing] to the electoral forces in the same direction as their elders" (16). If Achen is correct in his assertion that when turnout drops the youngest electors follow suit and drop the most, or similarly rise the most when turnout increases, it is reasonable to infer that this volatility among the young could apply to their perceptions and identification with conceptions of electoral duty as well, and this might account for the stronger relationships no matter the direction.

The data presented here supports this insight, showing, for example, that among dutiful respondents, the strongest positive correlation with interest is found when examining the youngest electoral cohort. Likewise, there is a heartier negative relationship between conditional duty and political trust when looking at young respondents. The fact that there is some identification with conditional duty on the part of older respondents invites us to consider a perspective where these perceptions, found among some older electors, are simply more concentrated in young electors. It could be that these alternative perceptions of 
electoral duty have been around for some time and are not unique to the young, but present more strongly in the minds of young people. These feelings of conditional duty could be increasing with intensity as new cohorts reach the age of eligibility. An alternative explanation may be that young electors are influencing the political attitudes and electoral choices of their elders.

Second, feelings of trust and external efficacy seem to play an important role in whether an elector identifies with the traditional or conditional dimensions of electoral duty, especially for young people. Broadly, electors who identify with traditional duty have a positive perception of the political system - trusting politicians and having confidence in Canadian political institutions. Those that associate with the dimension of conditional duty and its components, however, do not regard the political system as responsive. In addition to having negative senses of external efficacy, young electors that subscribe to feelings of conditional duty are distrustful of politics. It could be that these young people value having additional knowledge because it helps them navigate in a system that they do not trust and that they perceive as somewhat unresponsive to their interests. In other cases, factors that make an election particularly important, or at least more salient than usual, motivates involvement in a process that supports an organization they are not fond of. Electors associating with the rights portion of voting have negative orientations toward the external political environment too. Young people with this belief have especially low levels of faith in politicians and are more distrustful of the political system than other young potential voters.

Conditional duty supporters also differentiate from those who associate with the phrase I have a right not to vote based on their connection with internal efficacy and interest. These variables appear to influence which dimension an elector identifies with and hence act 
as motivating factors in the decision to participate. Much like the dutiful elector, positive internal sentiments are present for conditional duty identifiers. Correlations indicate that the more someone associates with this dimension the more likely they are to be confident in their ability to have their voice heard and exhibit an interest in politics. Although internal efficacy and political interest are not significantly correlated with 'voting as a right' the fact that no relationship is present suggests that there probably is not one. Furthermore, correlations for all electors indicate a negative direction, implying the presence of pessimistic internal feelings about engaging in politics.

The fact that greater recognition of the rights portion of voting is accompanied by less trust and less faith in political institutions and there are no positive internal orientations to offset this accounts for a disinclination to engage in elections. Findings suggest that for young electors feelings of 'voting because it is important' very much come from within, whereas recognition of voting as a right that is optional seems to be triggered by perceptions of the external system. This could mean that the system (government, political parties, etc.) is becoming less attractive, discouraging young people from seeing the benefits of voting in an electoral democracy, or it may be a consequence of the norms that are being passed on to these new electors. Perhaps there is not enough emphasis on their personal capacity to have a say. Of course, there is a possibility that these processes are occurring simultaneously. Either way, political attitudes appear to have an important influence on the way in which electors conceive of their citizen duty in an election.

Generally, there is a distinct difference in the profile of someone who embodies 'traditional duty' compared to the person who associates with the dimensions of 'conditional duty' or 'voting as a right', and this is particularly true among the young. Young people agree 
more than other potential voters with the statements that represent the new dimensions of duty. Their attitudes toward other variables popularly associated with political participation seem to be more strongly related. Though correlations could be stronger, analysis of this data indicates that there is more to the perception of electoral duty than the traditional belief in participation in all elections no matter the circumstances. This suggests that young people are considering other factors when rationalizing whether or not to cast a ballot. Furthermore, these norms of duty may have been passed on from the older generation and are either presenting more strongly in young electors or increasing with intensity as the years pass and value change has more time to take root.

Finally, these results suggest that young and old potential voters have different basic standards of electoral participation. While many established electors take voting as their baseline of involvement in elections, no matter the circumstances, young people are more likely to assume a neutral position where the decision to vote is based on various contextual factors. They are also more likely to recognize not voting as a viable option and do not possess the same strong feelings of electoral obligation to act as an override like older cohorts. Furthermore, the perception that 'sometimes' participation is acceptable means that electorally active youth are not prepared to censure their peers for failing to take part because of their recognition that deciding not to vote is a rational choice. This important difference in the basic level of citizen expectation in elections between young and older cohorts helps explain why youth turnout is lower and sheds light on the rationale that informs their decision not to participate in every election all the time.

\section{Conclusion}

The above analysis provides strong evidence that in its current operationalization the 
electoral portion of civic duty is too narrow. While agreement with traditional duty remains strong, young people identify more closely with 'voting as a right' than associate with traditional duty statements. Furthermore, many older electors also acknowledge and support the right not to vote, albeit the vast majority still conceives of voting in elections through a traditional lens. There is also relatively strong support for the statements that represent conditional duty among all age groups, but especially among the young. Overall then, while there is evidence of agreement for the new duty dimensions among all electors these feelings present more strongly in the youngest electors. The fact that older generations identify with these dimensions to a certain degree suggests they may be passed down and are now having more of an impact because they are more concentrated. Either way, the belief in 'sometimes participation' is rising, which is supported by scattered records of electoral involvement.

Identification with conditional participation and the rights component of voting seem to be connected with political attitudes. Negative feelings toward the political system are characteristic of these conceptions and are what differentiates these dimensions from traditional duty, which is distinguished by positive attitudes. The further difference between a conditional voter and an elector perceiving voting as a right is their internal feelings, including their interest in politics and personal beliefs regarding whether they can understand politics and have a say. An elector that possesses positive feelings about his/her ability to interact with the political system, even if it is unresponsive is what sets these dimensions apart.

The final chapter continues this analysis by discussing the implications of this project and conclusions that can be drawn from the research. Special attention is paid to what existing literature can take from these findings and suggestions for the further exploration of 
the dimensions that comprise the civic duty to vote. Chapter Eight also assesses implications for survey measurement and attitudinal studies. Finally, it explores what multidimensional electoral duty means for patterns of participation and low turnout in Canada and other western democracies, especially Britain and the US. 


\section{Chapter 8 : Final Comments}

\section{Overview of findings}

This work seeks to open debate about civic duty, its relevance, how it may be changing and the implications of how it is measured in surveys. By tracing the theoretical and methodological roots of civic duty over time it problematizes how the portion of civic duty that relates to elections and voting is operationalized and through primary survey research. attempts to shed light on contemporary conceptions of citizen duty. A second focus addresses electoral civic duty from a methodological perspective, outlining the deficiencies in the popular survey measurements of civic duty and crafting survey items that are a more accurate reflection of how the public thinks about civic duty during an election campaign and also behaves based on these attitudes. Both of these tasks are undertaken with a concentration on the youngest eligible electors of the population.

The focus on the young is adopted for many reasons. For one, the largest portion of voter turnout decline can be attributed to the abstention of young electors. Second, these young people are less likely to develop the habit of voting as older generations once did (Dalton, 2008; Pammett and LeDuc, 2003; Wattenburg, 2007). Third, changes in values (Inglehart, 1997; Nevitte, 1996), citizenship norms (Dalton, 2008a; 2008b) and perceptions of what it means to be a citizen (Pammett, 2009) indicate differences in the types of political activities young people engage in and how those patterns of participation are unfolding. Fourth, shifts or changes in these types of values are closely aligned with feelings about civic duty and elections and so it is plausible to expect there have been changes in the ways in which young people think about and perform during election time. Fifth, the values these young electors harbour are likely a more accurate reflection of where contemporary attitudes 
have shifted in recent years or will be in the future. Finally, young people are the future leaders of our society and their actions and inactions will help determine the function, structure and interactive quality of democracy moving forward.

Key findings from the qualitative and quantitative survey responses presented here show that while conceptualizing the civic duty to vote as a moral obligation in which participation is valued for the health of democracy is still an appropriate way of describing electors' beliefs about voting in elections, it misses other crucial dimensions of how citizens perceive their responsibility to participate in an election campaign. Many electors today, predominantly young people, do not believe 'real' citizens have a moral obligation to participate at every electoral opportunity. Instead, they describe feelings of electoral duty strengthening or weakening based on a host of contextual factors, including information or knowledge, major differences between parties or candidates, the closeness of the race, important issues, the perceived stakes of an election, etc. An additional group of electors' reports a stronger identification with the rights portion of voting than the duty component. They do not believe they have an overriding citizen responsibility to contribute in an election, viewing participation as a choice instead of a foregone conclusion. The overarching message for participation is that it is not always required. Alternatively, the perceived importance of an election and how well equipped electors believe they are to participate in it determines the likelihood they will cast a ballot. In contemporary Canadian society, participating 'sometimes' seems to be awarded the same level of social desirability that voting in all elections was given 50 years ago.

\section{New dimensions of duty}

Specifically, there are two new dimensions of electoral duty that emerge in this thesis. 
The strongest alternative dimension is termed 'conditional duty' because it takes the strength of an elector's sense of electoral obligation as being contingent upon various elements such as knowledge and the perceived importance of an election. According to this view, an elector's inclination to participate increases or decreases based on the presence of various contextual factors such as the electoral opportunity structure and their level of knowledge, information or the degree to which they have been paying attention during an election campaign. If any of these intervening factors are not perceived as particularly strong, abstaining and leaving electoral decisions to other more informed voters is perfectly acceptable. In this sense the strength of electoral duty, and hence motivation to participate, is conditional upon the occurrence of these various factors.

This conception paints a somewhat more encouraging picture than assertions that the electorate is becoming increasingly apathetic and 'tuned out' of electoral politics because it illustrates the presence of a sense of duty, albeit a different variety. It may be that electors today, particularly the young, are not giving up allegiance to dutiful citizen activities but rather that the relationship between participatory activities and citizenship obligations is changing. This could also represent changes to the ways in which civil society engages with the state and the channels they use to conduct this engagement.

For some, this could provide hope that a lingering sense of duty in any capacity signals the potential to revive the traditional notion of a citizen's commitment to participate in all elections. It can also be taken as evidence that strong bonds are not so easily broken and the relationships between citizenship, democracy and participation are enduring. Either way, the continued presence of duty, even a new kind, is hopeful for the future of participation. It is an indication that citizenship and elections are still linked to overarching notions of 
responsibility and contribution to the polity.

The second new dimension is referred to as 'voting as a right' since it represents a view wherein electors more closely associate with the rights component of voting than the duty portion. These electors maintain that in a democratic society their right not to participate should be taken as paramount over any citizen obligation, including the civic duty to vote in elections. Within this conception there are those who believe electors should always consider voting, but may choose to exercise the right to abstain if that is the more responsible choice (e.g. if they are uninformed and would be choosing a candidate blindly). There are also others who more readily dismiss electoral participation noting that in a 'free country' citizens can behave as they see fit. Qualitative responses link these varied conceptions of citizen duty to perceptions of citizenship, showing that those who perceive citizenship as a rich conception with many nuances and elements are more likely to recognize that participation is important, whereas those who view it as nothing more than a legal status are quite content dismissing any sort of obligation when it comes to citizen involvement in elections.

The latter dimension is less hopeful for a future characterized by an engaged citizenry or a civil society that actively partakes in the electoral process, but the combination of all three dimensions suggests the relationship between citizenship and elections is not homogenous and there are different elements we must explore to continue to learn about citizen involvement in elections.

\section{Importance of the research}

The efforts of this thesis are important because all major election studies (e.g. the ANES, BES and CES), regional or multi-country surveys (like the ISSP, Eurobarometer, ESS, 
and WVS), and other attitudinal studies addressing voting, participation and citizenship continue to refer to the conception of civic duty originally established in early American surveys and designed by researchers. There has been no refinement of the conception of duty, especially with input from electors themselves, or a thorough explanation of why that particular conception was decided on in the first place. The ambiguous roots of civic duty have made it difficult to distinguish its core determinants, contributing to the array of different and inconsistent survey items used to assess it.

Furthermore, a widespread belief that levels of duty were robust meant the concept was not investigated further until it was clear voting turnout was in decline. The result has been a hodge-podge of survey items, inconsistent testing, and a lack of attention to and development of the duty concept. Even when duty was put back in the attitudinal research roster, its conception was not explored for changes or to ensure an accurate reflection of public perception. More nuanced evaluation of other political attitudes and values (Inglehart, 1997; Nevitte, 1996) and citizenship norms (Dalton, 2008; Pammett, 2009) have greatly improved the caliber of analysis researchers have been able to perform in explaining trends in participation. Taking into consideration the explanatory power of electoral duty in models of turnout and the fact that rates of voter participation continue to fall, the omission of civic duty from more fulsome analysis and attention is perplexing.

\section{Key findings and analysis}

Findings suggest that these new, alternate conceptions of duty may be more concentrated in new generations reaching the age of eligibility. While there is evidence of agreement with the new duty dimensions among all electors, these feelings are expressed most strongly by young electors. The fact that older generations identify with these 
dimensions to a certain degree suggests that these attitudes may have been passed down to younger generations and are now having a greater impact because they are more intense. It may also be that attitudes and values are just generally felt and expressed more intensely among the young. Finally, there is a possibility that young people are influencing the participation attitudes and habits of older generations.

Looking at the relationship of political attitudes such as efficacy, trust and interest with traditional duty and conditional duty, the same pattern of robustness among the young is present. So, for example, while older electors identifying with traditional duty have strong levels of political interest, younger potential voters associating with the same dimension exhibit more potent trust scores. It may be true that young people are the 'canary in the coal mine' when it comes to electoral participation as Chris Achen (2009) suggests.

Next, identification with conditional participation, and the perception of the rights component of voting more than the obligation portion seem to be connected with political attitudes. Negative feelings toward the political system are characteristic of these conceptions and differentiate these dimensions from traditional duty; the latter is distinguished by positive attitudes, especially when found in young people. Broadly, electors with positive outlooks of the political system, who trust government and have faith in the responsiveness of political institutions, are more likely to associate with traditional civic duty. Potential voters with negative perceptions of the political system, by comparison, are likely to describe attachment to the conditional duty profile. Among the young, negative trust is also detected. Negative external orientations toward politics are also present for the 'voting as a right' conception, albeit not always to a statistically significant degree.

The further difference between an elector identifying with conditional duty and one 
who perceives voting as a right is their internal feelings, including their interest in politics and personal beliefs regarding whether they can understand politics and have a say. The possession of positive feelings about an elector's ability to interact with the political system, even if it is unresponsive, is what sets these dimensions apart. Therefore, those who associate with conditional duty, and evaluate whether or not to vote, do so because of positive orientations regarding their personal capacity to contribute. Electors more likely to associate with the rights portion of voting, by comparison, typically have very weak or negative feelings about their personal abilities or interest, which explains their lack of willingness to engage electorally. ${ }^{73}$

Finally, looking at conditional duty more specifically, those subscribing to this notion make their decision to participate or abstain based on a series of calculations that can involve their perceived informedness or level of political knowledge and other contextual factors such as whether the perceived stakes of the election are high or not. Particular issues, candidates, or a close race, among other variables, could determine these stakes. Based on the degree to which young people associate with these newer dimensions it can be argued that their basic level of expectation is different from older electors. Whereas many young people take the consideration of a vote or abstention as their baseline for involvement, older potential voters put voting first. The decision regarding whether to participate or abstain then rests in the individual elector's perception of the political system and the capacity of their personal skills. It is an evaluation and certainly not a sure thing.

This type of 'calculative' reasoning seems closely aligned with the logic of rational choice approaches to studying the voter calculus. As noted earlier, rational choice

\footnotetext{
${ }^{73}$ Traditional duty identifiers of course exhibit strong, positive internal attitudes.
} 
explanations of participation evaluate the decision to participate by assessing the costs and benefits of voting. Typically the chances of one's vote making a difference when countless others are being cast is so slim that the perceived cost outweighs any expected gains, making voting an irrational choice. A traditional sense of civic duty, however, has served to override these costs, providing, for many, the motivation and justification to participate.

The notion of 'conditional duty' makes the strength of duty contingent on a range of factors, which may make the decision to vote essential or, alternatively, something that is passed over without guilt until future electoral opportunities arise. In this sense, feelings that voting is obligatory, or the infamous ' $D$ ' term (Downs, 1957), can become more robust or weak depending on an elector's perception of the electoral opportunity structure and other factors, particularly knowledge. Though not the focus of this thesis, it may be that a potent and strong $\mathrm{D}$ can sufficiently override the perceived costs of voting in an election, whereas a frail or delicate sense of $D$ makes abstention an acceptable practice in certain circumstances. Either way it would probably be a mistake to take 'duty' in rational choice equations as a static term that is the same in all instances. While many of these factors such as a close race have been considered when making the decision to vote it has not been as clear that these same contextual variables may have an important impact on an elector's sense of electoral duty, which in turn determines whether he/she decides to participate.

Although one study cannot warrant a definitive change in the survey measures used to gauge civic duty in elections, the results presented here should help change the way we think about duty and promote further exploration of these and other untapped dimensions. Ideally these new dimensions of duty will be evaluated in other country studies or regional surveys to determine whether electors, particularly younger cohorts, in other jurisdictions exhibit 
similar attitudes about citizenship obligations during an election. In addition, these duty dimensions may require further refinement, as various phrasing approaches to survey questions may perform better than others. There is also the possibility that there are additional dimensions of electoral civic duty that remain undetected or that will emerge as public values continue to change. So while continued work on these dimensions is important, regular re-evaluation of electoral civic duty and its components will be important to understanding future trends in electoral participation as well as the evolution of the relationship between the responsibilities of citizenship and regular elections.

Lessons from this thesis, work on efficacy (Morrell, 2003) and research into measuring levels of political information (Lupia, 2008b) highlight that many of the attitudes used to explain trends in electoral participation and patterns of political behaviour may require reassessment, particularly to better answer questions relating to participation declines. It is important for researchers to assess the relevance of concepts like civic duty to ensure they are capturing contemporary public interpretations of these terms and that the measures they use are an accurate reflection of these beliefs. There needs to be a balance between using the same measures over time for comparison and consistency and revisiting items to ensure more accurate assessment.

In addition to testing these new dimensions in other country settings and reviewing empirical survey items, findings presented here also suggest other potential research trajectories. One possibility that presents itself, but is not explored fully, is the notion of an internal citizen duty and an external citizen duty. Internal duty relates to expectations electors have of themselves or the level of expectation they believe should be anticipated of a 'real' citizen. External duty, by comparison, refers to broader expectations of citizens in an 
election or what would be required of an 'ideal' citizen. Many times throughout the primary research of this project respondents expressed a difference in the expectations of themselves as electors and as a more upstanding, knowledgeable citizen. While this may be young people trying to pass responsibility to others, it could also be that in addition to alternate conceptions of duty there may be internal and external components as well, much like those outlined for the attitude of efficacy.

Another opportunity for research is to further explore the notion that younger and older electors may embrace very different default positions of participation. This suggested finding provides support for new dimensions of duty and may help explain the way young people see themselves interacting with the system and the changing relationship between civil society and the state or government. Interestingly, this finding may present evidence to refute rather than support rational choice claims given a difference in what is perceived as 'rational'.

\section{Conclusion}

Based on the salience of traditional civic duty in explaining and accounting for patterns of turnout, and the established connection between civic responsibility and voting in elections it is not surprising the two are witnessing a corresponding decline. As value change permeates, young people develop weaker senses of community and are increasingly less likely to live up to the expectations of civic duty established during an era where interpersonal connections and community ties were robust. As cohorts of citizens are socialized generation after generation they absorb increasingly fragile senses of traditional community and grow up with an enhanced sense of individualism, which has a significant impact on their conceptions of citizenship, voting, and civic duty (Howe, 2010). The result is a 
citizen that is very different from the portrait of the 'good citizen' researchers became accustomed to studying in the 1950s, 1960s and 1970s.

The decline of the traditional community has been accompanied by a proliferation of newfound space that has allowed for the formation of different communities and groups and the emergence of new opportunities for activism (e.g. Internet networks such as MySpace, Facebook, YouTube, and Twitter) (Milner, 2010; Norris, 2002a, 2002b). These new networks may influence the foundation of what it means to be a modern citizen and, as a consequence, may have a profound impact on what civic duty means to young individuals today. This may or may not rank voting high on the list of civic norms and values. Given that societal changes in recent decades have likely had a direct effect on citizenship norms, including the electoral portion of duty, the concept of civic duty merits a re-evaluation. For these reasons, and all of the others echoed throughout the pages of this thesis, it is important to explore the notion of civic duty vis a vis elections, both as a measure and concept in political science literature, and as a practical activity that has great relevance for governments, political parties, citizens and the future of political participation.

The staunchly dutiful elector, who participates in elections regularly as an expression of loyal citizenship, still exists, but is slowly becoming more and more elusive. Generational replacement is producing increasingly fragile senses of traditional civic responsibility and new ways of thinking about citizen obligations during an election are taking its place. The notion of a conditional or contingent sense of duty, or a perspective where there is stronger identification with the rights portion of voting than the obligation component, both present viable alternate dimensions of electoral civic duty. It is imperative we revisit civic duty through the lens of contemporary citizens so that we are better able to understand and 
interpret changes in political participation and the evolving relationship between citizens and elections. Life today is starkly different that it was 50 or 60 years ago and so is the profile of a 'citizen'. Likewise, there are different perceptions about what it means to be a citizen during an election. If traditional duty is what brought voters out when levels of turnout were consistently high perhaps it should be expected that changes in this overriding sense of electoral duty are linked to increased rates of abstention. While the answer to declining rates of electoral participation will not likely wholly be found in shifting ideas of duty, failing to spend enough time critically examining the civic duty concept will mean we are missing a key piece of the voter turnout puzzle. 


\section{Appendix 1: 2008 Facebook study matrices}

\section{Vertical Axis: Voting}

The vertical axis was consistent on all matrices. Scores were averaged from four pretest measures, and one from after the election.

Did you vote in the 2004 election? : yes

Did you vote in the 2006 election?: yes

Did you vote in the 2007 election?: yes no no

Do you intend to vote in this election yes no not old enough

Did you vote?

\section{Horizontal Axis: Conceptions of Citizenship Matrix}

How would you describe what it means to be a Canadian citizen today?

Some young people see citizenship very broadly including responsibility to community, identity, and diversity, whereas others described being a citizen as abiding by the laws and having rights. Where do you place yourself and do you see consequences of these different conceptions for society and/or democracy?

\section{Horizontal Axis: Citizen's Role Matrix}

You don't have to vote to contribute to society.

It doesn't take too much time and effort to be active in politics and public affairs.

You have to be involved in politics to be a good citizen.

How should a citizen act in an election campaign? 


\title{
Appendix 2: AskingCanadians ${ }^{\mathrm{TM}}$ information
}

\section{Qskingcanadians"}

\author{
a Delvinia company
}

\section{AskingCanadians ${ }^{\mathrm{Tm}}$ Backgrounder \\ May 2012}

\begin{abstract}
About AskingCanadians ${ }^{\mathrm{TM}}$
AskingCanadians ${ }^{\mathrm{TM}}$, a Delvinia company, was established in 2005 as an online data collection firm dedicated to helping market researchers gather high quality information from Canadian consumers. We own and manage the AskingCanadians ${ }^{\mathrm{TM}}$ online research community, and its French counterpart $Q u^{\prime}$ en pensez vous ${ }^{\mathrm{MC}}$, which includes a panel of more than 200,000 demographically representative and profiled Canadians who have opted-in to participate in online surveys that significantly influence today's leading brands. AskingCanadians ${ }^{\top M}$ and Qu'en pensez vous ${ }^{\mathrm{MC}}$ are built through incentive partnerships with Aeroplan, HBC Rewards and Walmart. The result is an average response rate that eclipses the industry.
\end{abstract}

AskingCanadians ${ }^{\mathrm{TM}}$ manages online communities for many other clients, such as Four Seasons, HBC, Random House, SavvyMom and the Canadian Opera Company, among others. We are active members of the ESOMAR and MRIA communities and we have been designated as a Gold Seal member by MRIA standards.

\section{Respondents and Quality Control}

The AskingCanadians ${ }^{\mathrm{Tm}}$ panel is 100 per cent Canadian and is nationally representative by region. Panellists complete a two part opt-in process that is followed by three additional profiling surveys which provide us with more than 500 profiling variables. Profiling survey data is carefully screened and checked for fraud, inconsistencies and inaccuracies.

We make it clear to new panellists that they are joining a market research panel that collects information about the attitudes, demographics, behaviours and opinions of Canadians. They understand and agree to receive invitations to complete online surveys about a variety of subjects in return for the incentive of their choice when they complete a survey.

Ensuring our clients receive the highest quality data is critically important to us, and we have established a variety of quality assurance check-points throughout all of our AskingCanadians ${ }^{\mathrm{TM}}$ processes and procedures. We adhere to strict privacy policies and panellists' our panellists' names and contact information is never shared with a third party.

For more information, please visit corporate.askingcanadians.com.

Contact: Raj Manocha, VP, AskingCanadians ${ }^{\mathrm{Tm}}$

416.364.1455 ext.227,rmanocha@askingcanadians.com 


\section{Appendix 3: Delvinia AskingCanadians ${ }^{\mathrm{TM}}$ survey, final civic duty questionaire}

\section{Demographic Questions:}

1. What is your age?

2. What is your gender? (Please select one option only)

Male

Female

3. What is the highest level of education that you have completed? (Please select one option only)

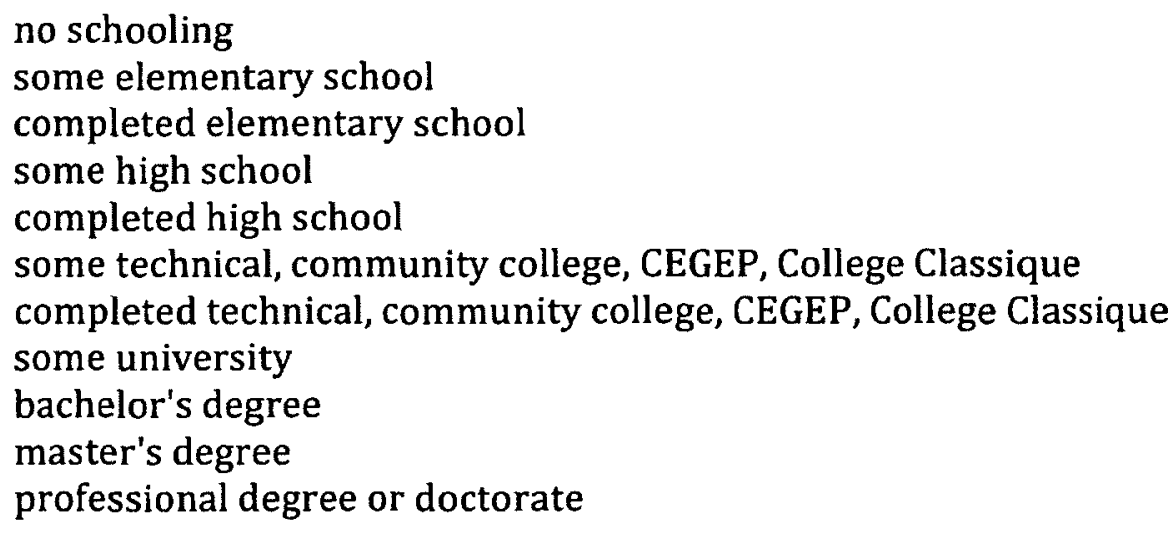

4. Which of the following represent your current marital status? (Please select one option only)
Single
Married
Common Law
Divorced
Widow/Widower
Don't know

5. In which of the following classifications does your total household income fall (before taxes]?
Under $\$ 20,000$
$\$ 20,000$ - $\$ 29,999$
$\$ 30,000-\$ 54,999$
$\$ 55,000$ - $\$ 84,999$
$\$ 85,000-\$ 109,999$
$\$ 110,000$ - $\$ 139,999$
$\$ 140,000$ or more
Student 
Prefer not to answer

Don't know

\section{Survey Questions:}

1a. Did you vote in the most recent municipal or local election in your community?

Yes

No

Don't remember

Not eligible

1b. Did you vote in the most recent provincial election?

Yes

No

Don't remember

Not eligible

1c. Did you vote in the most recent federal election?

Yes

No

Don't remember

Not eligible

2a. How likely are you to vote in the next municipal or local election in your community?

Very likely

Somewhat likely

Not likely

Not likely at all

2b. How likely are you to vote in the next provincial election?

Very likely

Somewhat likely

Not likely

Not likely at all

2c. How likely are you to vote in the next federal election?

Very likely

Somewhat likely

Not likely

Not likely at all 
3a. If you could vote online how likely would you be to use that method to vote in a future election? (Please select one of the following options.)

Very likely ASK Q.3bi

Somewhat likely ASK Q.3bi

Not likely ASK Q.3bii

Not likely at all ASK Q.3bii

3bi. If you indicated you would be 'very likely' or 'likely' to make use of Internet voting, why do you say that? (Please specify in the space below).

3bii. If you indicated you would be 'not very likely' or 'not likely at all' to make use of Internet voting, why do you say that? (Please specify in the space below).

4. Being able to vote online would make elections more accessible for some groups of people.

Strongly Agree

Agree

Neither Agree nor Disagree

Disagree

Strongly Disagree

5. If Internet voting were available I would be more likely to vote in elections.

Strongly Agree

Agree

Neither Agree nor Disagree

Disagree

Strongly Disagree

6. Would you favour or oppose having the Internet as an added method of voting in elections?

I am completely in favour

I am mostly in favour

I am mostly against

I am completely against

7. Generally speaking, how interested are you about what's going on in government and politics?

Extremely interested

Very interested

Moderately interested

Slightly interested

Not interested at all 
8. Most of the time we can trust people in government to do what is right.

Strongly Agree

Agree

Neither Agree nor Disagree

Disagree

Strongly Disagree

9. Most politicians are in politics only for what they can get out of it personally.

Strongly Agree

Agree

Neither Agree nor Disagree

Disagree

Strongly Disagree

10. I consider myself well-qualified to participate in politics.

Strongly Agree

Agree

Neither Agree nor Disagree

Disagree

Strongly Disagree

11. I feel I have a pretty good understanding of the important political issues facing Canada.

Strongly Agree

Agree

Neither Agree nor Disagree

Disagree

Strongly Disagree

12. People like me don't have any say about what the government does.

Strongly Agree

Agree

Neither Agree nor Disagree

Disagree

Strongly Disagree

13. I don't think the government cares much what people like me think.

Strongly Agree

Agree

Neither Agree nor Disagree

Disagree 


\section{Strongly Disagree}

14. I have a duty to vote in every election even if I'm busy or not very interested.

\section{Strongly Agree}

Agree

Neither Agree nor Disagree

Disagree

Strongly Disagree

15. The more you know about politics, the greater your obligation to vote.

Strongly Agree

Agree

Neither Agree nor Disagree

Disagree

Strongly Disagree

16. It is more important to vote in elections where the outcome is likely to be close.

Strongly Agree

Agree

Neither Agree nor Disagree

Disagree

Strongly Disagree

17. Voting in elections is more a right than it is a responsibility.

Strongly Agree

Agree

Neither Agree nor Disagree

Disagree

Strongly Disagree

18. If I know what is going on in an election I have a greater duty to vote than if I haven't been paying attention.

Strongly Agree

Agree

Neither Agree nor Disagree

Disagree

Strongly Disagree

19. I would be seriously neglecting my duty as a citizen if I didn't vote.

Strongly Agree

Agree 
Neither Agree nor Disagree

Disagree

Strongly Disagree

20. I have a greater duty to vote in elections when there are major differences between parties and candidates.

Strongly Agree

Agree

Neither Agree nor Disagree

Disagree

Strongly Disagree

21. People who are informed about politics have a greater responsibility to vote than those who know little or nothing.

Strongly Agree

Agree

Neither Agree nor Disagree

Disagree

Strongly Disagree

22. I would feel very guilty if I did not vote in a general election.

Strongly Agree

Agree

Neither Agree nor Disagree

Disagree

Strongly Disagree

23. It is more important for people to vote in elections where the stakes are considered high.

Strongly Agree

Agree

Neither Agree nor Disagree

Disagree

Strongly Disagree

24. I have a right not to vote.

Strongly Agree

Agree

Neither Agree nor Disagree

Disagree

Strongly Disagree 


\section{Bibliography}

\section{Data Sources}

American National Election Studies and Codebooks, 1952-2008.

Audit of Political Engagement, 2003-2011.

British Election Studies and Codebooks, 1987-2010.

British Social Attitudes Surveys, 1998-2011.

Canadian Election Studies and Codebooks, 1972-2008.

Delvinia, Internet Voting Survey 2010.

Eurobarometer Survey and Eurobarometer Special Surveys.

European Social Surveys, 2001-2011.

Goodman, Nicole, Heather Bastedo, Lawrence LeDuc, and Jon H. Pammett. 2008. Facebook Participation Study: 2008 Federal Election.

Goodman, Nicole. 2010.111 Carleton undergraduate students aged 18 to 26.

Goodman, Nicole. 2010. 97 Google survey respondents, all ages.

International Social Survey Program.

World Values Surveys.

\section{Web Sources}

Elections Canada website: www.elections.ca

Simon Fraser University. 2012. "Elections" webpage. Managed by Professor Andrew Heard: http://www.sfu.ca/ aheard/elections/results.html

\section{Bibliography}

Abramson, Paul R., Brian D. Silver, and Barbara A. Anderson. 1987. "The Effects of Question Order in Attitude Surveys: The Case of the SRC/CPS Citizen Duty Items," American Journal of Political Science, 31/4:900-908.

Achen, Chris. 2009. “Does Tingsten's Law Hold in Taiwan? A Comparison of 
2008 Presidential and Legislative Yuan Turnout in International Perspective," Presented at the Conference on Electoral Politics in Taiwan: Origins and Consequences of Electoral Reform, Columbia, South Carolina, February 6-8.

Aldrich, John H. 1976. "Some Problems in Testing Two Rational Models of Participation." American Journal of Political Science, 20/4:713-733.

Almond, Gabriel and Sidney Verba. 1963. The Civic Culture. Boston: Princeton University Press.

American National Election Studies, "Justification for Political Participation Questions." Available at: www.reginfo.gov/public/do/DownloadDocument?documentID. Last accessed May 11, 2012.

Archer, Keith and Jared Wesley. 2006. And I Don't Do Dishes Either!: Disengagement from Civic and Personal Duty. Presented at the Annual Meeting of the Canadian Political Science Association, York University, Toronto, Ontario, June 2, 2006.

Aristotle, 1941. The Basic Works of Aristotle. New York: Random House.

Barker, Ernest Sir. 1946. The Politics of Aristotle. Oxford: Clarendon Press.

Bélanger, Éric. 2004. Antipartyism and Third-Party Vote Choice: A Comparison of Canada, Britain, and Australia. Comparative Political Studies, 37:1054-1078.

Berelson, Bernard R., Paul F. Lazarsfeld, and William N. McPhee. 1954. Voting: A Study of Opinion Formation in a Presidential Campaign. Chicago: University of Chicago Press.

Black, Jerome H. 2003. "From Enumeration to the National Register of Electors: An Account and an Evaluation." IRPP Choices, 9/7:3-36.

Blais, André and Young. 1996. "Why do Young People Vote? An Experiment in Rationality." Political Economy Research Group, University of Western Ontario.

Blais, André and Robert Young. 1999. "Why Do People Vote? An Experiment in Rationality." Public Choice 99/1:39-55.

Blais André. 2000. To Vote or Not to Vote: The Merits and Limits of Rational Choice Theory. Pittsburgh: University of Pittsburgh Press.

Blais, André, Elisabeth Gidengil, Richard Nadeau and Neil Nevitte. 2002. Anatomy of a Liberal Victory: Making Sense of the 2000 Canadian Election. Peterborough, Ontario: Broadview Press.

Blais, André, Elisabeth Gidengil, Neil Nevitte and Richard Nadeau. 2004. Where Does Turnout 
Decline Come From. European Journal of Political Research, 43/2:221- 236.

Blais, André. 2009. "What does it take to get to the polls preference and/or duty." Presented at the Annual Meeting of the Midwest Political Science Association, Chicago, Illinois, April 2-5.

Blais, André and Christopher H. Achen. 2010. "Taking Civic Duty Seriously: Political Theory and Voter Turnout." Unpublished Manuscript. Available at:

www.princeton.edu/csdp/events/Achen031110/Achen031110.pdf. Last accessed May $17,2012$.

Blais, André, Professor, Université de Montréal. Personal Communication. July 14, 2010.

Blais, André and Peter Loewen. 2011. Youth Electoral Engagement in Canada. A Report prepared for Elections Canada.

Blais, André and Daniel Rubenson. Forthcoming. The Source of Turnout Decline: New Values or New Contexts?, Comparative Political Studies available at: http://www.politics.ryerson.ca/rubenson/research.htm

Birch, Sarah. 2008. Electoral institutions and popular confidence in electoral processes: A cross-national analysis. Electoral Studies, 27:305-320.

Bubeck, Diemut. 1995. "Thin, Thick and Feminist Conceptions of Citizenship." Paper presented at the 1995 Contemporary Political Studies Association Meeting in Belfast, UK.

Butler, David and Donald Stokes. 1971. Political change in Britain: Forces Shaping Electoral Choice. London: Penguin Books.

Butler, David and Donald Stokes. 1974. Political Change in Britain: the Evolution of Electoral Choice. London: Macmillan.

Butler David and Donald Stokes. 1975. Political Change in Britain, Second College Edition. New York: St. Martin's Press.

Campbell, Angus, Philip E. Converse, Warren E. Miller, and Donald E. Stokes. 1960. The American Voter. New York: Wiley.

Campbell et al. "establish the existence of duty...they measure whether something other than self-interest is at work" and were intended to tap the important components of citizen duty (Blais, 2000:94; Campbell et al., 1957:194).

Campbell Angus, Gerald Gurin, and Warren E. Miller. 1957. The Voter Decides. Evanston IL: Row, Peterson. 
Campbell, David. 2006. Why We Vote: How Schools and Communities Shape Our Civic Life. Princeton: Princeton University Press.

CIRCLE (Centre for Information \& Research on Civic Learning and Engagement. 2006. "Special Report: Youth Voter Mobilization Tactics." Available at:

www.civicyouth.org/PopUps/Young Voters Guide.pdf. Last accessed: July 14, 2012.

Clarke, Harold D., David Sanders, Marianne C. Stewart and Paul F. Whiteley. 2009.

Performance Politics and the British Voter. New York: Cambridge University Press.

Clarke, Harold D., Allan Kornberg, John MacLeod, and Thomas Scotto. 2005. “Too Close to Call: Political Choice in Canada, 2004." PS: Political Science and Politics, 38/2:247-253.

Clarke, Harold D., David Sanders, Marianne C. Stewart and Paul Whiteley. 2004. Political Choice in Britain. New York: Oxford University Press.

Clarke, Harold D., David Sanders, Marianne C. Stewart, Paul F. Whiteley. 2001. "Britain (Not) at the Polls, 2001". Available at: www.essex.ac.uk/bes/papers/notpolls.pdf. Last accessed May 11, 2012.

Clarke, Harold D., David Sanders, Marianne C. Stewart and Paul F. Whiteley. 2002. "Downs, Stokes and Modified Rational Choice: Modeling Turnout in 2001" In Lynn Bennie, Lynn, Colin Rallings, Jonathan Tonge and Paul Webb Eds., British Elections \& Parties Review: Volume 12 The 2001 General Election, pp 28-47.

Clarke, Harold D., Lawrence LeDuc, Jane Jenson and Jon H. Pammett. 1996. Absent Mandate: Canadian Electoral Politics In an Era of Restructuring. Toronto: Gage Educational Publishing Company.

Conover, Pamela, Leonard Johnson, T. Stephen, and Donald D. Searing, 1993. "Duty Is a FourLetter Word: Democratic Citizenship in the Liberal Polity", in George E. Marcus \& Russell L. Hardin, Eds., Reconsidering the Democratic Public. University Park, PA.: Penn State Press., pp. 147-171.

Crick, Bernard. 2004. “Foreword.” In Derek Benjamin Heater's Citizenship: The Civic Ideal in World History, Politics and Education. New York: Manchester University Press.

Cross, William. 2004. Political Parties. Vancouver: UBC Press.

Cross, William and Lisa Young. 2004. The Contours of Political Party Membership in Canada. Party Politics, 10/4:427-444.

Curtice, John. 1986. "Election Pluralism." Parliamentary Affairs, 8:115-118.

Curtice, John and Alison Park. 2010. Will Anyone Vote? Prospects for Turnout in the General Election. British Social Attitudes and National Centre for Social Research Report. 
Dahl, Robert. 1998. On Democracy. New Haven: Yale University Press.

Dalton, Russell J. 2006. "Citizenship Norms and Political Participation in America: The Good News Is :..the Bad News Is Wrong." The Centre for Democracy and Civil Society, Georgetown University, Occasional Paper Series, pp.1-14.

Dalton, Russell J. 2008. The Good Citizen: How a Younger Generation is Reshaping American Politics. Washington, DC: CQ Press.

Dalton, Russell J. 2011. "Youth and Participation Beyond Elections" in Russell Dalton Eds., Engaging Youth in Politics. New York: Open Society Institute.

Delli Carpini, Michael X. 2000. Gen.com: Youth, Civic Engagement, and the New Information Environment. Political Communication, 17:341-349.

Delli Carpini, Michael X. and Scott Keeter. 1996. What Americans Know About Politics and Why It Matters. New Haven: Yale University Press.

Dennis, Jack. 1970. "Support for the Institution of Elections by the Mass Public." The American Political Science Review, 64/3:819-835.

DeVellis, Robert F. 1991. Scale development. Newbury Park, CA: Sage Publications.

Downs, Anthony. 1957. An Economic Theory of Democracy. New York: Harper \& Row.

Elections Canada website www.elections.ca (see Past Elections and Voter Turnout at Federal Elections and Referendums).

European Commission. 2005. Special EUROBAROMETER 225 "Social values, Science \& Technology" Wave 63.1, June. Available at: ec.europa.eu/public_opinion/archives/ebs/ebs_225_report_en.pdf. Last accessed May $21,2012$.

European Social Survey. 2008. Exploring public attitudes, informing public policy: Selected findings from the first three rounds.

Faulks, Keith. 2000. Citizenship. New York: Routledge.

Ferejohn, John A., and Morris P. Fiorina. 1975. "Closeness Counts Only in Horseshoes and Dancing." American Political Science Review. 69/3:920-25.

Ferejohn, John A., and Morris P. Fiorina. 1974. "The Paradox of Not Voting: A Decision Theoretic Analysis." American Political Science Review, 68:525-536.

Franklin, Mark. 1996. "Electoral Participation" in Lawrence LeDuc, Richard G. Niemi and 
Pippa Norris Eds. Comparing Democracies: Elections and Voting in Global Perspective. London: Sage Publications.

Franklin, Mark N. 2004. Voter Turnout and the Dynamics of Electoral Competition in Established Democracies since 1945. Cambridge, UK: Cambridge University Press.

Gardner, Paul L. 1995. "Measuring Attitudes to Science: Unidimensionality and Internal Consistency Revisited." Research in Science Education, 25/3:283-289.

Garland, Ron. 1991. "The Mid-Point on a Rating Scale: Is it Desirable?" Marketing Bulletin, 2:66-70.

Gidengil, Elisabeth, Hiram Mills Professor, McGill University. Personal Communication. June 9, 2010.

Gidengil, Elisabeth, Hiram Mills Professor, McGill University. Personal Communication. June $10,2010$.

Gidengil, Elisabeth, André Blais, Joanna Everitt, Patrick Fournier and Neil Nevitte. 2005. "Missing the Message: Young Adults and the Election Issues." Electoral Insight, 7:6-11.

Gidengil, Elisabeth, Andre Blais, Neil Nevitte and Richard Nadeau. 2004. Citizens. Vancouver: UBC Press.

Gidengil, Elisabeth, André Blais, Neil Nevitte and Richard Nadeau. 2003. "Turned Off or Tuned Out? Youth Participation in Politics." Electoral Insight, 5: 9-14.

Gidengil, Elisabeth, André Blais, Richard Nadeau, Neil Nevitte. 2002. "Changes in the Party System and Anti-Party Sentiment" in William Cross Eds., Political Parties, Representation, and Electoral Democracy in Canada. Toronto: Oxford University Press, pp.68-83.

Goodman, Nicole. 2005. The Culture of Detachment. Master's Thesis prepared for the University of Guelph.

Goodman, Nicole, Heather Bastedo, Lawrence LeDuc, and Jon H. Pammett. 2011. "Young Canadians in the 2008 federal election campaign: Using Facebook to probe perceptions of citizenship and participation." Canadian Journal of Political Science, 44/4:1-23.

Goodman, Nicole and Lesley Copeland. 2011. “Candidates do it, why can't election agencies? The Town of Markham's use of Facebook in the 2010 Municipal Election." Paper presented at the Bell Chair Graduate Student Conference in Canadian Politics, Parliament Hill, Ottawa, February 11.

Green, Donald P. and Alan S. Gerber. 2008. Get Out The Vote: How to Increase Voter Turnout. Washington: Brookings Institution Press. 
Gueorguieva, Vassia. 2008. Voters, MySpace, and YouTube: The Impact of Alternative Communication Channels on the 2006 Election Cycle and Beyond. Social Science Computer Review, 26:288-300.

Hansard Society. 2009. Audit of Political Engagement 6: The 2009 Report with a focus on political participation and citizenship. Available at: www.hansardsociety.org.uk/files/folders/1755/download.aspx. Last accessed May 21, 2012.

Haste, Helen and Amy Hogan. 2006. Beyond conventional civic participation, beyond the moral-political divide: young people and contemporary debates about citizenship. Journal of Moral Education, 35/4:473-493.

Heater, Derek Benjamin. 2004. Citizenship: The Civic Ideal in World History, Politics and Education. New York: Manchester University Press.

Henn, Matt, Mark Weinstein, and Dominic Wring. 2002. A generation apart? Youth and political participation in Britain. British Journal of Politics and International Relations, 4/2:167-192.

Holbrook, Allyson L. and Jon A. Krosnick. 2010. "Social Desirability Bias in Voter Turnout Reports: Tests Using the Item Count Technique." Public Opinion Quarterly, 74/1:37-67.

Howe, Paul. 2003. Electoral Participation and the Knowledge Deficit. Electoral Insight, 5:2025.

Howe, Paul. 2006. "Political Knowledge and Electoral Participation in the Netherlands: Comparisons with the Canadian Case." International Political Science Review, 27/2:137166.

Howe, Paul. 2007. Voter Participation in New Brunswick and the Political Disengagement of the Young in William Cross Eds., Democratic Reform in New Brunswick. Canadian Scholars' Press, Toronto, ON, pp.240-272

Howe, Paul. 2010. Citizens Adrift: The Democratic Disengagement of Young Canadians. Vancouver: UBC Press.

IDEA. 2002. Voter Turnout Since 1945: A Global Report.

Inglehart, Ronald. 1990. Culture Shift in Advanced Industrial Society. Princeton New Jersey: Princeton University Press.

Inglehart, Ronald. 1997. Modernization and Postmodernization: Cultural, Economic, and Political Change in 43 Societies. Princeton, New Jersey: Princeton University Press. 
Isin, Engen F. and Bryan S. Turner. 2002. Handbook of Citizenship Studies. Thousand Oaks, CA: SAGE Publications.

Jackson, Robert. 1995. "Clarifying the Relationship Between Education and Turnout." American Politics Quarterly 23:279-99.

Johnston, Richard and Andre Blais. 2008. "The Past and Future of the Canadian Election Study." Unpublished Manuscript.

Kalberg, Stephen. 1993. "Cultural foundations in modern citizenship," in Bryan S. Turner Eds., Citizenship and social theory. London: SAGE Publications.

Karp, Jeffrey A. and David Brockington. 2005. "Social Desirability and Response Validity: A Comparative Analysis of Overreporting Voter Turnout in Five Countries." Journal of Politics, 67/3:825-840.

Katz, Richard S. 1997. Democracy and Elections. New York, New York: Oxford University Press.

LeDuc, Lawrence, Jon H. Pammett and Heather Bastedo. 2008. "The Problem of Young Voters: a Qualitative and Quantitative Analysis." Paper presented to the annual meeting of the American Political Science Association, Boston MA.

Lipset, Seymour Martin and William Schneider. 1983. "The Decline of Confidence in American Institutions." Political Science Quarterly, 98/3:379-402.

Lochner, Kimberly, Ichiro Kawachi and Bruce P. Kennedy. "Social capital: a guide to its measurement." Health \& Place, 5:259-270.

Luevano, Pat, American National Election Studies. Personal Communication, September 18, 2008.

Lupia, Arthur. 2008a. "Procedural Transparency and the Credibility of Election Surveys." Electoral Studies 27: 732-739.

Lupia, Arthur. 2008b. "Questioning Our Competence: Improving the Practical Relevance of Political Knowledge Measures." Manuscript presented at the Annual Meeting of the American Political Science Association, Boston Massachusetts, August 28.

McNabb, David E. 2010. Research Methods in Political Science: Quantitative and Qualitative Approaches, Second Edition. New York: M.E. Sharpe.

Milan, Ann. 2009. "Willing to Participate: Political Engagement of Young Adults," in George A. MacLean and Brenda O'Neill Eds., Ideas, Interests and Issues: Readings in Introductory Politics. 
Miller, Warren Edward and Santa Traugott. 1989. American National Elections Studies Data Sourcebook, 1952-1986. Harvard University Press.

Milner, Henry. 2010. The Internet Generation: Engaged Citizens and Political Dropouts. Lebanon, NH: University Press of New England.

Milner, Henry. 2004. Steps Toward Making Every Vote Count: Electoral System Reform in Canada and its Provinces. Peterborough: Broadview Press.

Milner, Henry. 2002. Civic Literacy: How Informed Citizens Make Democracy Work. Vancouver, BC: UBC Press.

Morrell, Michael E. 2003. "Survey and Experimental Evidence for a Reliable and Valid Measure of Internal Political Efficacy." The Public Opinion Quarterly, 67/4:589-602.

Nevitte, Neil, Professor, University of Toronto. Personal Communication. July 13, 2010.

Nevitte, Neil, André Blais, Elisabeth Gidengil and Richard Nadeau. 2000. Unsteady State: The 1997 Canadian Federal Election. Don Mills: Oxford University Press.

Nevitte, Neil. 1996. The Decline of Deference. Toronto: Broadview Press.

Niemi, Richard G, Stephen C. Craig and Franco Mattei. 1991. "Measuring Internal Political Efficacy in the 1988 National Election Study." The American Political Science Review, 85/4: 1407-1413.

Niemi, Richard G. 1986. "The Dynamics of Public Opinion." In Herbert F. Weisberg, ed., Political Science: The Science of Politics. New York: Agathon Press. Norris, Pippa. 2002. Democratic Phoenix: Reinventing Political Activism. Cambridge: Cambridge University Press.

Norris, Pippa. 2002. "Democratic Phoenix: Agencies, Repertoires, \& Targets of Political Activism." Paper presented at the annual meeting of the American Political Science Association, Boston August 29 to September 1.

O'Neill, Brenda. 2003. "Examining Declining Electoral Turnout Among Canada's Youth." Electoral Insight, 5:15-19.

O'Neill, Brenda. 2007. Indifferent or Just Different? The Political and Civic Engagement of Young People in Canada: Charting the Course for Youth Civic and Political Participation. CPRN Research Report.

Oppenheim, A.N. 1992. Questionnaire Design, Interviewing and Attitude Measurement. New York: Pinter Publications. 
Pammett, Jon H. and Lawrence LeDuc. 2003. Explaining the Turnout Decline in Canadian Federal Elections: A New Survey of Non-voters. Report prepared for Elections Canada. Available at: www.elections.ca.

Pammett. Jon H. 2009. "Participation and the Good Citizen" in Joan DeBardeleben and Jon Pammett, Eds., Participation and the Good Citizen. Baskingstoke: Palgrave.

Pateman, Carole. 1970. Participation and Democratic Theory. Cambridge: Cambridge University Press.

Phelps, Edward. 2006. "Young citizens and Declining electoral turnout: trends and Explanations." Paper presented at The Elections, Public Opinion and Parties annual conference, Nottingham University.

Prewitt, Kenneth and Norman Nie. 1971. Election Studies of the Survey Research Center. British Journal of Political Science, 1/4: 479-502.

Preuss, Ulrich K. 2003. "The ambiguous meaning of citizenship." Paper presented at the University of Chicago Law School to the Centre for Comparative Constitutionalism, December 1. Available at: ccc.uchicago.edu/docs/preuss.pdf. Last accessed May 12, 2012.

Print, Murray. 2007. "Citizenship Education and Youth Participation in Democracy." British Journal of Education Studies, 55/3:325-345.

Putnam, Robert. 1993. Making Democracy Work. Princeton, New Jersey: Princeton University Press.

Putnam Robert D. 2000. Bowling Alone: The Collapse and Revival of American Community. New York: Simon \& Schuster.

Raney, Tracey and Loleen Berdahl. 2009. "Birds of a Feather? Citizenship Norms, Group Identity, and Political Participation in Western Canada." Canadian Journal of Political Science, 42/1:187-209.

Riker, William H., and Peter C. Ordeshook. 1968. "A theory of the calculus of voting." American Political Science Review, 62:25-42.

Rosenstone, Steven J., and John Mark Hansen. 1993. Mobilization, Participation, and Democracy in America. New York: Macmillan.

Rubenson, Daniel, André Blais, Patrick Fournier, Elisabeth Gidengil and Neil Nevitte. 2004. "Accounting for the Age Gap in Turnout." Acta Politica. 39:407-421.

Sanders, David, Professor, University of Essex. Personal Communication. June 16, 2010. 
Sanders David, Harold D. Clarke, Marianne C. Stewart and Paul Whiteley. 2007. "Does Mode Matter for Modelling Political Choice? Evidence From the 2005 British Election Study." Political Analysis

Schumpeter, Joseph A. 1950. Capitalism, Socialism and Democracy. New York: Harper.

Silver, Brian D., Paul R. Abramson and Barbara A. Anderson. 1986. "The Presence of Others and Overreporting of Voting in American National Elections." Public Opinion Quarterly, 50/2:228:239.

Simon Fraser University. Election's website, Available at: http://www.sfu.ca/ aheard/elections/historical-turnout.html. Last accessed May 4, 2012.

Small, Tamara. 2010. "Canadian Politics in 140 Characters: Part Politics in the Twitterverse." Canadian Parliamentary Review, 33/3:39-45.

Small, Tamara A. 2008. "The Facebook Effect? On-line Campaigning in the 2008 Canadian and US Elections." Policy Options, (November):85-87.

Smith, Rogers M. 2002. "Modern Citizenship," in Engin Fahri Isin and Bryan S. Turner Eds., Handbook of Citizenship Studies. London: SAGE Publications.

Soule, Suzanne and Jennifer Nairn. 2009. "Youth Turnout in the 2008 Presidential Election: Delving Deeper with Data from the We the People Civic Education Alumni Network." Paper presented at the Midwestern Political Science Meeting, Chicago, Illinois, April 25.

Stolle, Dietlind, Michele Micheletti, Daniel Berlin. 2010. "Young People and Political Consumerism." published in Swedish as "Politik, konsumtion och delaktighet" in the report Fokus 10. En analys av ungas inflytande, the Swedish National Board for Youth Affairs. Available at www.ungdomsstyrelsen.se. English version available at: http://www.sustainablecitizenship.com/publications.html. Last accessed May 8, 2012.

Sullivan, John L. and Eric Riedel. 2001. "Efficacy: Political." Originally published in International Encyclopedia of the Social and Behavioral Sciences, pp. 4353-4356. Available at: www.leadershipreview.org/2004fall/WilliamsArticle.pdf. Last accessed May 11, 2012.

"Talking about a revolution: A fascinating and unwieldy movement in search of a narrative." The Economist, April 7, 2012.

Theiss-Morse, Elizabeth. 1993. "Conceptualizations of Good Citizenship and Political Participation." Political Behaviour, 15/4:355-380.

Thomassen, Jacques. 1994. "Introduction: The intellectual history of election studies." 
European Journal of Political Science, 25:239-245.

Thompson, Dennis F. 1970. The democratic citizen: social science and democratic theory in the twentieth century. London: Cambridge University Press.

Tilly, Charles. 1996. Citizenship, Identity and Social History Eds. New York: University of Cambridge Press.

Turcotte, André. 2005. Different Strokes: Why Young Canadian Don't Vote. Electoral Insight, 7:12-16.

Turcotte, André. 2007. "What Do You Mean I Can't Have a Say?" Young Canadians and Their Government. CPRN Research Report.

"Twitter's influence on the Arab Spring." The Globe and Mail, August 19, 2011.

Verba, Sidney, Henry E. Brady, and Key Lehman Scholzman. 1995. "Beyond Ses: A Resource Model of Political Participation." American Political Science Review, 89/2:271-294.

Verba, Sidney, and Norman Nie. 1972. Participation in America: Political Democracy and Social Equality. New York: Harper \& Row.

Wattenburg, Martin. 2007. Is Voting For Young People? With a Postscript on Citizen Engagement. New York: Pearson Longman.

Wolfinger, Raymond E. and Steven J. Rosenstone. 1980. Who Votes? New Haven and London: Yale University Press. 